\title{
Penetration Tests on J-SIIDS Barriers
}

R. T. Moore

Measurements Automation Section

Information Processing Technology Division

Institute for Computer Sciences and

Technology

Washington, D. C. 20234

June 4, 1973

Interim Report for Period March 13 - 16, 1973

Prepared for

Defense Nuclear Agency Washington, D. C. 20305 



\section{PENETRATION TESTS ON J-SIIDS BARRIERS}

R. T. Moore

Measurements Automation Section

Information Processing Technology Division

Institute for Computer Sciences and

Technology

Washington, D. C. 20234

June 4,1973

Interim Report for Period March 13 - 16, 1973

\section{Prepared for}

Defense Nuclear Agency

Washington, D. C. 20305

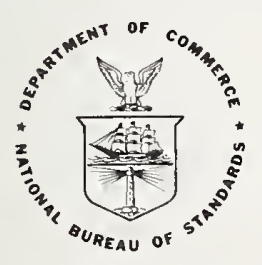

U. S. DEPARTMENT OF COMMERCE, Frederick B. Dent, Secretary 



\section{ILLUSTRATIONS}

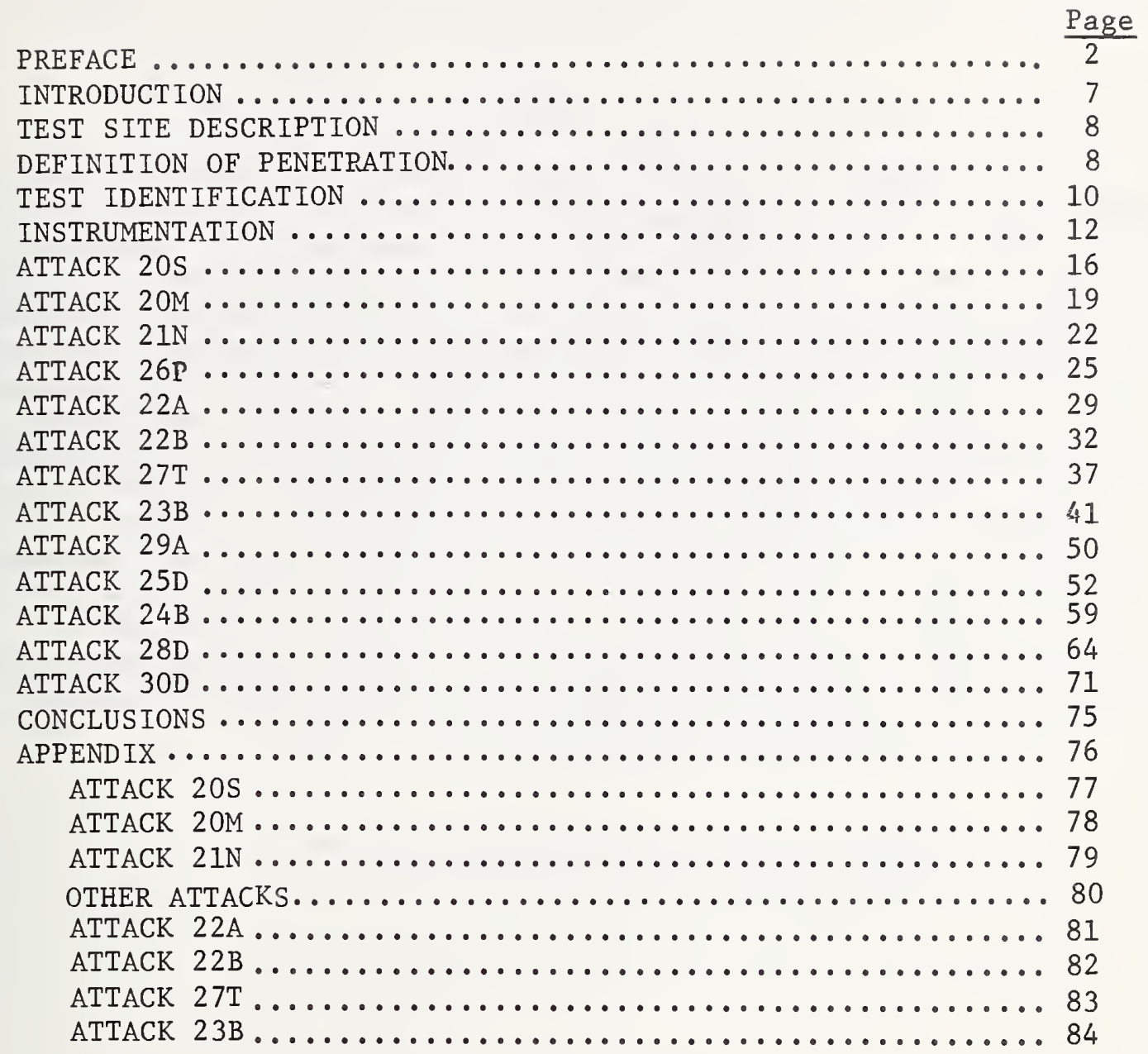




\section{PREFACE}

The cooperation and active support of many individuals in several organizations made the collection of these barrier penetration test data possible. In particular, we wish to thank the U. S. Army, Mobility Equipment Research and Development Center for providing the opportunity to conduct the tests, and for providing overall test support including photographic coverage. James $W$. Owen and Robert L. Barnard and the many other MERDC participants were key contributors. Attack tooling and much of the instrumentation was provided by the U. S. Army, Inte11igence Materiel Development Office, Fort Holabird, Maryland, ably represented by Frank C. Veirs. Penetrations were accomplished by personnel from the Naval Security Group under the direction of Richard F. Blackmon. R. S. Koyanagi of the Vibration Section of the National Bureau of Standards provided support in the collection of the vibrational disturbance data and T. L. Quindry of the Applied Acoustics Section provided the acoustical data shown in the appendix. The guidance and active participation of Marvin C. Beasley, Defense Nuclear Agency Task Officer for this project is gratefully acknowledged. 
Figure

1

2
Title

Layout for Simulated Arms Rooms

Locations of Attack Areas on Simulated Arms Room Test Facility

Data Collection Instruments

Attack 20S

Acoustical Disturbances Made by Hand-operated Brace and Bit

Acoustical Disturbances from Electric Saber Saw

Vibrational Disturbances from Electric Saber Saw Attack 20M

Acoustical Disturbances from Rotary Electric Saw

Vibrational Disturbances from Rotary Electric Saw

Acoustical Disturbances from 3/4" Wood Bit Used with 3/8" Variable Speed Electric Drill

Vibrational Disturbances from $3 / 4$ " Wood Bit and Electric Drill

Attack $21 \mathrm{~N}$

Rotary Electric Saw, Acoustical

Rotary Electric Saw, Vibration Through Eight-foot Transmission Path

Vibration produced by Handsaw Cutting Rafter

Interior View of Opening Produced by Attack 21N

Attack 26P

Acoustical Disturbances from Oxyacetylene Cutting Torch

Vibration from Cutting Torch 
Multiple Sweep of Acoustical Disturbances from Breaking Glass Window

Breaking Glass Window with Bolt Cutters

Attack 22A

Acoustical Disturbance from Sledgehammer Prior to Breakthrough

Vibrational Disturbances from Attack 22A

Acoustical Disturbance from Attack on Brick Veneer

Vibration from Attack on Brick Veneer

Attack 22B

Acoustical Disturbance from Rotohammer Attack on Cinder Block

Vibration from Attack on Cinder Block

Acoustical Disturbances from Cutting Torch

Vibrational Disturbances from Cutting Torch

Attack $27 \mathrm{~T}$

Vibration During Bolt-cutter Attack

Ambient Vibrational Background at Location 27T

Multiple Sweep of Acoustical Disturbances

Produced by Bolt Cutters

Vibration from Sledgehammer Attack on Draw Bolt Attack 23B

Acoustical Disturbance from Drilling

Vibrational Disturbance from Drilling

Acoustical Disturbance from Spalling

Vibration from Spalling 
43

44

45

46

47

48

49

50

51

52

53

54

55

56

57

58

59

60

61

62

63

Abrasive Wheel Cutoff Saw Used in Attack 23B

Acoustical Disturbances from Abrasive Wheel Cutoff Saw

Vibration from Abrasive Wheel Cutoff Saw

Opening Made by Attack 23B

Acoustical Disturbances from Sledgehammer

Vibration from Sledgehammer

Acoustical Disturbances from the Cutting Torch

Attack 29A

Vibration from Sledgehammer on Cinder-block Wall

Attack 25D

Acoustical Disturbances from Drilling Reinforced Concrete

Vibration from Drilling Reinforced Concrete

Interior of the Wall with Spalling Nearly Complete

Multiple Sweep of Acoustical Disturbances Produced by Spalling

Vibration from Spalling with Transducer Mounted $10^{\prime}$ from Attack Point

Vibration from Spalling with Transducer Mounted $20^{\prime}$ from Attack Point

Vibration from 20-pound Sledgehammer

Vibration from 10-pound Sledgehammer

Vibration from Rotohammer

Acoustical Disturbances from Spalling

Vibration from Spalling 
Use of Tapered Punch in Attack 24B

Vibration from File

Acoustic Disturbances from Drilling on Vault Door

Vibration from Drilling on Vault Door

Acoustical Disturbances from Rocket Torch

Vibration from Rocket Torch

Comparison of Cuts Made by Rocket Torch (Wide) and Oxygen-fed Electric Arc (Narrow)

Acoustical Disturbances from the Electric Arc Torch

Vibration from the Electric Arc

Burning Bar Melting a Hole Through Concrete

Acoustical Disturbance from Burning Bar Attack on Concrete

Vibration from Burning Bar Attack on Concrete

Burning Bar Cutting Reinforcing Rod at Location 24B

Acoustical Disturbance from Burning Bar Attack on Expanded Metal

Vibration from Burning Bar Attack on Expanded Metal 


\section{PENETRATION TESTS \\ ON \\ J-SIIDS BARRIERS}

by

R. T. Moore

\section{INTRODUCTION}

The degree of protection that is afforded to computers, money or negotiable securities, weapons, classified materials, or other valuable items, is dependent upon the effectiveness of the physical security measures which are employed to safeguard them. Current physical security measures are usually based on the concept of employing one or more barriers, such as fencing, a strong room or a vault to enclose a protected area coupled with one or more electronic sensors which are intended to detect penetration of the barrier(s) or any intrusion into the protected area. Detection of barrier penetration or area intrusion causes an alarm and initiates some form of reaction on the part of guards, police or other forces. To be effective in safeguarding the protected area, the time that is required for a potential intruder to penetrate the barriers must be greater than the total time required for detection of the penetration and the response of the reactionary force. Thus, an evaluation of the effectiveness of a physical security system requires, among other things, some basis for developing estimates of the time which might be required to penetrate a given barrier.

This report describes the results of a series of penetration tests which were made on three simulated arms rooms located at the U. S. Army Mobility Equipment Research and Development Center (MERDC) test facility, Woodbridge, Virginia, during a one week period beginning March 13,1973. The objectives of these tests were to develop estimates of

(a) the times required to make man-passable penetration openings;

(b) the times required for the electronic intrusion systems with which the simulated arms rooms were equipped to respond to the penetration attacks;

(c) the acoustic, ultrasonic and vibrational disturbances produced by the various attacks; and finally,

(d) (not reported herein) to evaluate the performance of the JointService Interior Intrusion Detection System (J-SIIDS) in detecting these penetration attacks and to assess the vulnerability of this system to countermeasures. 1 f

I/ Intrusion Detection Test Report, J-SIIDS Equipment, Robert Barnard, U. S. Army, MERDC. 


\section{TEST SITE DESCRIPTION}

The simulated arms room facility consisted of a three-room structure located inside of the $45^{\prime} \mathrm{X} 90^{\prime}$ west wing of one of the Harry Diamond-Laboratories buildings at Woodbridge, Virginia. The general arrangement of the structure is shown in figure 1. Room 1 was fabricated of wood with a double planking of nominal one-inch thick wood siding cver $2^{\prime \prime} \times 4^{\prime \prime}$ studs and no interior finish. The flat roof was similarly planked over $2^{\prime \prime}$ X 6" rafters. The roof height was approximately $9^{\prime}$ and was level with that of the other two rooms.

Room 2 had exterior walls of $8^{\prime \prime}$ cinder block with 5/8" reinforcing bars inserted vertically in the cores of the blocks with a spacing of about 14". The cores of the blocks were filled with mortar and three $1 / 8^{\prime \prime}$ steel wires were used as horizontal reinforcement in every second course. One of the exterior walls had a single layer of block veneer laid up with a one-inch air space between the veneer and the block and tied to every second course of block with sheet metal ties.

Room 3 had walls of $8^{\prime \prime}$ concrete reinforced with $3 / 4^{\prime \prime}$ rod on $12^{\prime \prime}$ centers vertically and horizontally. The room was equipped with a GSA Class 6 vault door. The roof of this room and of Room 2 was of 5-1/2" thick reinforced concrete with $1 / 2^{\prime \prime}$ reinforcing bars on 8 " $\mathrm{X} 12^{\prime \prime}$ centers.

These rooms had been constructed by MERDC in support of the J-SIIDS development effort and were instrumented with appropriate components of this intrusion detection system during the penetration tests. The rooms were intended to be representative of the broad range of structural barriers which might be found in existing arms rooms.

\section{DEFINITION OF PENETRATION}

A barrier is considered to have been penetrated when an opening has been made which is large enough for a small man to wriggle through. It is generally accepted that an opening having an area of 96 square inches with one dimension of at least 6" will meet this criterion. In these tests, attack areas were marked out on the barriers in the form of either an $8^{\prime \prime} \times 12^{\prime \prime}$ rectangle or an $11.1^{\prime \prime}$ diameter circle as appropriate to the attack tooling which was employed. In those instances where the attack produced an opening larger than, or significantly different from these sizes, its dimensions are reported. 


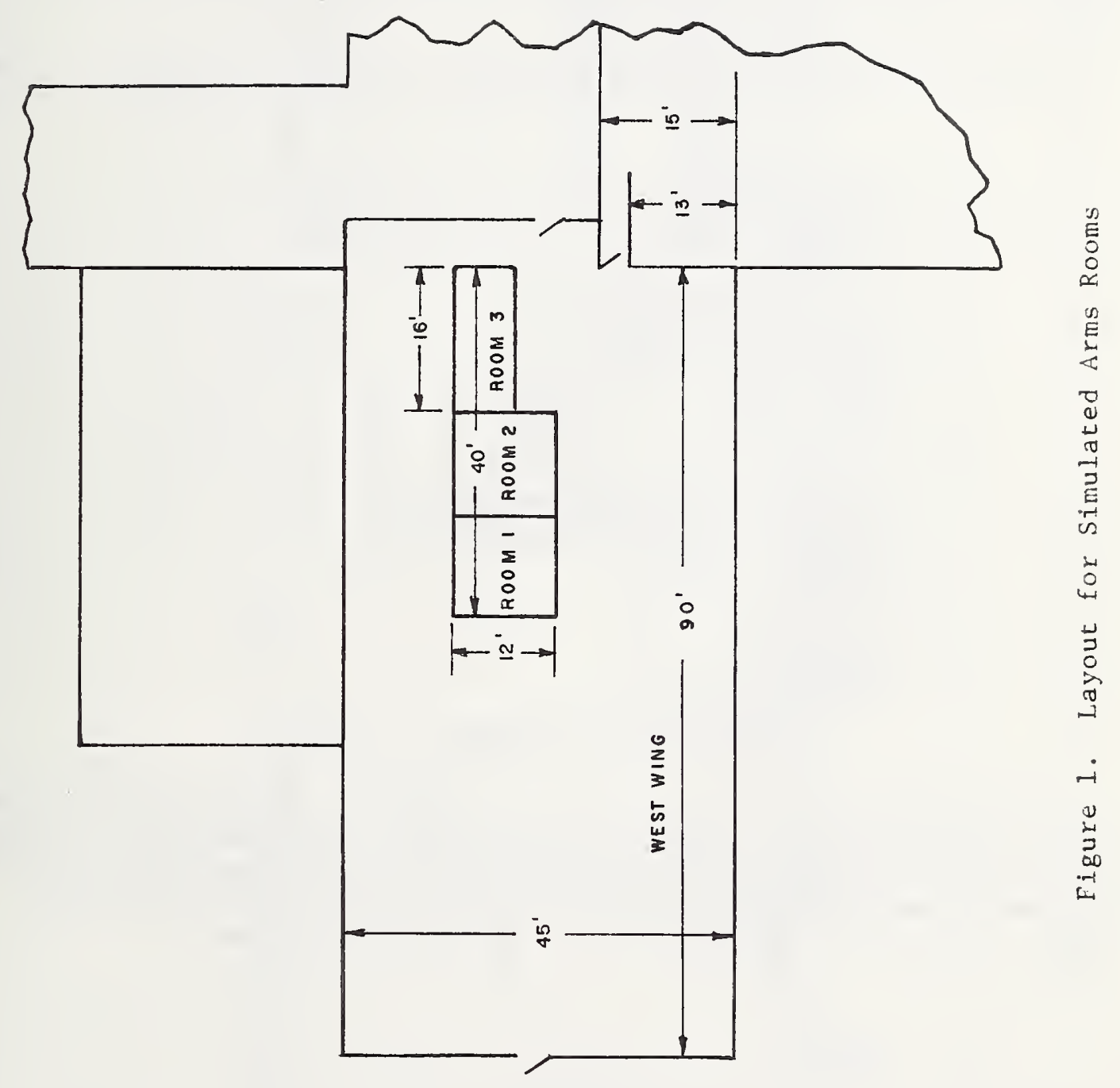




\section{TEST IDENTIFICATION}

Each proposed target area for a penetration attack was assigned an alphanumeric identifier which was painted on the external surface of the selected barrier adjacent to the perimeter of the planned opening. It is used to label test data from each attack and is especially helpful in identifying photographic records. The identifier consists of a number-letter-number sequence in which the first number indicates the barrier to be attacked. The following letter indicates the area of the attack and the general nature of the initial tooling used on that area. The final number is a sequence number associated with changes in tooling or to identify individual measurements. The sequence number is used in connection with data from the instrumentation and does not appear in the photographic records.

Letters designating initial tooling were selected from the following list:

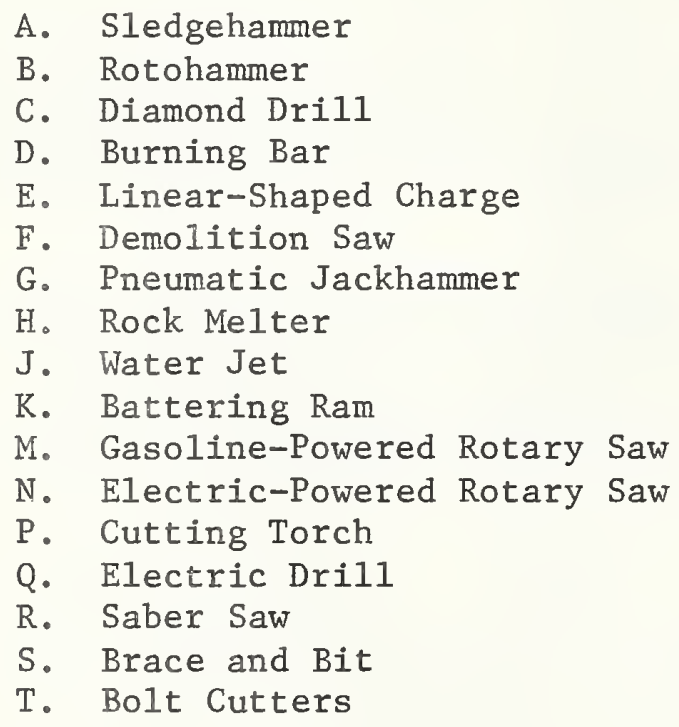

Some deviation from this list of designators occurred when changes in the test plan were occasionally made after the identifiers had been painted on the barrier. Rather than delay the test series to repaint the identifier, the testing proceeded using the original markings. Figure 2 shows the locations of all of the attack areas. 


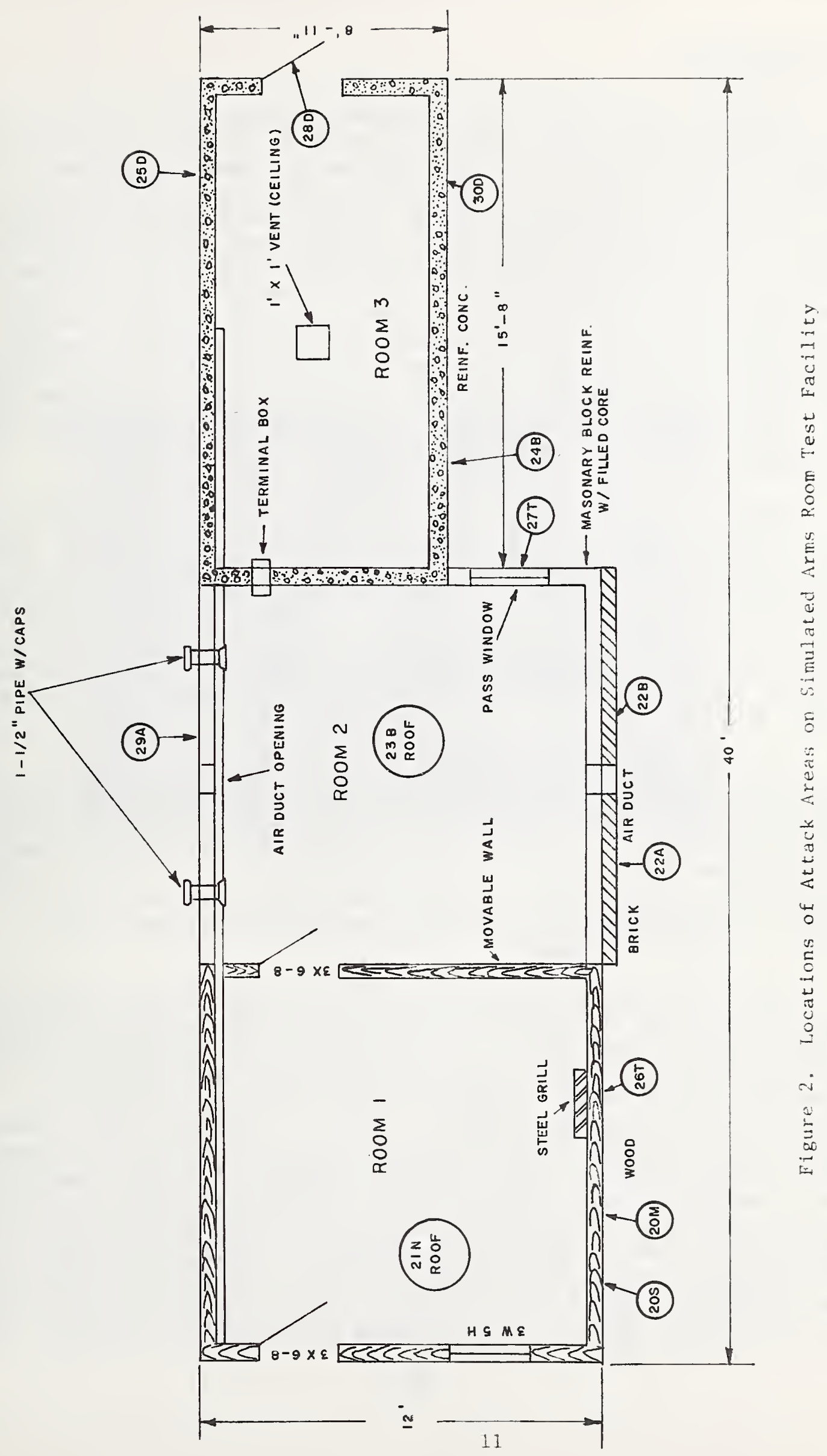


Acoustic and ultrasonic disturbances produced by the various attacks were observed using a $1 / 4^{\prime \prime}$ microphone having a nominally flat frequency response to above $50 \mathrm{kHz}$. This was mounted on a small tripod and together with its preamplifier and power supply was positioned inside the room involved during each attack. The distance from the microphone to the inner surface of the area under attack ranged from a minimum of about $6^{\prime}$ to a maximum of about $12^{\prime}$. Since the variation in attenuation over this distance range is less than the variation in sound pressure levels which may result from reinforcement or cancellation caused by reflections from the walls and corners of the room itself, no attempt has been made to normalize the observed data or to compensate for minor deviations in the frequency response of the microphone. All sound presarre levels (SPL)are expressed as dB reference a zero level of .0002 dynes per square centimeter and, for the reasons noted above, should be considered only as representative values.

Vibrational disturbances were picked up by piezoelectric transducers mounted on the interior surface of the room under attack. These had a frequency response extending to over $100 \mathrm{kHz}$. Their associated charge amplifiers were located nearby in a protective enclosure and were coupled by a 50-ohm transmission line to the data recording position which was external to the simulated arms rooms. The nominal separation between attack point and vibration transducer is reported with the data presented for each attack. Vibrational spectra are expressed in terms of peak g values.

The transmission lines from the charge amplifiers and microphone preamplifier were each $50^{\prime}$ long and terminated at a selector switch box arranged so that either one could be selected as the input to a real-time spectrum analyzer. The output of the spectrum analyzer was displayed on a storage tube oscilloscope and photographs were taken of samples of the spectra of the disturbances. The data recording instrumentation was typically clustered outside the arms rooms adjacent to the attack location as shown in figure 3 .

The spectrum analyzer was operated with a sweep width of $50 \mathrm{kHz}$, a sweep rate of $5 \mathrm{kHz}$ per cm (on the display), a sweep speed of $30 \mathrm{~ms}$ per $\mathrm{cm}$ and a bandwidth of $500 \mathrm{~Hz}$. The vertical axis of the display showed the spectral amplitude in a logarithmic mode with sensitivity of $10 \mathrm{~dB}$ per cm and covered a dynamic range of $60 \mathrm{~dB}$. The type of spectrum analyzer used does not have memory; that is, it displays those spectral components of the signal which are within its passband at the "instantaneous" center frequency of the sweeping passband. A single sweep provides a reasonably good representation of continuous signals such as from a motor-driven tool or a cutting torch, but on intermittent signals, such as hammer blows, many sweeps may be required to develop an estimate of their spectrum over the full $50 \mathrm{kHz}$ sweep width. This is because on one hammer blow the passband of the analyzer may be sweeping past the $5 \mathrm{kHz}$ region and on the next it may be sweeping past the $35 \mathrm{kHz}$ region. Under 


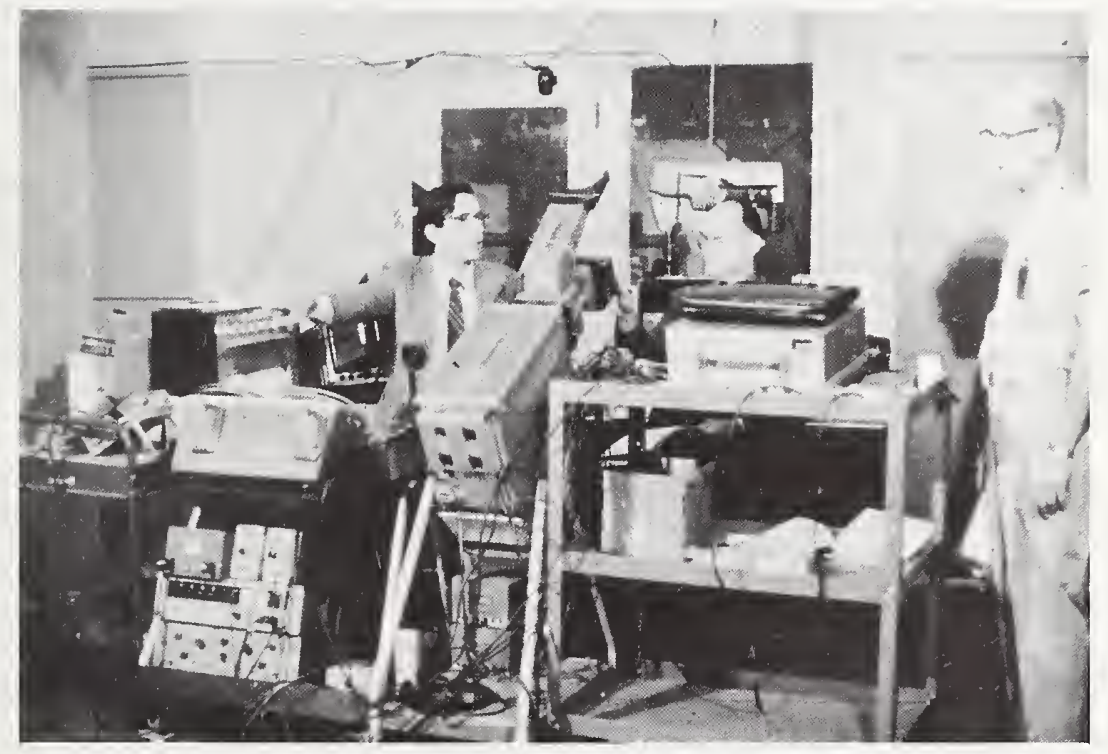

Figure 3. Data Collection Instruments 
circumstances such as these, multiple sweeps were collected on the storage tube oscilloscope prior to photographing them whenever the attack duration was long enough for this to be feasible.

On some of the tests, peak sound pressure levels were also recorded from a position outside of the arms rooms using a hand-held sound pressure level meter equipped with a $1 / 2^{\prime \prime}$ microphone. These observations are reported as external SPL values $(\mathrm{dB})$ together with the distance from the attack point to the observer.

During a portion of the tests, audio frequency disturbances were picked up using a one-inch microphone within the room under attack. These data were recorded on magnetic tape and subsequently analyzed and reduced to $1 / 3$ octave bandwidth sound pressure levels in the 20 to $20,000 \mathrm{~Hz}$ frequency bands. The resulting tabulations are presented in the appendix.

Throughout the test sequence, each penetration that was made into one of the rooms was covered over by an aluminum panel before the next penetration was begun. The aluminum panels were held in place with 4" wide pressure sensitive tape and were intended to reduce the level of acoustical disturbance within the room resulting from normal test crew activities outside the room.

Timing information on the penetration tests was derived from a variety of sources including a hand-held stopwatch, a strip chart event recorder and by manual control of the application of power to a selfstarting electric clock with a sweep-second hand. A test plan objective was to try to accumulate three time values associated with each attack: (a) working time, (b) elapsed time, and (c) time from start of attack until the first J-SIIDS alarm. Working time is considered that amount of time during which the attack tooling is being actively employed. It does not include intervals required for changing tools, selecting the next place to drill a hole, changing to a fresh operator when the first attacker becomes fatigued, or similar interruptions to an attack which would be necessary with even a skilled team of determined attackers. Elapsed time was planned to take into account these additional factors. For a number of reasons it was not always possible to.obtain a value for elapsed time which could be considered representative of what could be accomplished by a determined team of attackers. Where values were obtained which were considered nonrepresentative, they are omitted from this report.

The accuracy of all of the timing information was also slightly degraded by the fact that nearly all of the attacks were purposely stopped on from one to several occasions so that changes could be made in the sensitivity settings of the J-SIIDS equipment to permit the development of information on the gain control settings required for response to the various attacks. Thus, in most instances, attack time and elapsed time values represent the sum of a number of discrete time increments. There is a probable uncertainty on the order of at least \pm 1 second in the 
determination of each such increment. The uncertainty in the length of time between the start of the attack and the initiation of the first alarm is also believed to be about one second. 
The first attack was on the wooden wall of Room 1 . A hand brace with $1^{\prime \prime}$ wood bit was used to make two holes in diagonally opposite corners of the rectangular perimeter outline. Then an electric saber saw with a $6 "$ course-toothed blade was used. The blade was inserted in each hole and two cuts were then made outward to each of the remaining corners of the rectangle freeing the central plug (see fig. 4). A vibration transducer was mounted on the interior of the wall at a distance of $3^{\prime}$ from the center of the opening.

The first hole required 19 seconds working time. The second hole was aborted after 28 seconds when the lead screw of the bit entered a crack between plarks of the inner layer and the bit would not feed. A new hole was then started and was completed 16 seconds later. A sample of the acoustical disturbances is shown in figure 5. The vibrational disturbances were not noticeable above the ambient vibrational backgrount. Sawing required 45 seconds with acoustical and vibrational spectra as shown in figures 6 and 7 , respectively.

In this attack, the total working time was 1.33 minutes, the elapsed time was 1.55 minutes, and the first J-SIIDS alarm occurred 27 seconds after the attack was started.

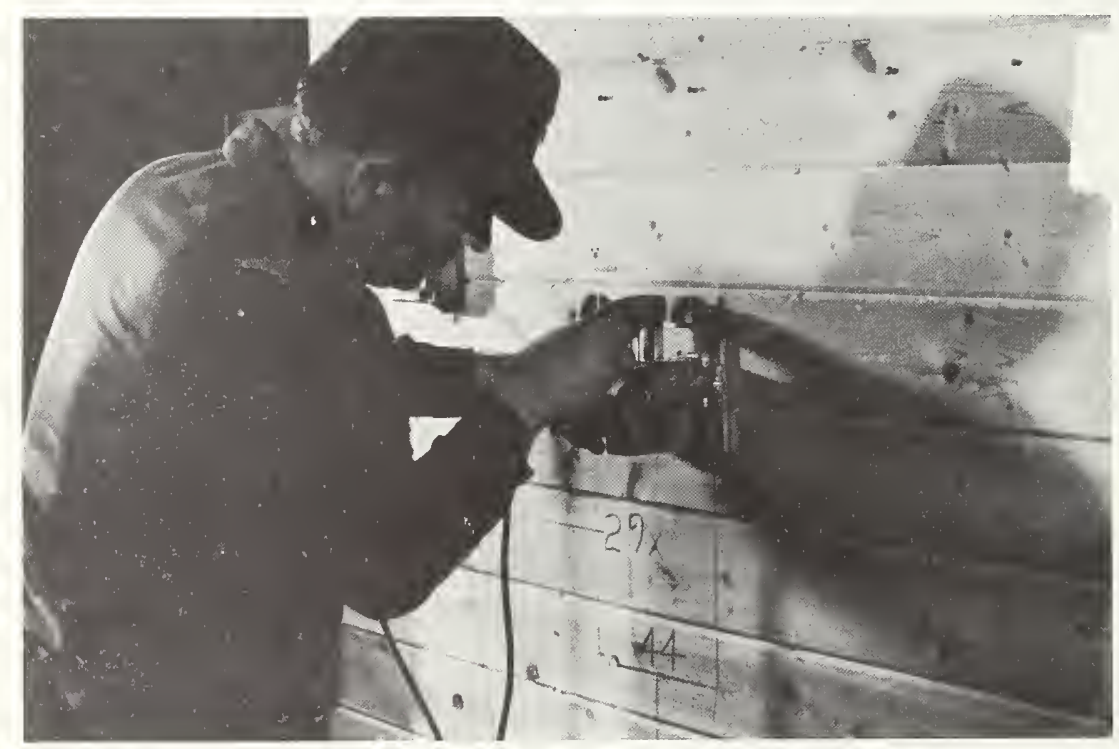

Figure 4. Attack 20S 


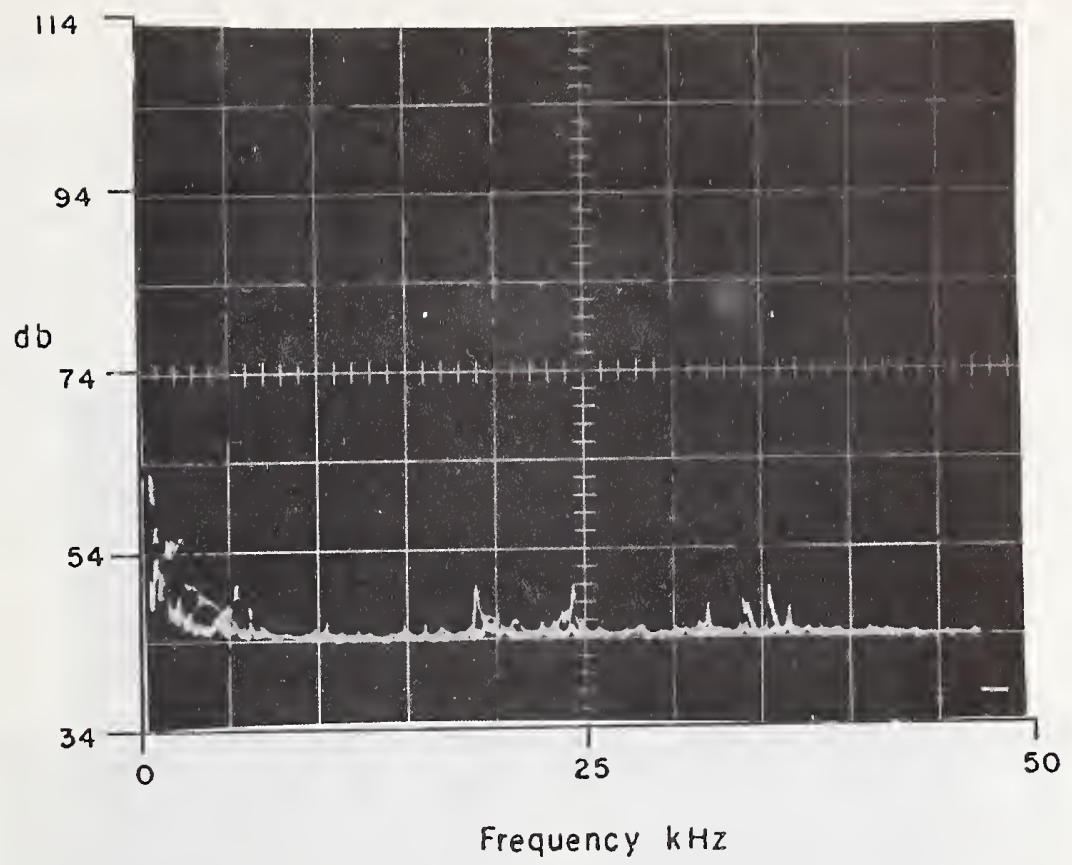

Figure 5. Acoustical Disturbances Made by Hand-operated Brace and Bit

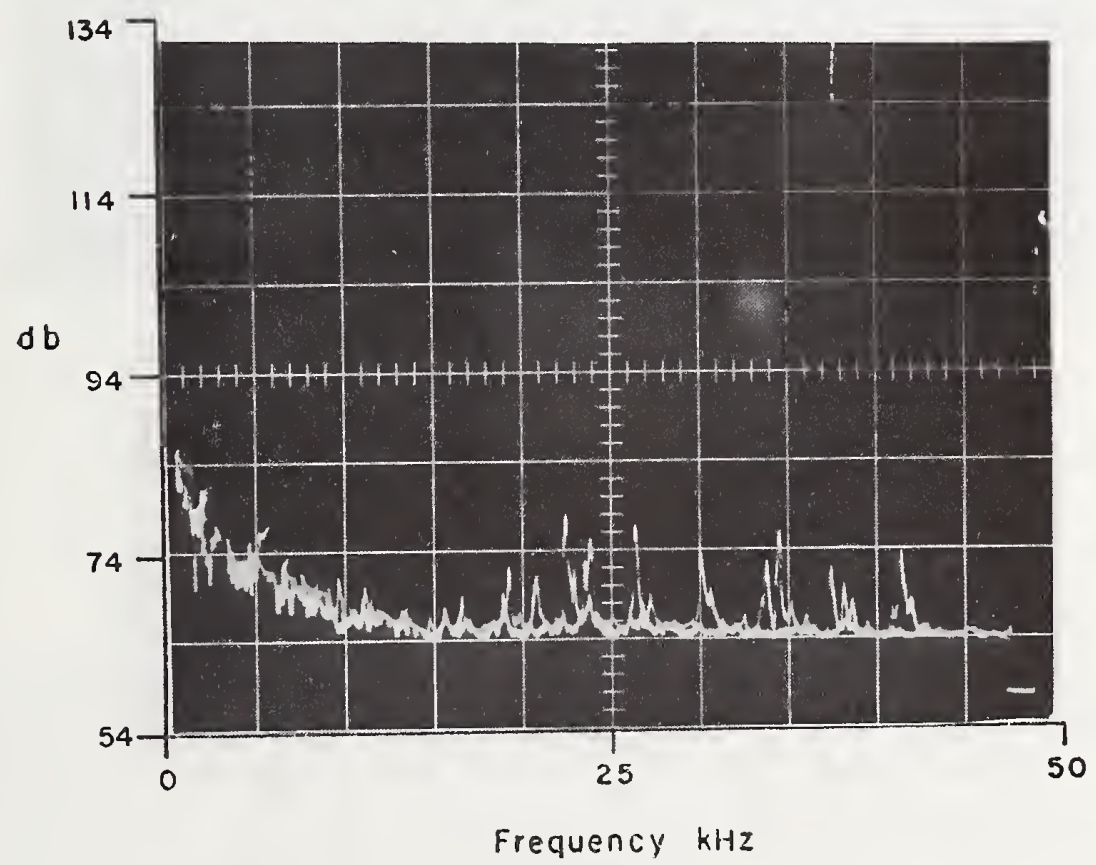

Figure 6. Acoustical Disturbances from Electric Saber Saw 


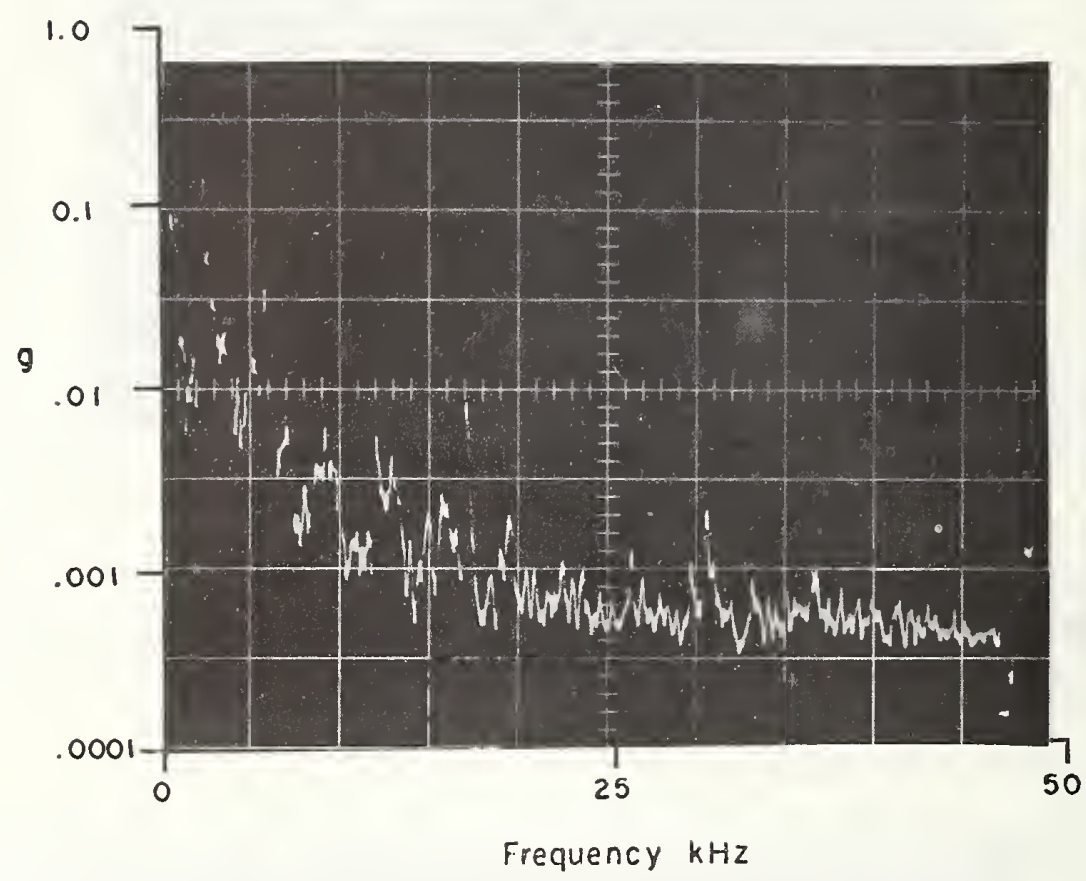

Figure 7. Vibrational Disturbances from Electric Saber Saw 
Location $20 \mathrm{M}$ was adjacent to $20 \mathrm{~S}$ and centered $3^{\prime}$ from the unchanged vibration transducer position. A gasoline-powered rotary saw had been scheduled for use in this attack. Because of mechanical problems, an electric-powered rotary handsaw with a 7-1/4" carbide-tipped blade was substituted and was used to make 4 cuts along the sides of the rectangular opening as shown in figure 8. Then the plug was knocked out with one blow from a sledgehammer. The working time was 1.30 minutes, the elapsed time 1.62 minutes, and the first J-SIIDS alarm occurred 5 seconds after the attack started. Acoustical and vibrational disturbances are shown in figures 9 and 10 .

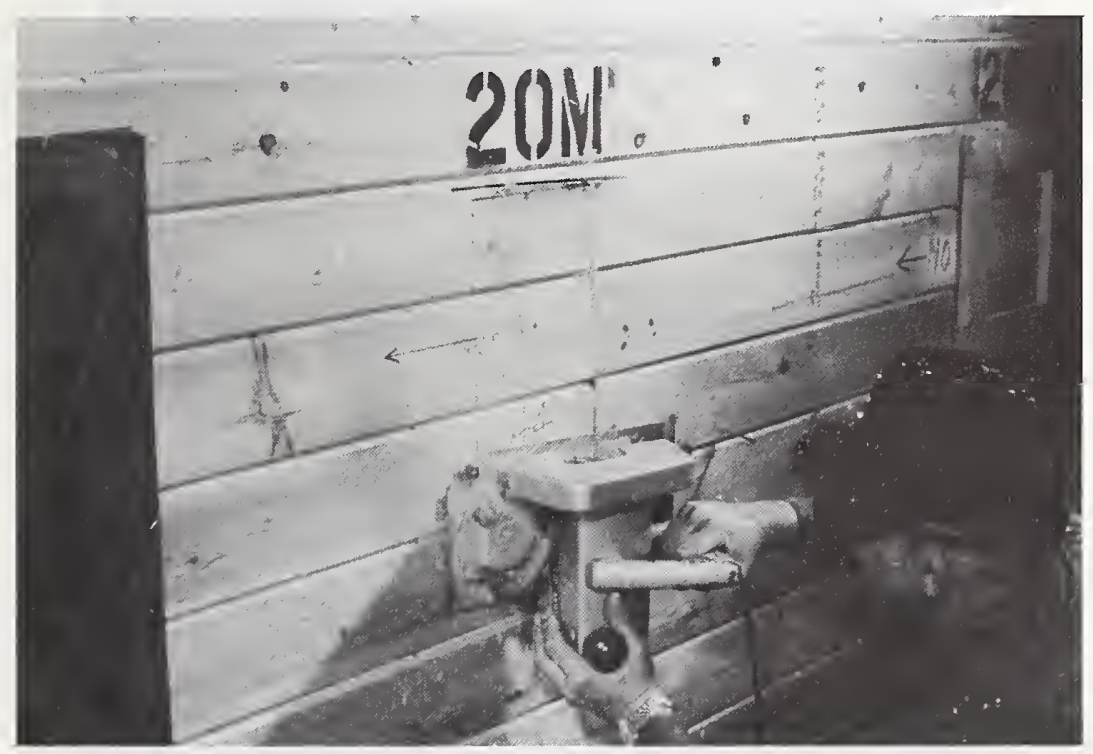

Figure 8. Attack $20 \mathrm{M}$

Following attack 20M, a brief test was made to estimate the disturbances likely to be produced by a power-driven wood bit. This was accomplished by drilling sample holes in the area between the previous two attacks. A $3 / 4^{\prime \prime}$ wood bit was used in a $3 / 8^{\prime \prime}$ variable speed electric drill. Acoustical disturbances are shown in figure 11 and vibrational disturbances in figure 12. 


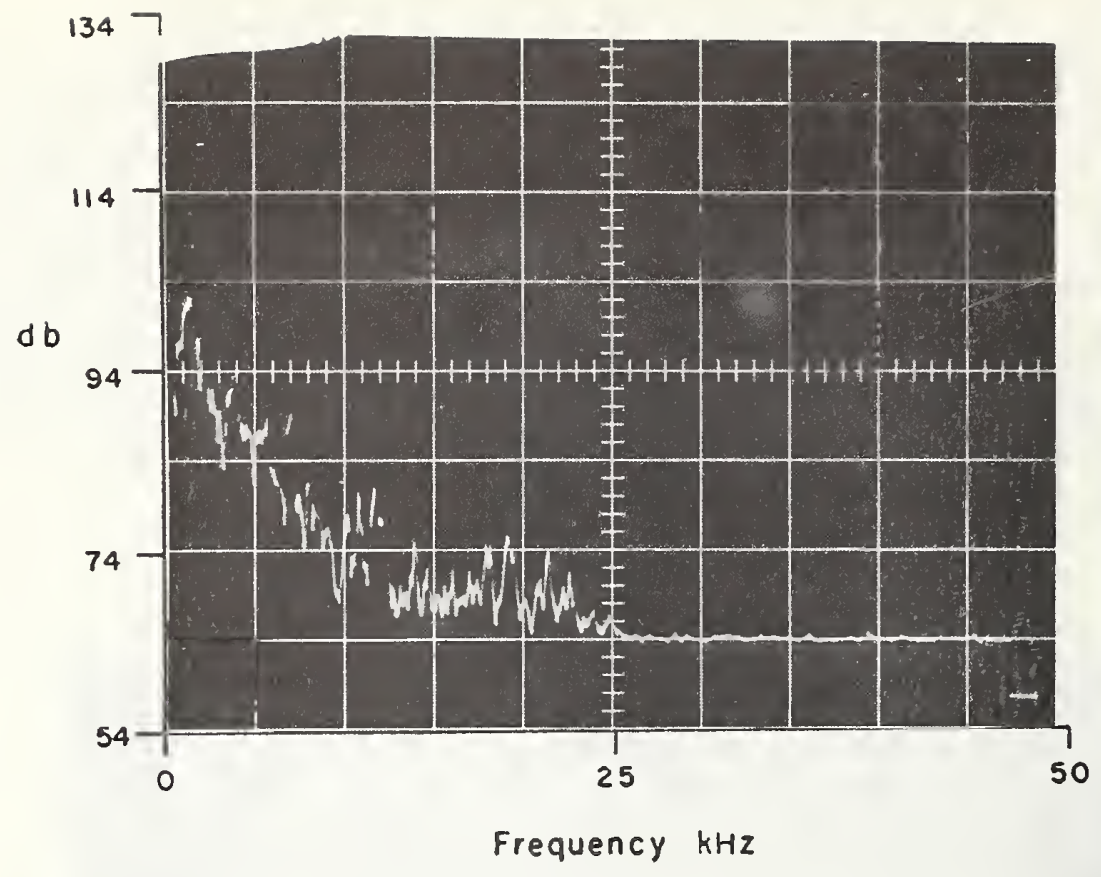

Figure 9. Acoustical Disturbances from Rotary Electric Saw.

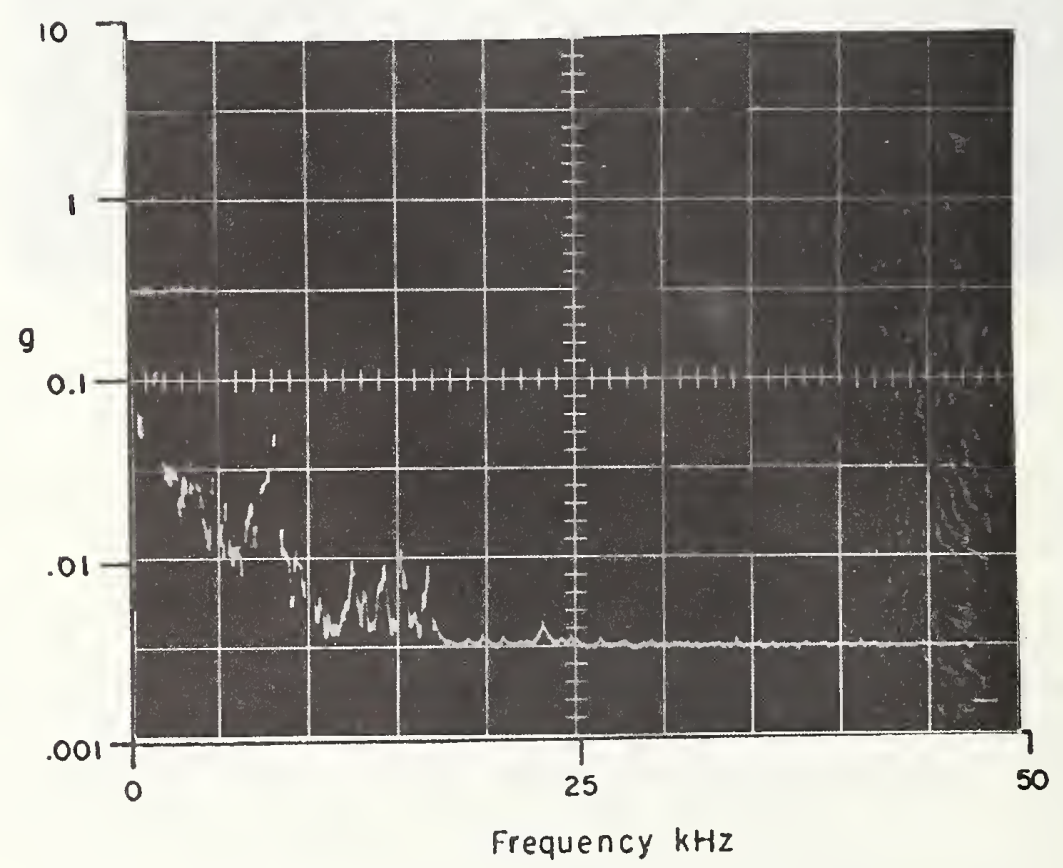

Figure 10. Vibrational Disturbances from Rotary Electric Saw 


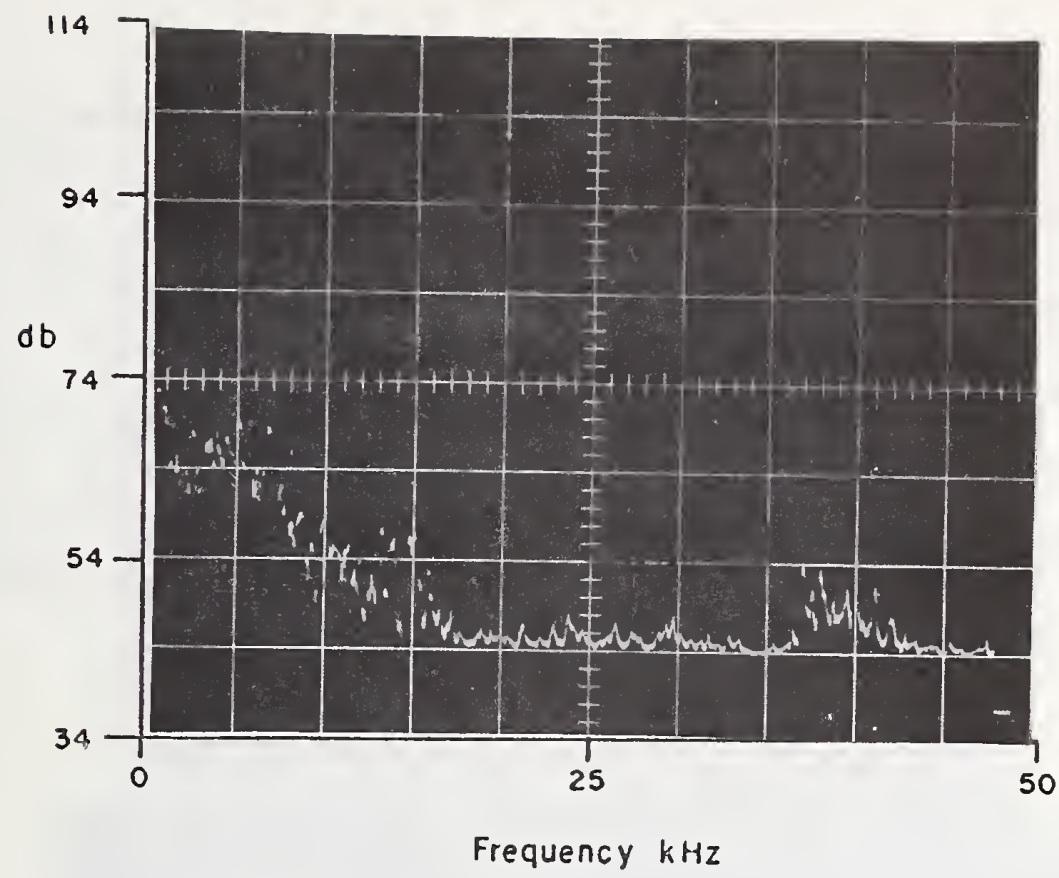

Figure 11. Acoustical Disturbances from 3/4" Wood Bit Used with 3/8" Variable Speed Electric Drill

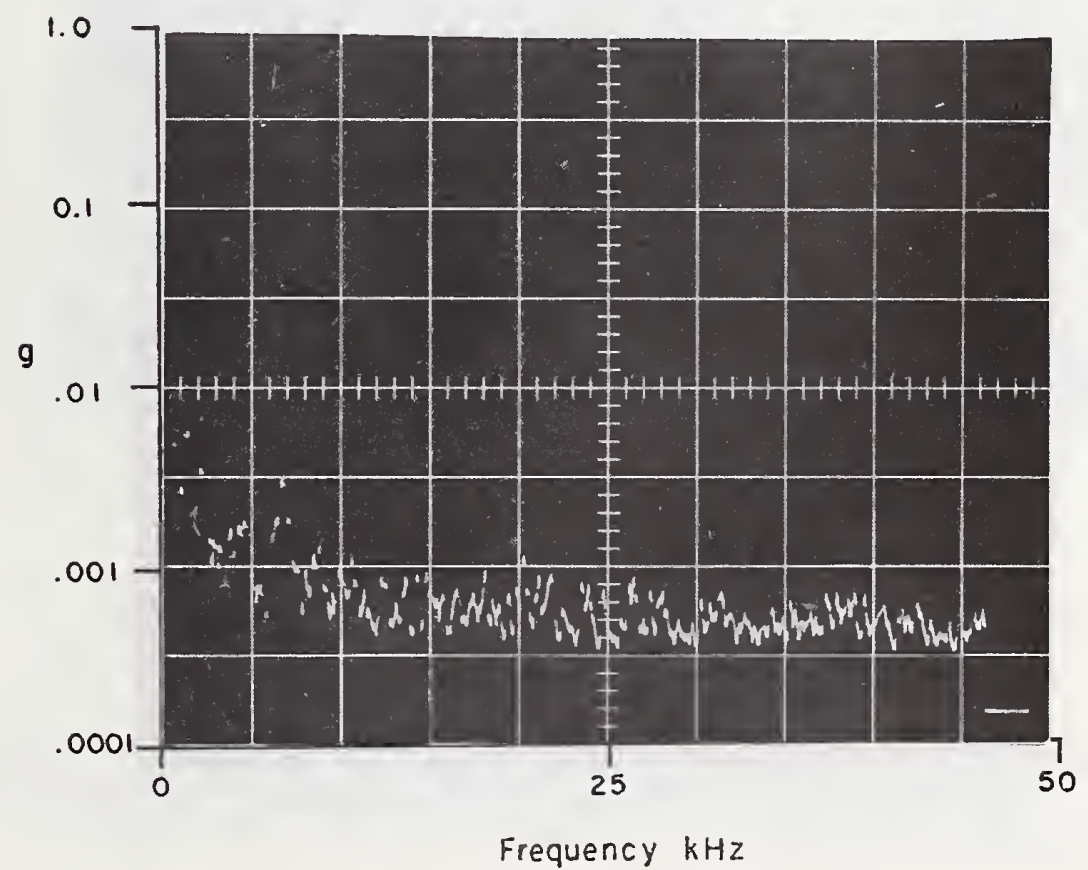

Figure 12. Vibrational Disturbances from 3/4" Wood Bit and Electric Drill 
Location $21 \mathrm{~N}$ was centered on the roof of Room 1 at a distance of $8^{\prime}$ from the vibration transducer. The vibration transducer was mounted on an interior wall of the room at a point 2' below the roof. Thus, the transmission path included $2^{\prime}$ of wall and $6^{\prime}$ of roof of the structure. The attack location was chosen so that the opening would straddle one of the $2^{\prime \prime} \times 6^{\prime \prime}$ wooden rafters so that this would have to be cut in two places to complete the penetration. A $1-1 / 2$ horsepower electric saw with a 7-1/4" combination blade was used to cut through the planking along the rectangular perimeter of the opening in 0.5 minute. The rafters were then cut with a carpenter's handsaw in 0.96 minute, as shown in figure 13. The total working time was 1.47 minutes with elapsed time of 1.73 minutes. The initial J-SIIDS alarm occurred 5 seconds after the attack began.

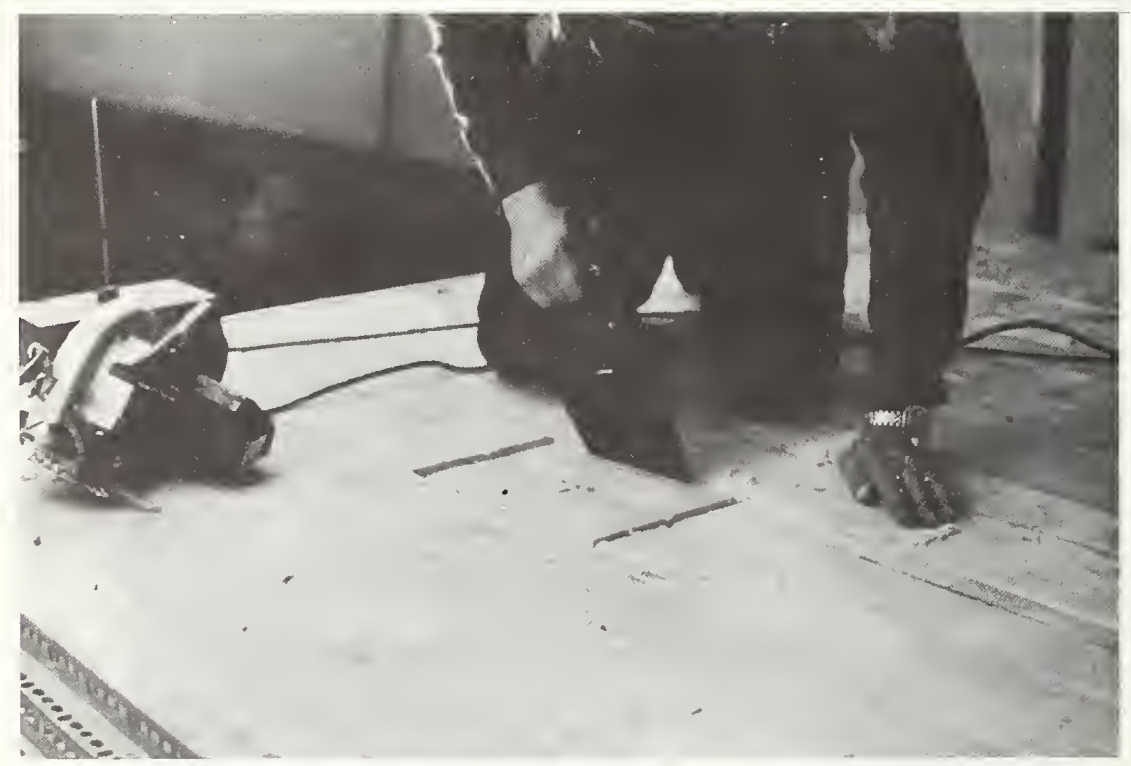

Figure 13. Attack $21 \mathrm{~N}$

Samples of the acoustical, figure 14 , and vibrational, figure 15 , disturbances from the electric saw were quite similar to those observed from the different electric saw and blade used in Attack $20 \mathrm{M}$. 
The vibrational disturbances produced by the handsaw are shown in figure 16. The handsaw produced a peak SPL of $98 \mathrm{~dB}$ observed at a distance of approximately $5^{\prime}$.

The opening produced by the attack is shown in figure 17 .

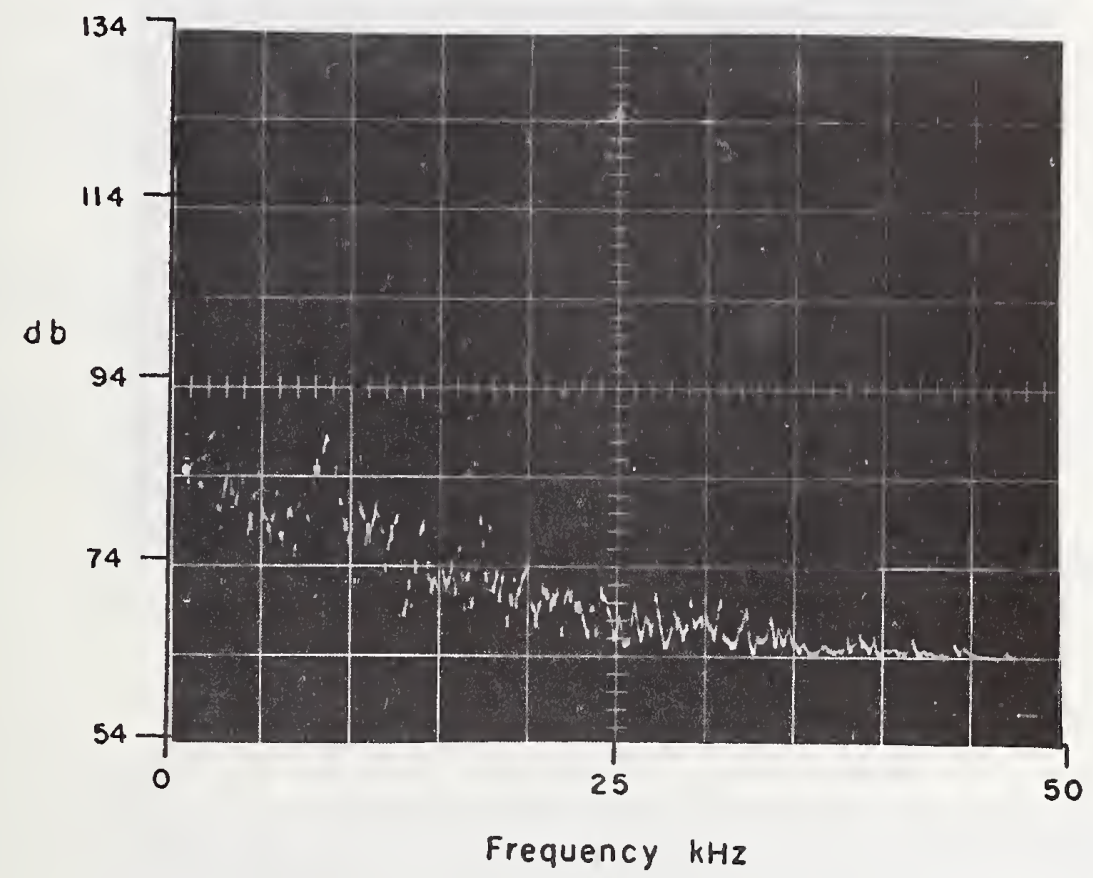

Figure 14. Rotary Electric Saw, Acoustical

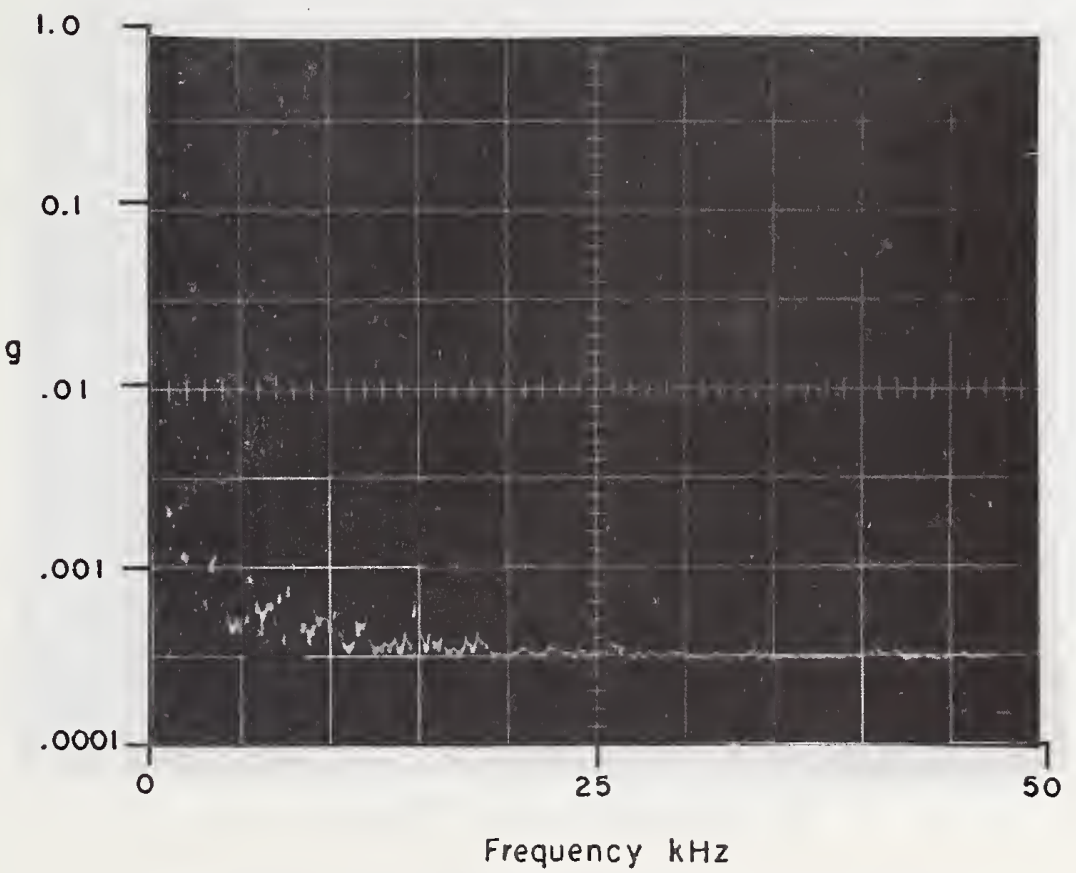

Figure 15. Rotary Electric Saw, Vibration through Eight-foot Transmission Path 


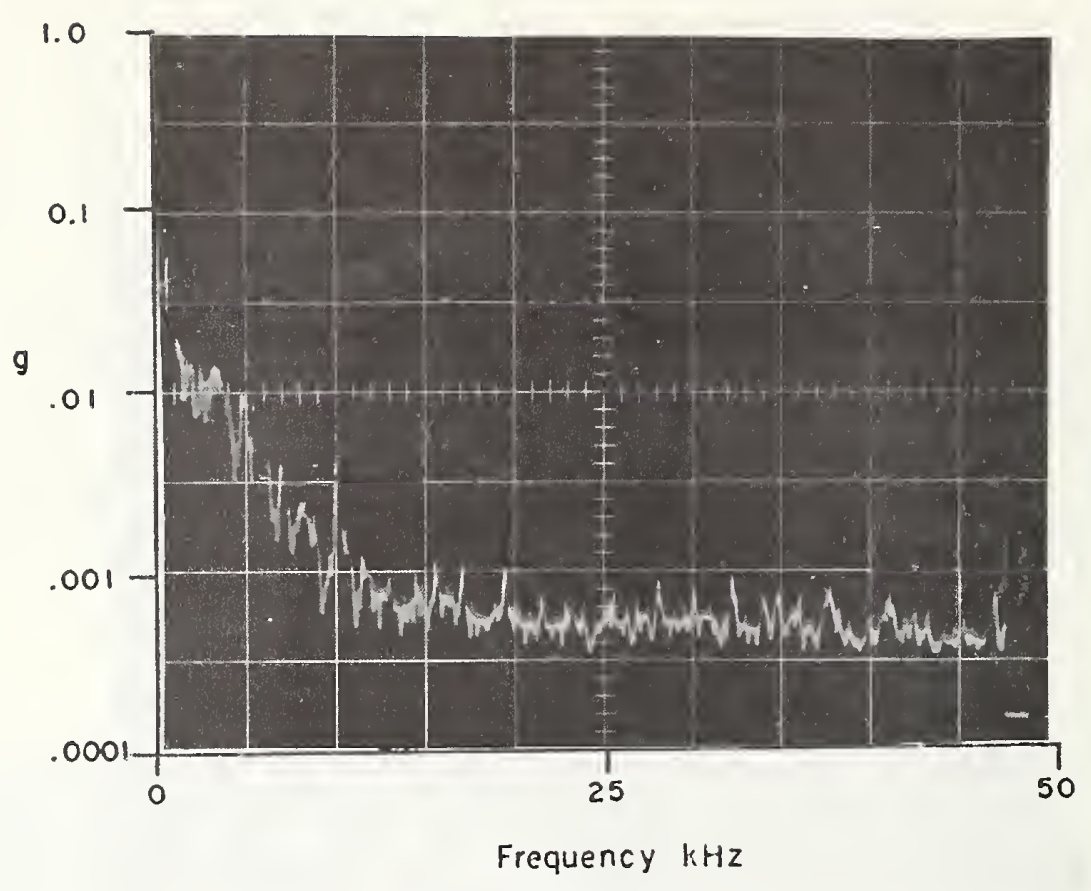

Figure 16. Vibration Produced by Handsaw Cutting Rafter

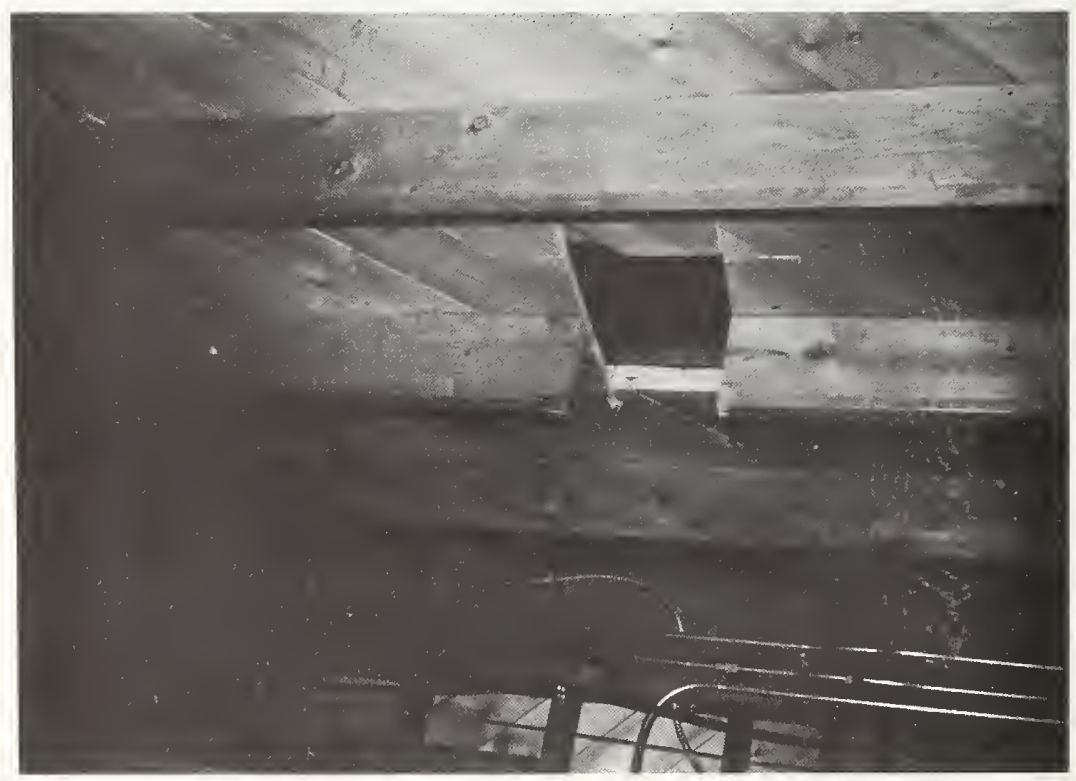

Figure 17. Interior View of Opening Produced by Attack 21N 
Location $26 \mathrm{P}$ was centered on a $3 / 16^{\prime \prime}$ thick expanded steel grill which was fastened to a window-like opening in Room 1, as shown in figure 18. The attack involved the use of an oxygen-acetylene cutting torch to cut out along the targeted rectangular perimeter. The torch was used with a No. 5 cutting tip and oxygen pressure of 30 p.s.i. and acetylene pressure of 12 p.s.i. The cutting required 3.05 minutes working time and 3.14 minutes elapsed time. A J-SIIDS alarm was initiated within 5 seconds after the torch was ignited and before the first cut was started.

The vibration pickup was located on the wall of Room 1 approximately $6^{\prime}$ from the grill and in the same position that it occupied during the earlier attacks.

Samples of the acoustical disturbances are shown in figure 19 and of the vibration disturbances in figure 20 .

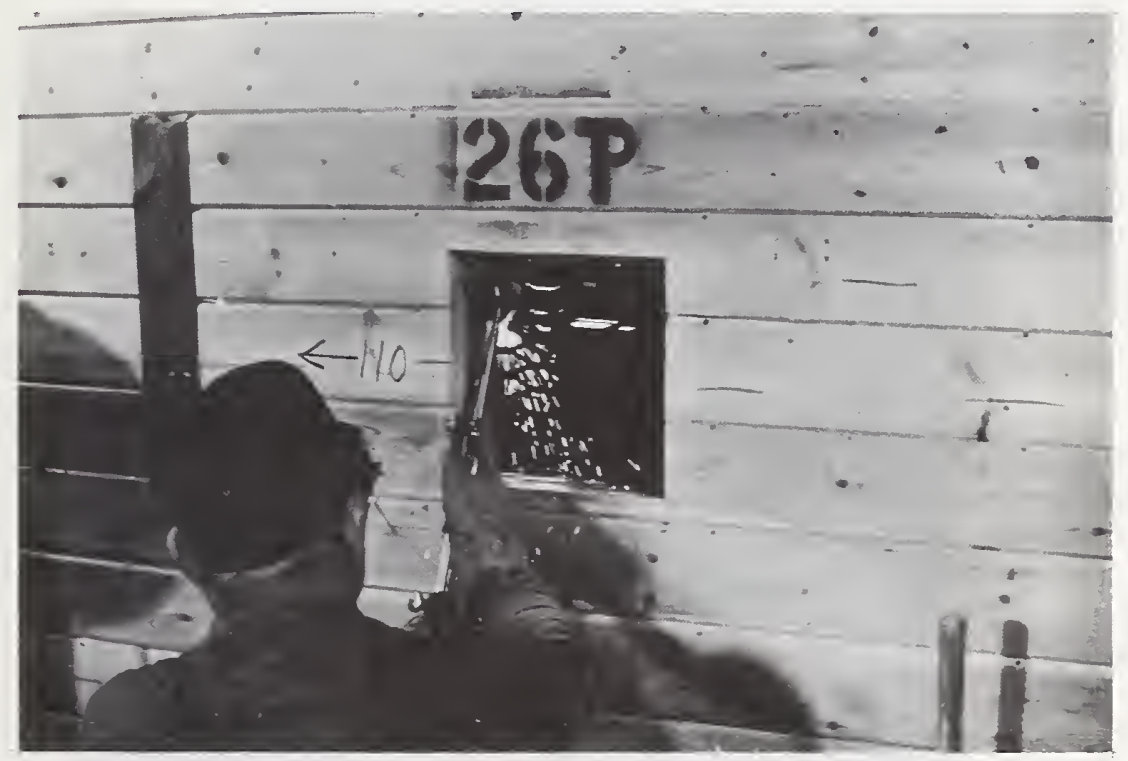

Figure 18. Attack 26P 


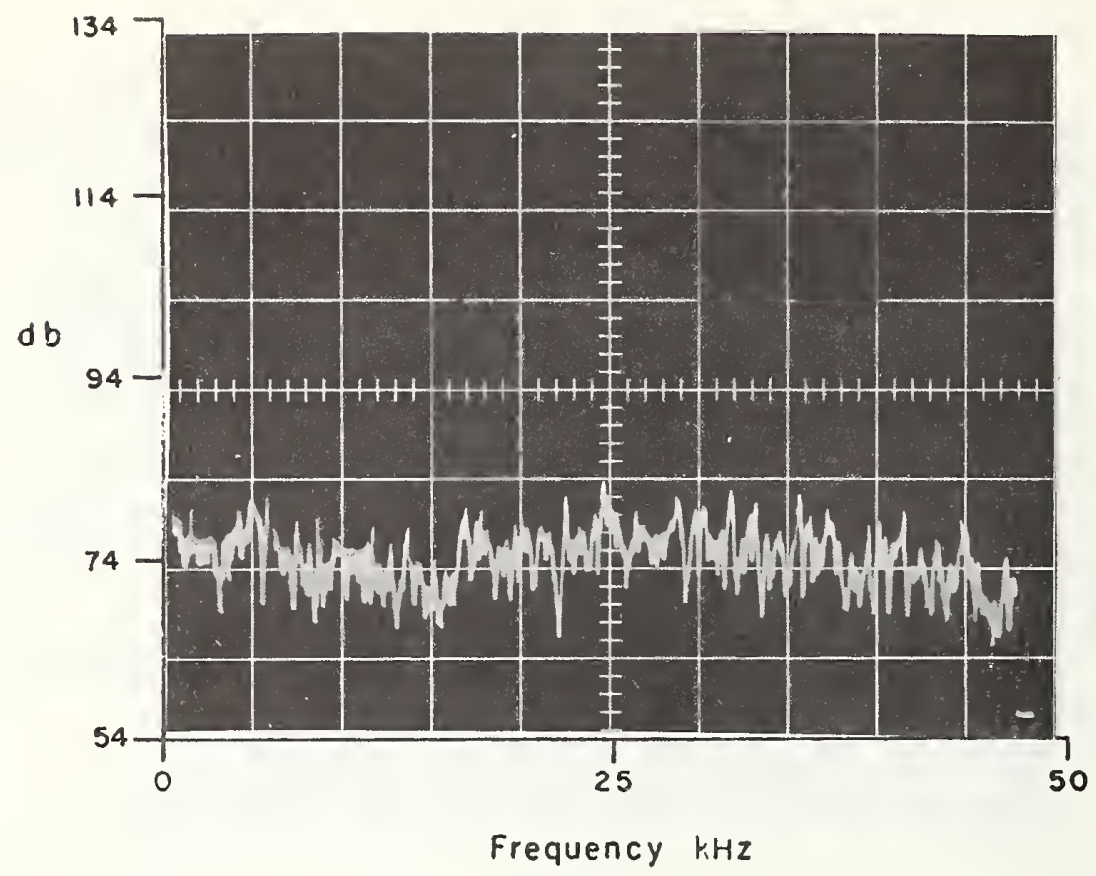

Figure 19. Acoustical Disturbances from Oxyacetylene Cutting Torch

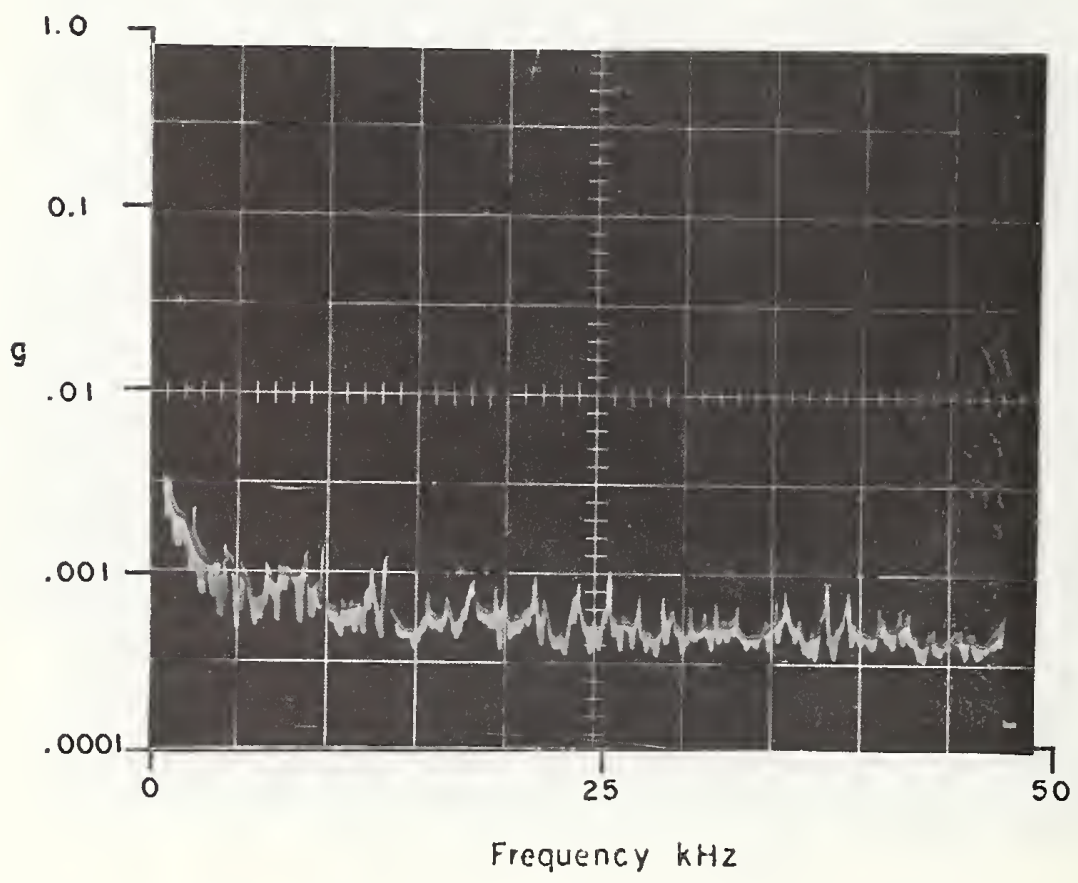

Figure 20. Vibration from Cutting Torch 
To conclude the activities in Room 1, another unscheduled test was performed. This involved breaking the glass in a window located at the west end of the room and cutting a coarse wire mesh attached rather flimsily to the inside of the window frame. The glass was quickly broken with a hammer and samples of the acoustic disturbances are shown in the multiple trace photograph of the spectrum analyzer output in figure 21. When a bolt cutter was used to cut the wire mesh, see figure 22 , it fell off of the window frame on the second or third cut so no actual total times are available. It is estimated that this penetration could have been completed in less than 30 seconds if the mesh had remained in place.

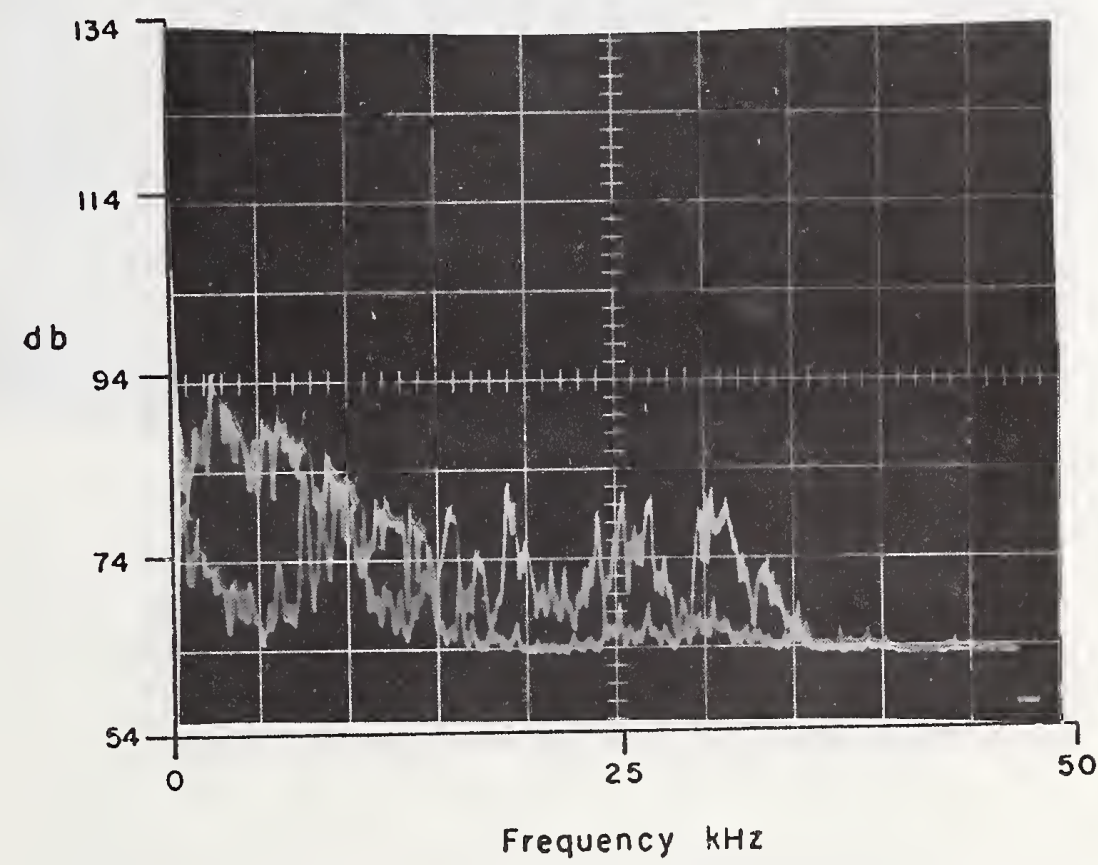

Figure 21. Multiple Sweep of Acoustical Disturbances from Breaking Glass Window 


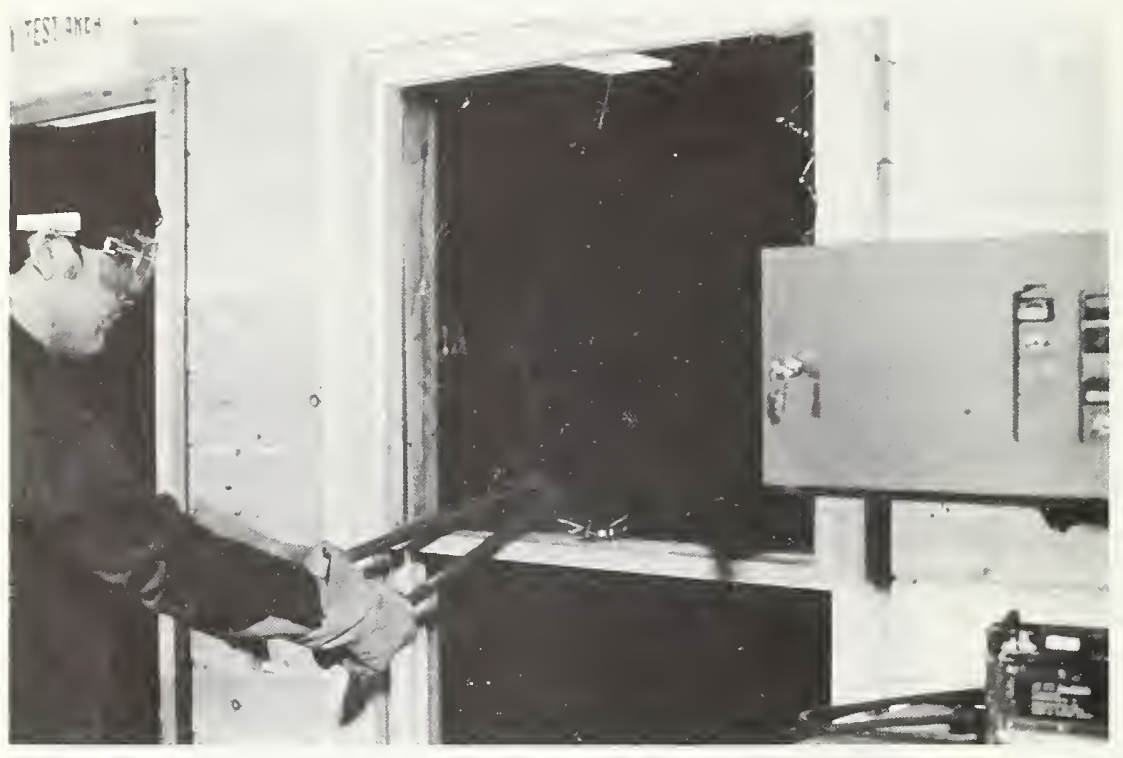

Figure 22. Breaking Glass Window with Bolt Cutters 
Attack 22A was conducted on Room 2 on a wall made up of a layer of brick veneer over 8"-thick cinder block. The brick was spaced out from the cinder block $1^{\prime \prime}$ and tied to every second course of block by metal ties. The block was reinforced with $5 / 8^{\prime \prime}$ diameter rod inserted vertically in the cores on approximately $14^{\prime \prime}$ centers. The cores of the block were presumably to have been filled with mortar. After the attack, examination showed the mortar filling to be rather loose and crumbly with a large number of voids.

The vibration transducer was mounted on the interior surface of the wall at a distance of $5^{\prime}$ from the center of the target area.

The attack was begun with a 10-pound sledgehammer and 28 blows produced an oversize opening through the brick veneer. These produced a peak SPL of $94 \mathrm{~dB}$ as observed at a distance of $10^{\prime}$ outside of the room. This was followed by 16 blows with a 12-pound sledgehammer, see figure 23, and 28 blows with a 10-pound sledgehammer which produced a break measuring approximately $2^{\prime \prime} \times 4^{\prime \prime}$ through the cinder block. Twelve more blows, with the end of the 10-pound sledgehammer being used as a ram, enlarged the opening to $10-1 / 2^{\prime \prime} \times 11-1 / 4^{\prime \prime}$. This required a tota1 of only 64 blows with a working time of only 2.12 minutes. By chance, the opening did not intercept one of the infrequent reinforcing bars so a cutting torch was not required. Samples of the acoustical disturbances prior to breakthrough are shown in figure 24 and of the vibrationa1 disturbances in figure 25. Both of these figures show multiple sweeps of the spectrum analyzer.

The first J-SIIDS alarm occurred 5 seconds after the attack was started. 


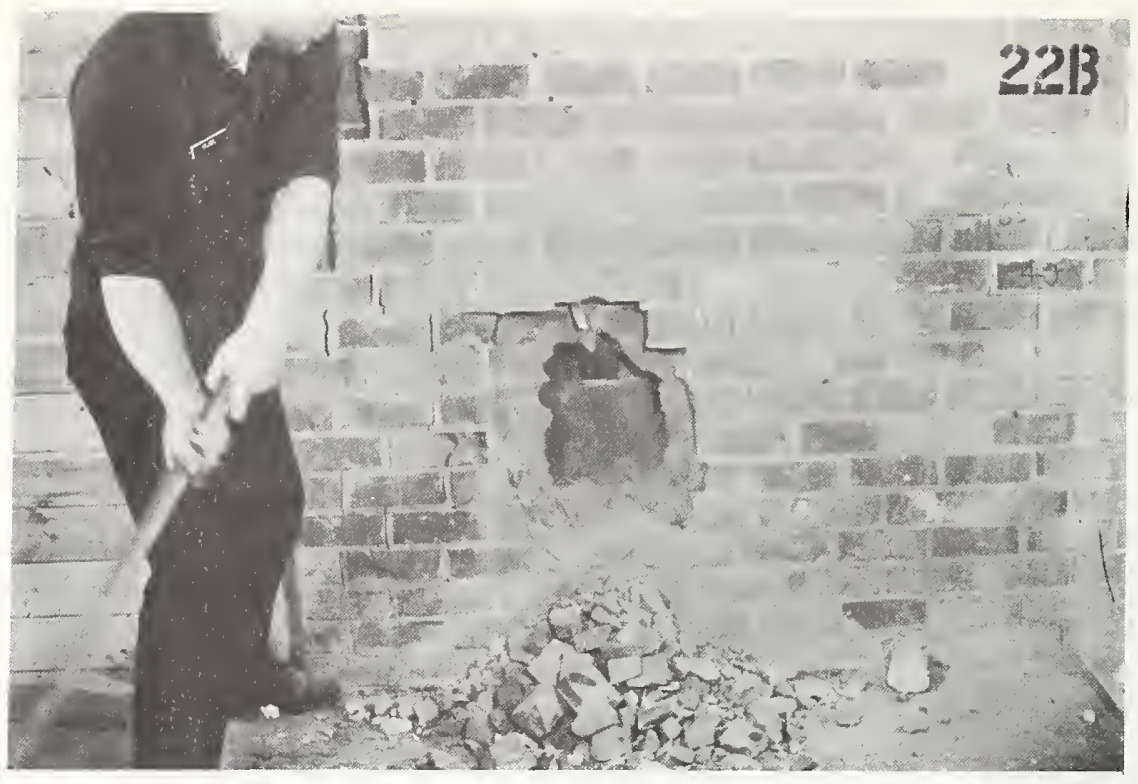

Figure 23. Attack 22A

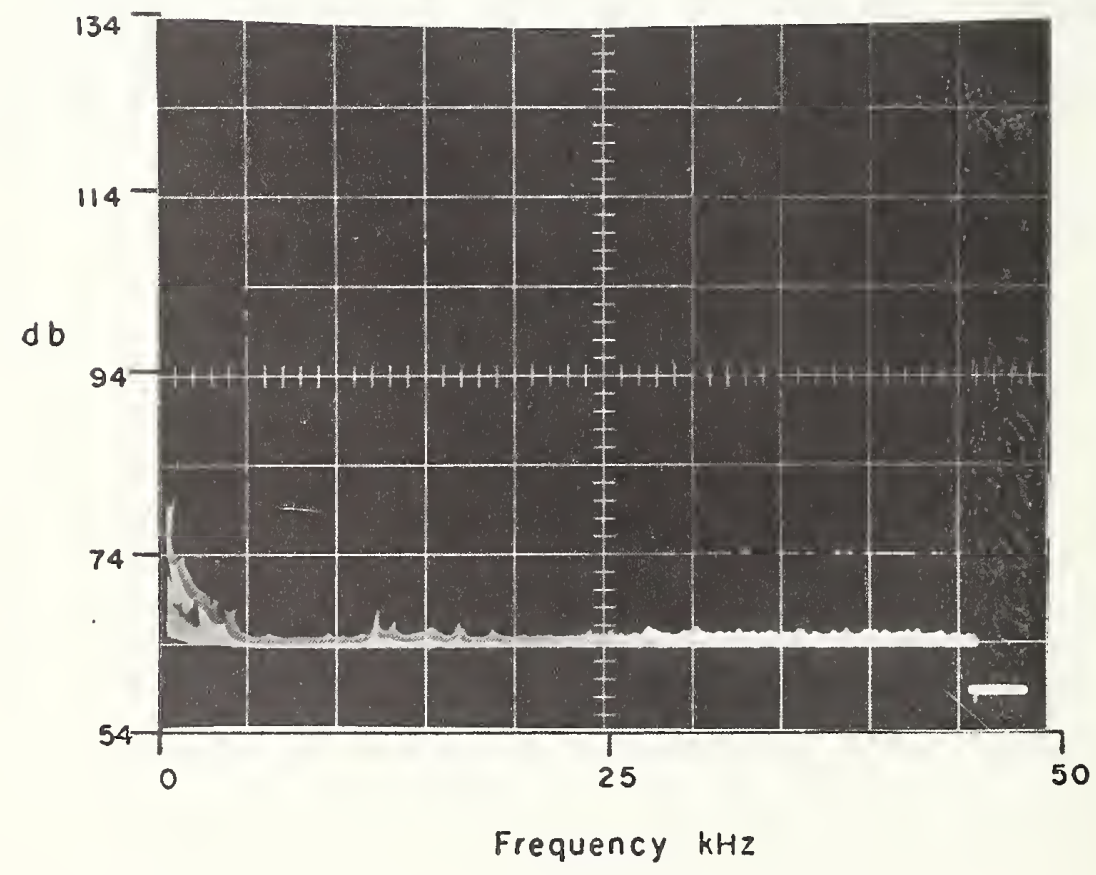

Figure 24. Acoustical Disturbance from Sledgehammer Prior to Breakthrough 


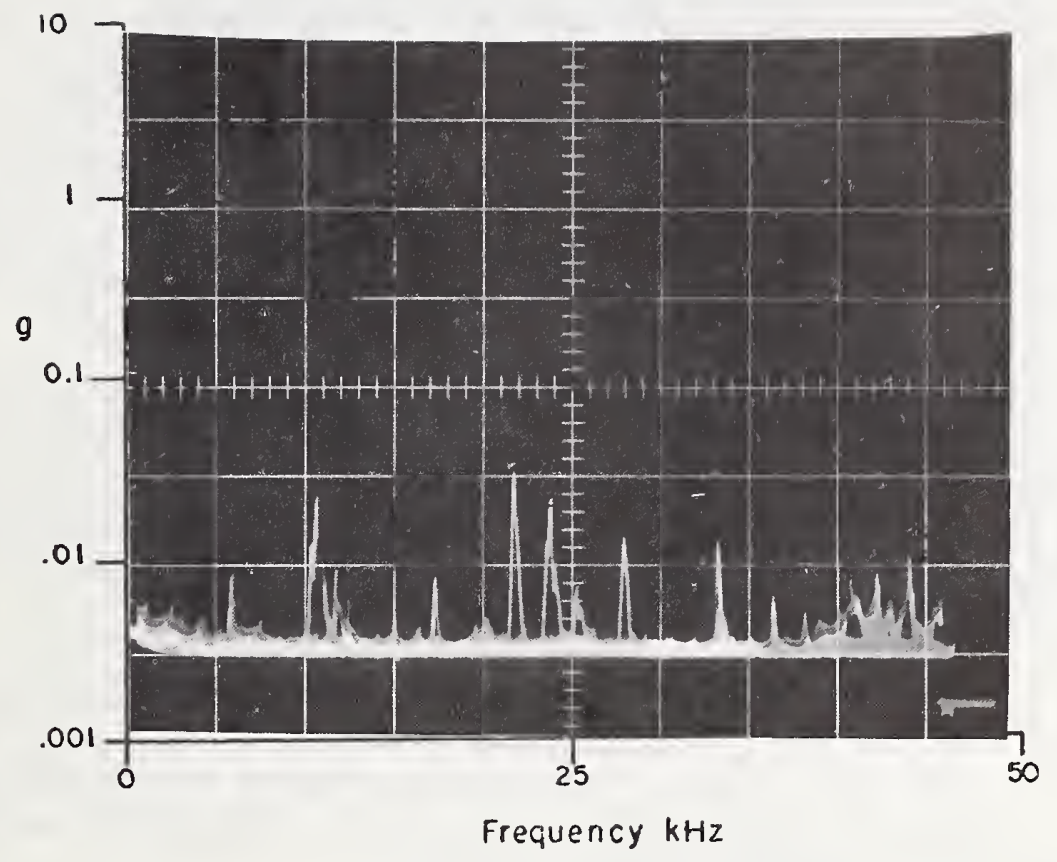

Figure 25. Vibrational disturbances from Attack 22A 
Attack 22B occurred on the same wall as $22 \mathrm{~A}$ and at a location centered 18" from the vibration transducers. This attack employed a rotohammer and $1-1 / 2$ " toothed-chisel to cut along the perimeter of the targeted opening. Mortar joints were prime targets to the extent that they reasonably corresponded with the perimeter. It required 4.87 minutes to clear a somewhat oversize opening through the brick veneer. This activity produced a SPL of 95 to $100 \mathrm{~dB}$ as observed at a distance of $12^{\prime}$ and produced acoustical disturbances inside the room as shown in figure 26 . Vibrational disturbances are shown in figure 27 .

Then the cinder block was attacked through the opening in the brick veneer as shown in figure 28 . It took 3.5 minutes with the rotohammer and approximately 0.25 minute with a sledgehammer to clear the block away making a suitably-sized hole containing a single reinforcing rod. Acoustical disturbance produced by the rotohammer are shown in figure 29 and vibrational disturbances in figure 30 .

Finally, the reinforcing rod was cut in 1.1 minutes with an oxygen acetylene torch using a No. 5 tip, oxygen pressure of 30 p.s.i. and acetylene pressure of 12 p.s.i.. The torch produced a peak SPL of $82 \mathrm{~dB}$ at $10^{\prime}$. Acoustic disturbances are shown in figure 31 and vibrational disturbances in figure 32 .

The total working time for this attack was 9.71 minutes and the first J-SIIDS alarm occurred 5 seconds after the attack started.

The opening produced was $13-1 / 4^{\prime \prime}$ high, 6-1/2" wide at the bottom, and $8-1 / 2^{\prime \prime}$ wide at the top. 


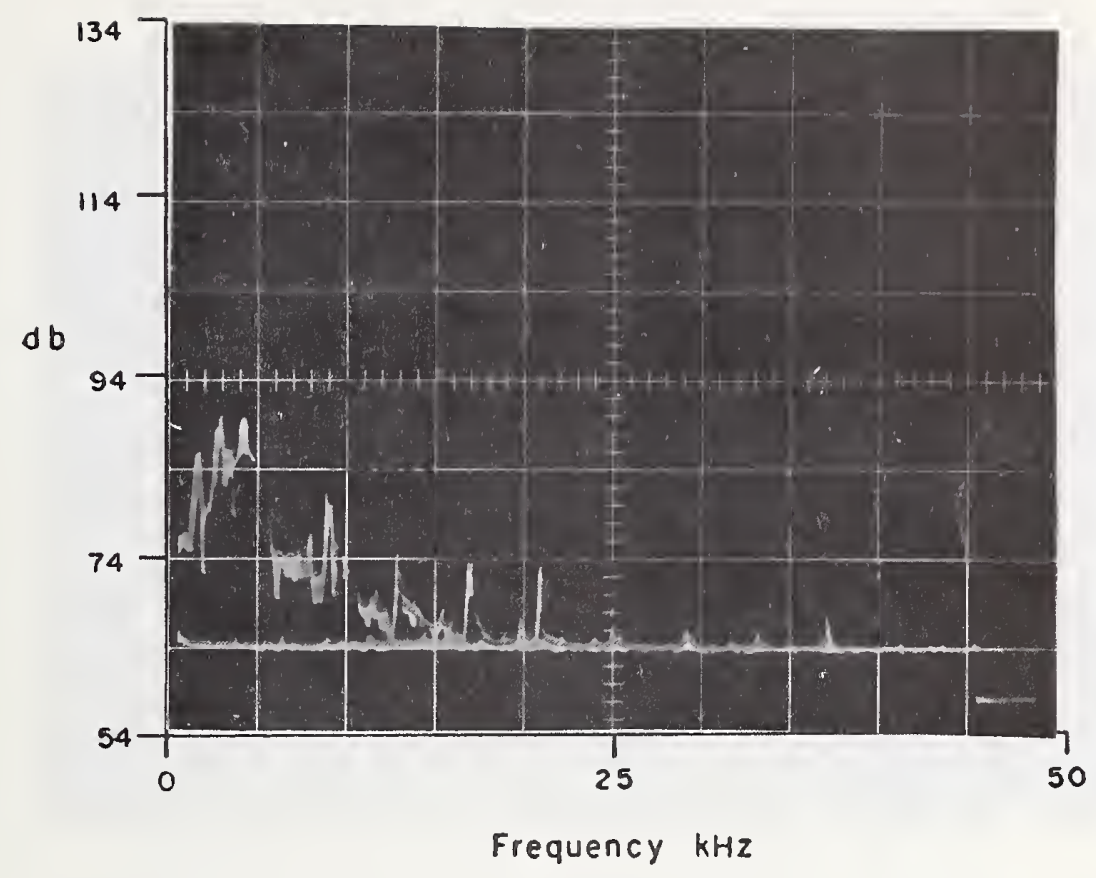

Figure 26. Acoustical Disturbance from Attack on Brick Veneer

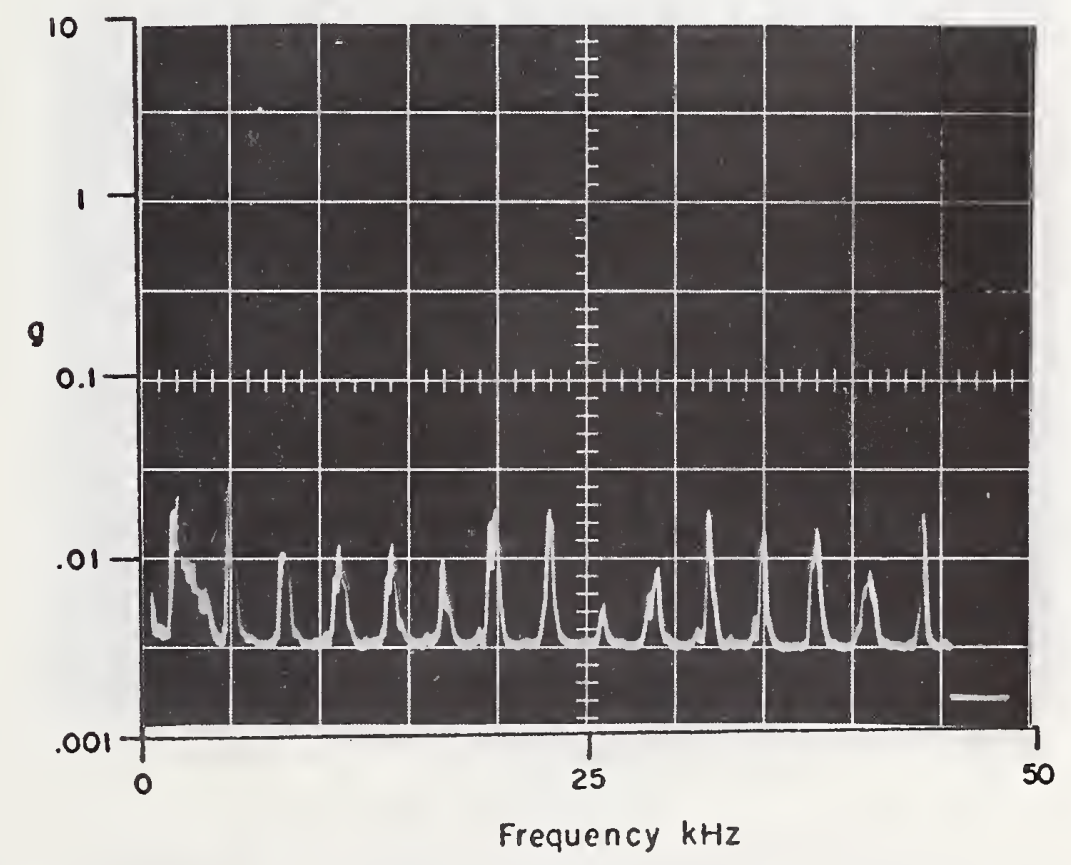

Figure 27. Vibration from Attack on Brick Veneer 33 


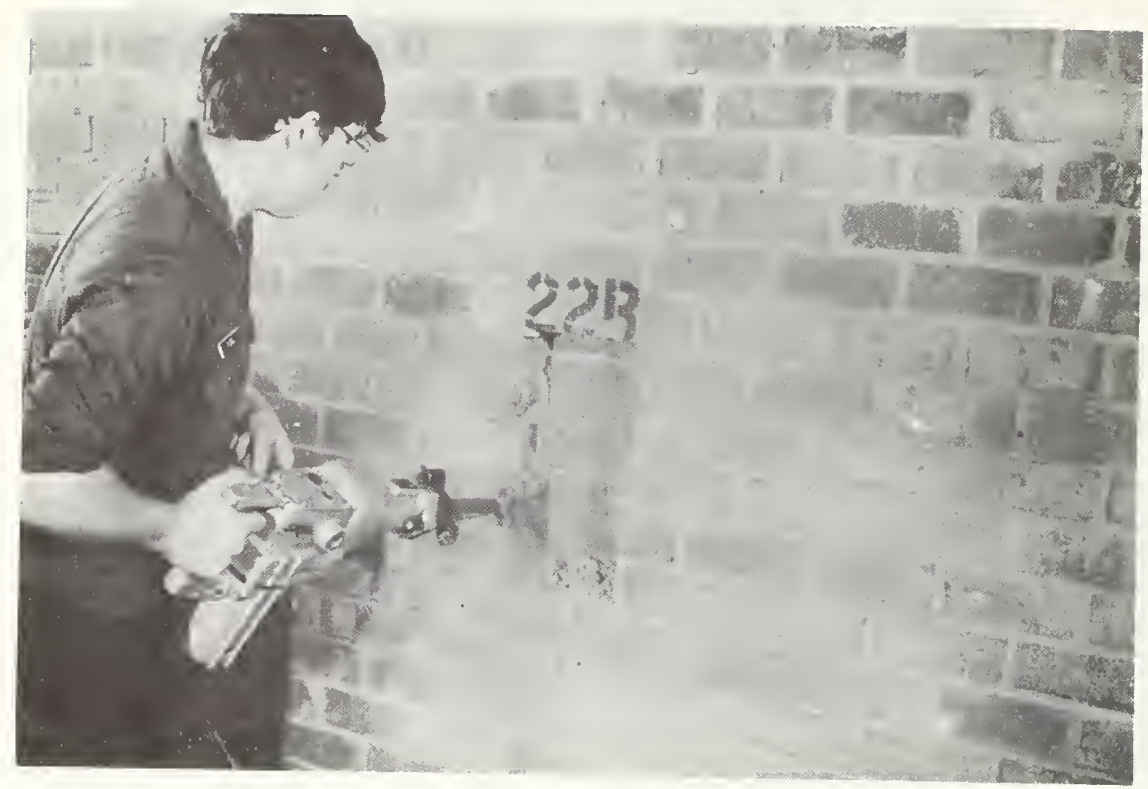

Figure 28. Attack 22B

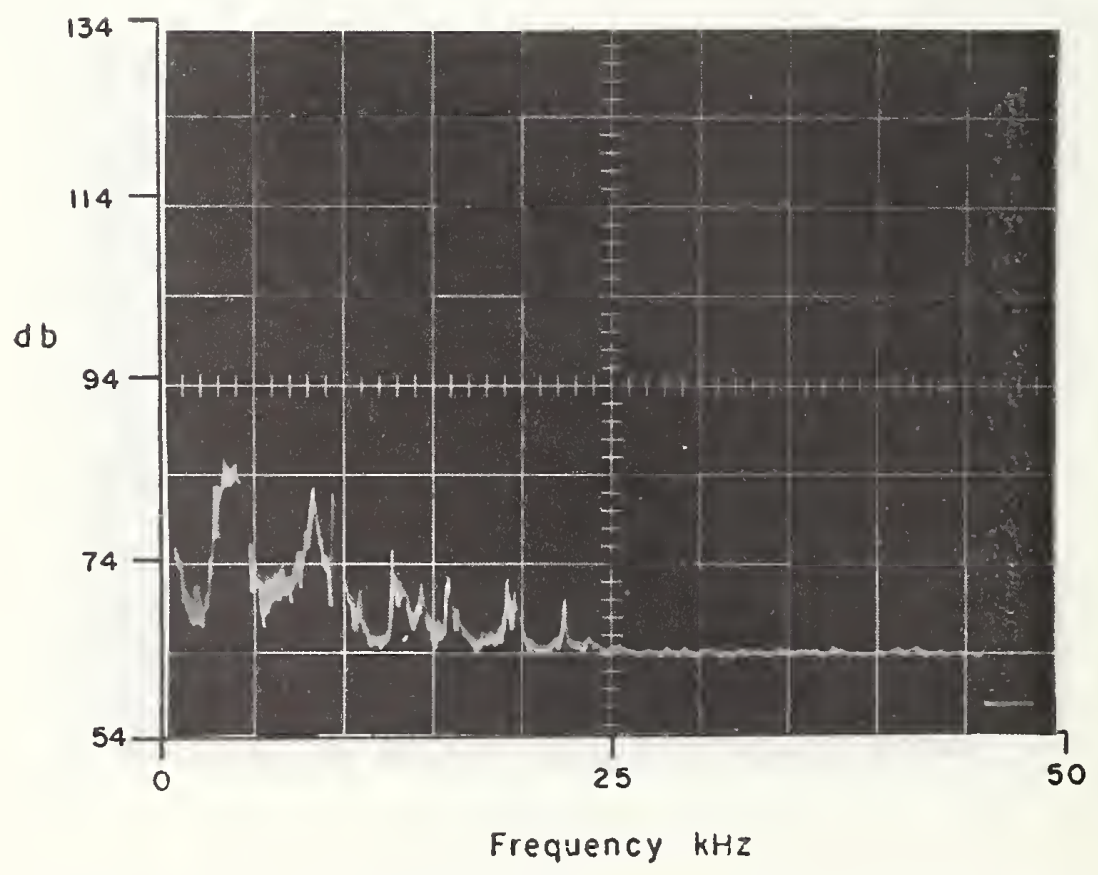

Figure 29. Acoustical Disturbance from Rotohammer Attack on Cinder Block 


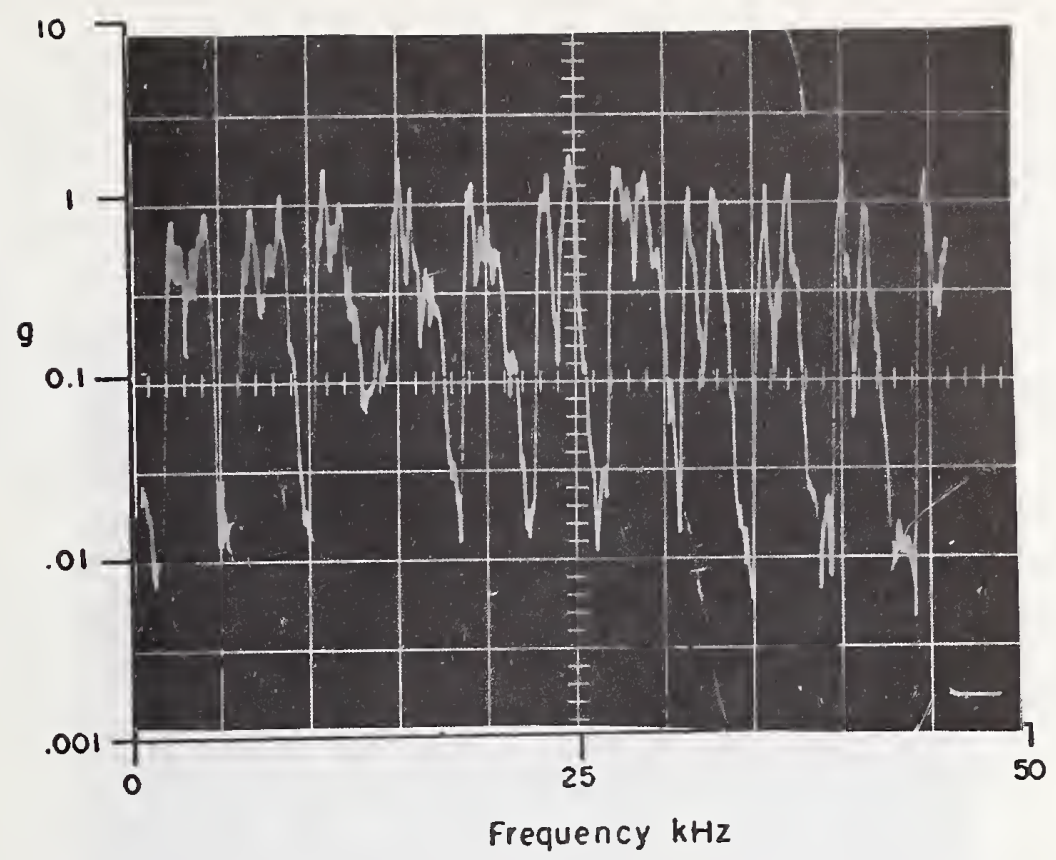

Figure 30. Vibration from Attack on Cinder Block

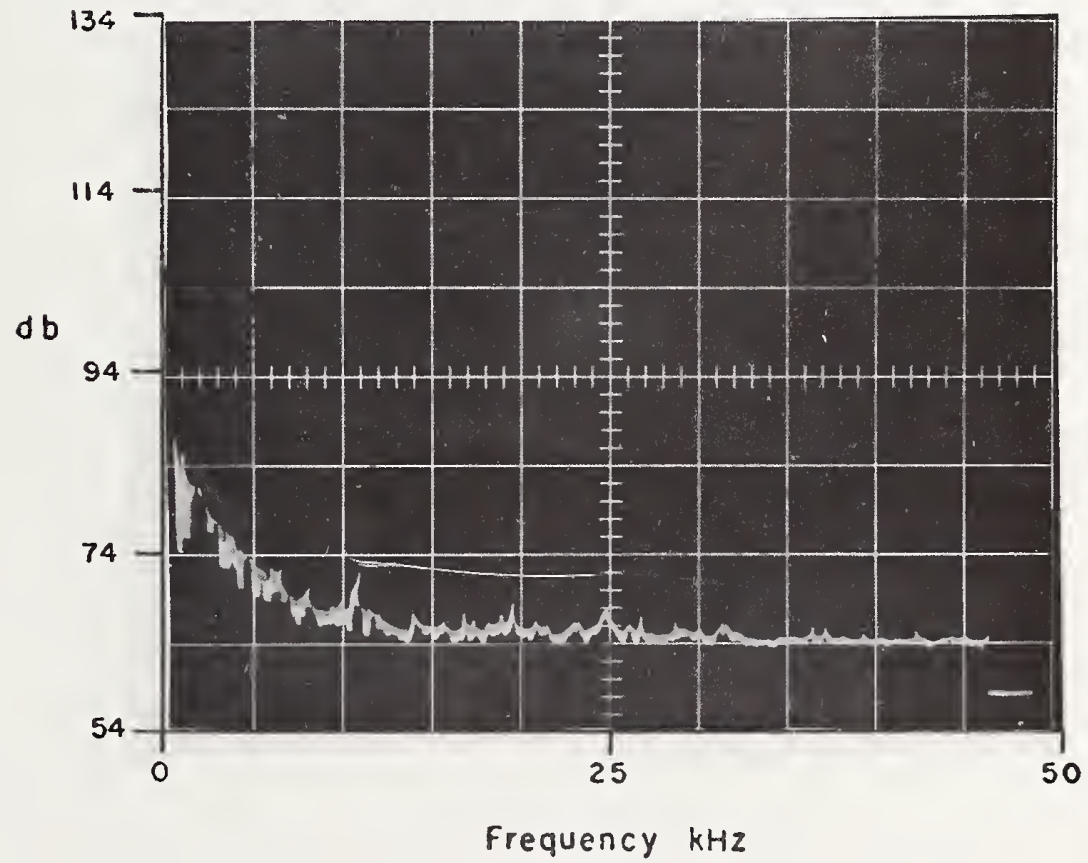

Figure 31. Acoustical Disturbances from Cutting Torch 


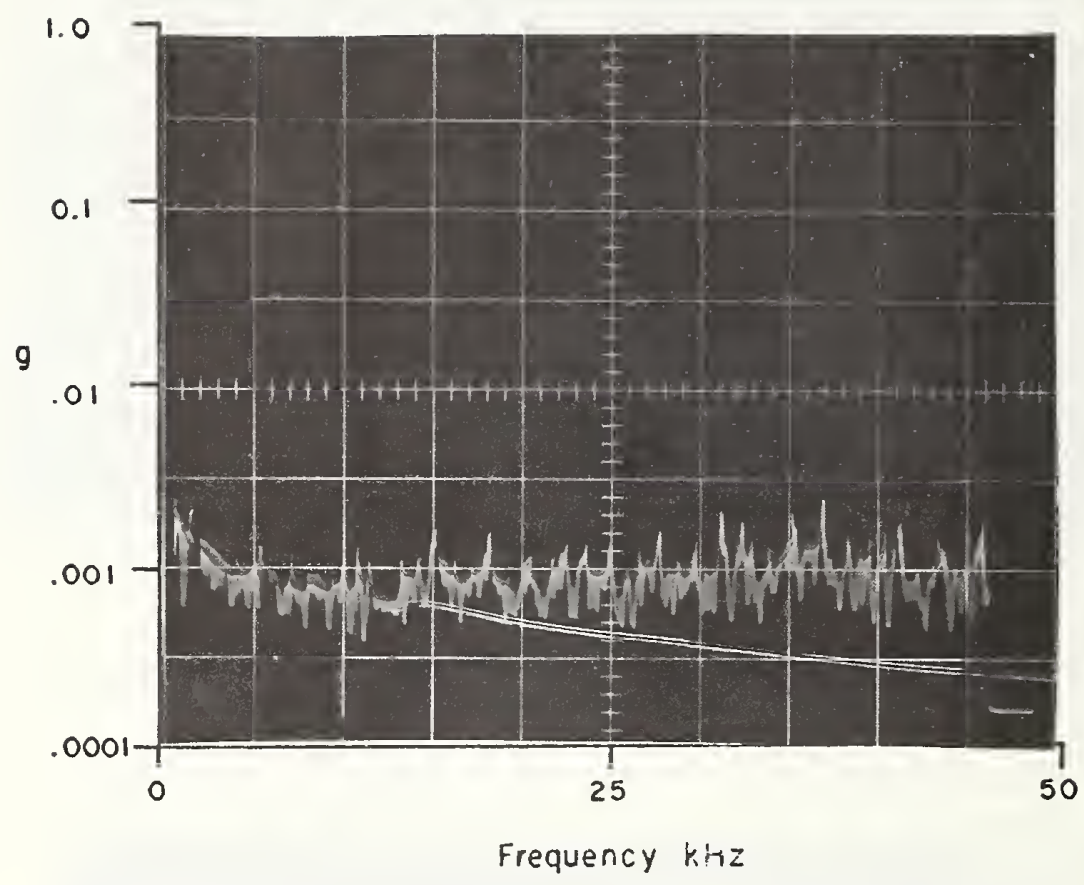

Figure 32. Vibrational Disturbances from Cutting Torch 
Location $27 \mathrm{~T}$ was a pass window screened with $1 / 8^{\prime \prime}$-thick expanded metal and backed by a metal-clad wooden half door which was hinged on one side and secured to the frame by a draw bolt on the other. The targeted opening was located on one edge of the grill centered over the draw-bolt position. As shown in figure $33,3 / 8^{\prime \prime}$ capacity bolt cutters were used to cut 3 sides of the perimeter of the opening leaving a flap of expanded metal which could be bent back out of the way. Two blows with the sledgehammer were then sufficient to break off the draw bolt permitting the half door to swing open. The working time for this attack was 3.25 minutes and the elapsed time 3.58 minutes. The first J-SIIDS alarm occurred 7 seconds after the attack began.

During this attack, the vibration transducer was located in the same position as in Attacks $22 \mathrm{~A}$ and $22 \mathrm{~B}$ and at a distance approximately $8^{\prime}$ away. Vibrational disturbances observed during the bolt cutter attack are shown in figure 34 which does not materially differ from the background disturbance level prior to the attack as shown in figure 35 . A multiple sweep of acoustical disturbances produced by the bolt cutters is shown in figure 36 . The vibrational disturbance from the sledgehammer breaking the draw bolt is shown in figure 37 . 


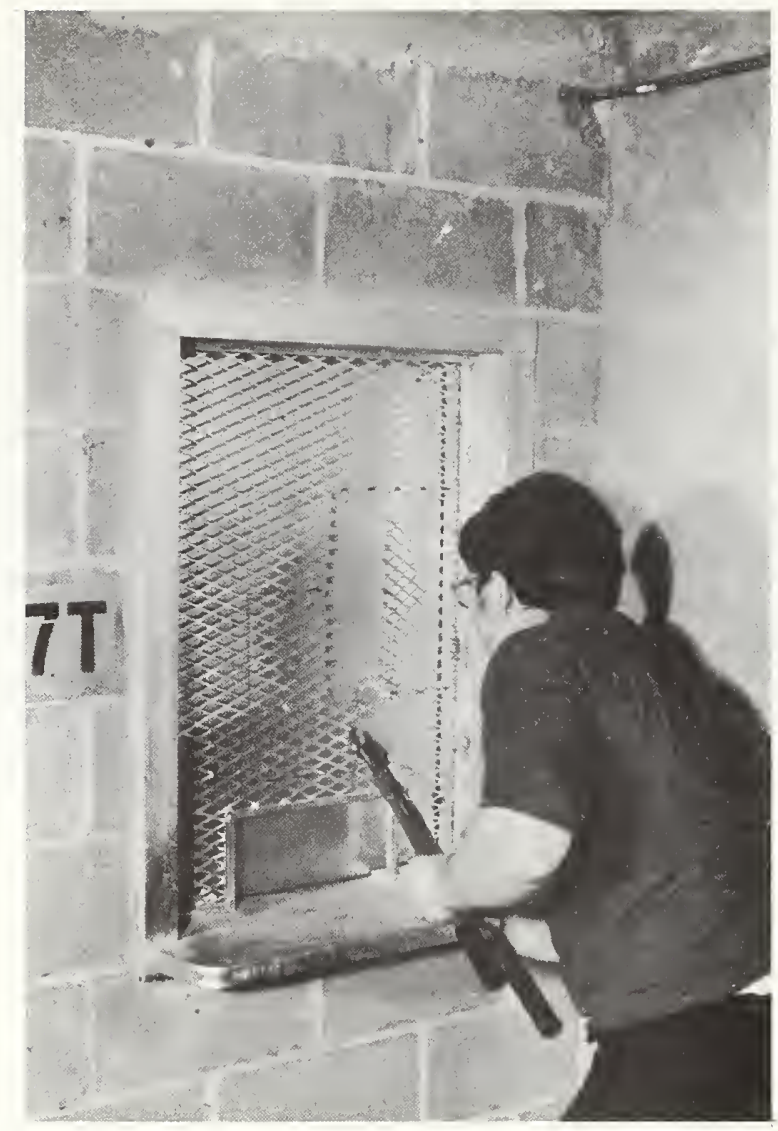

Figure 33. Attack $27 \mathrm{~T}$ 


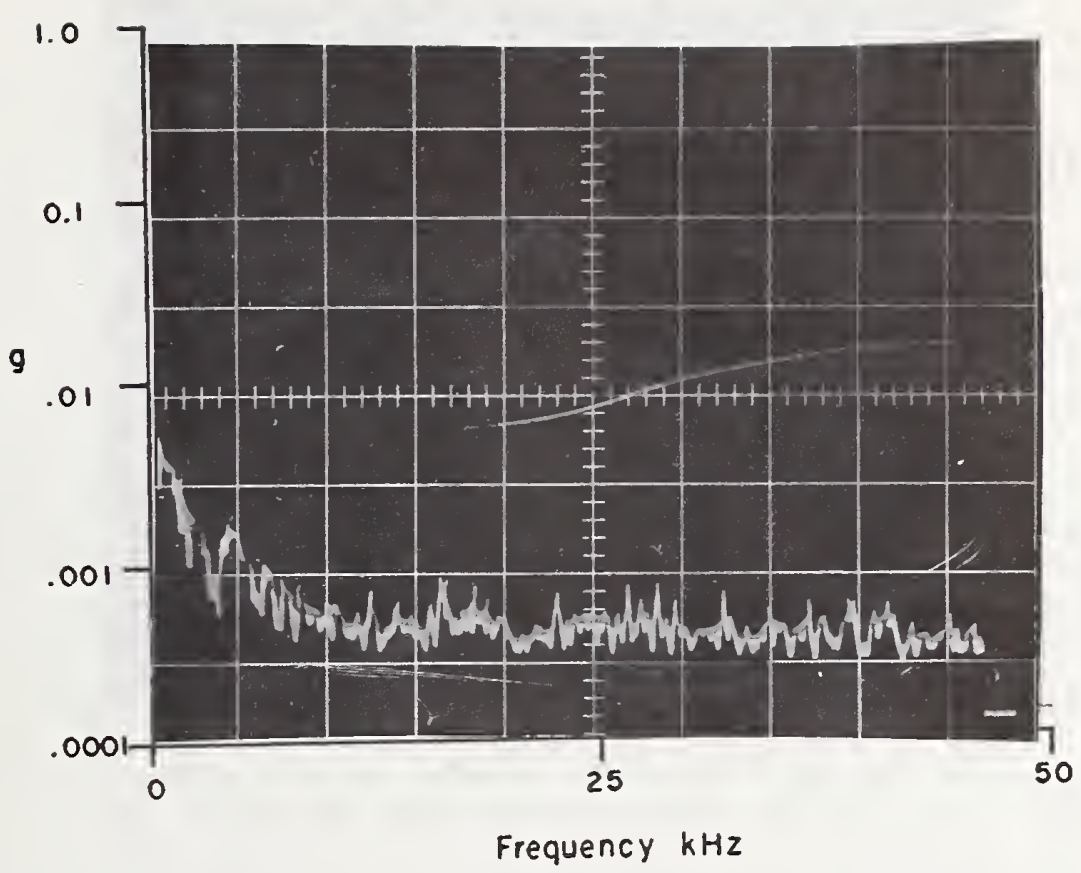

Figure 34. Vibration During Bolt Cutter Attack

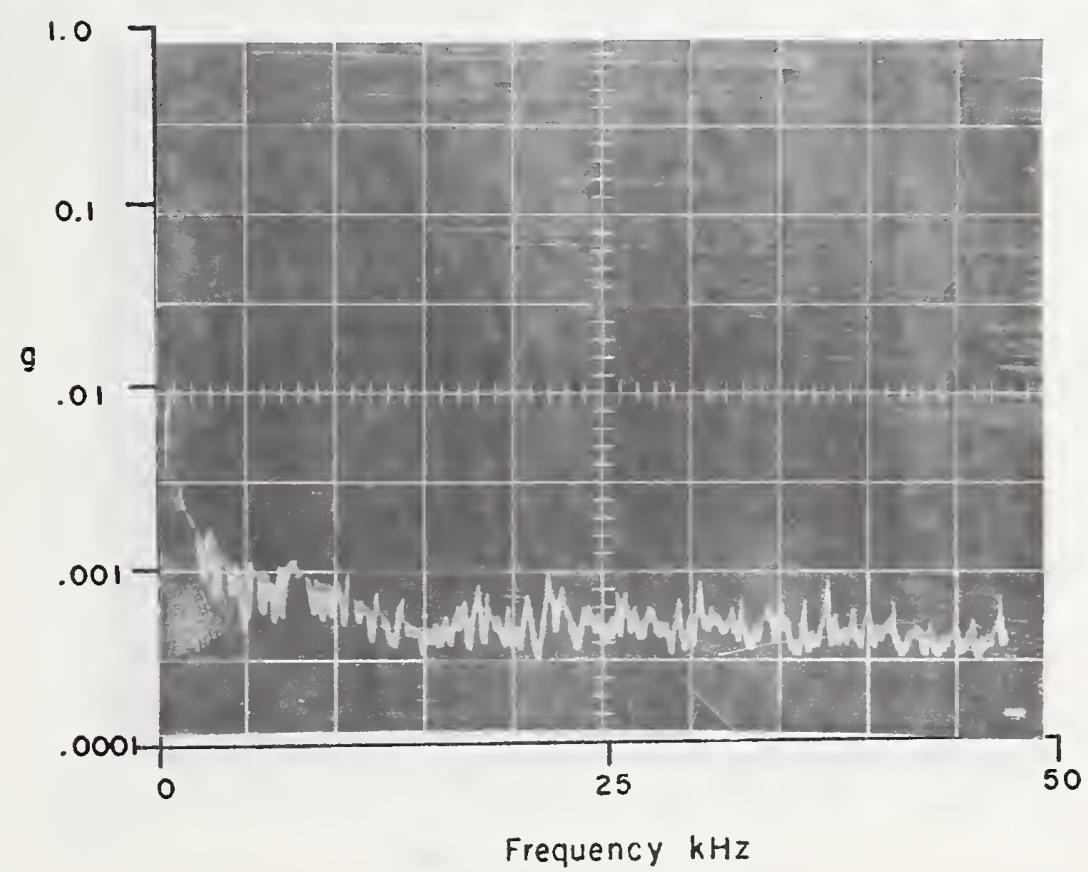

Figure 35. Ambient Vibrational Background at Location $27 \mathrm{~T}$ 


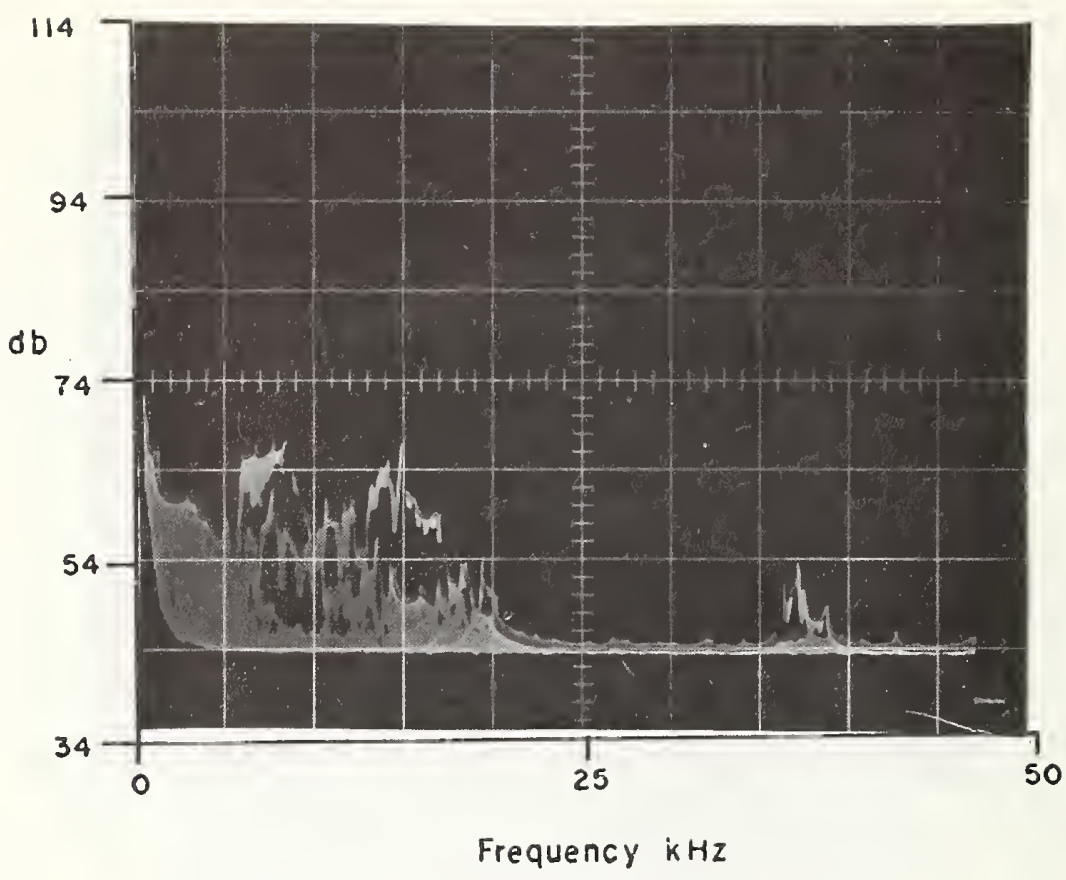

Figure 36. Multiple Sweep of Acoustical Disturbances Produced by Bolt Cutters

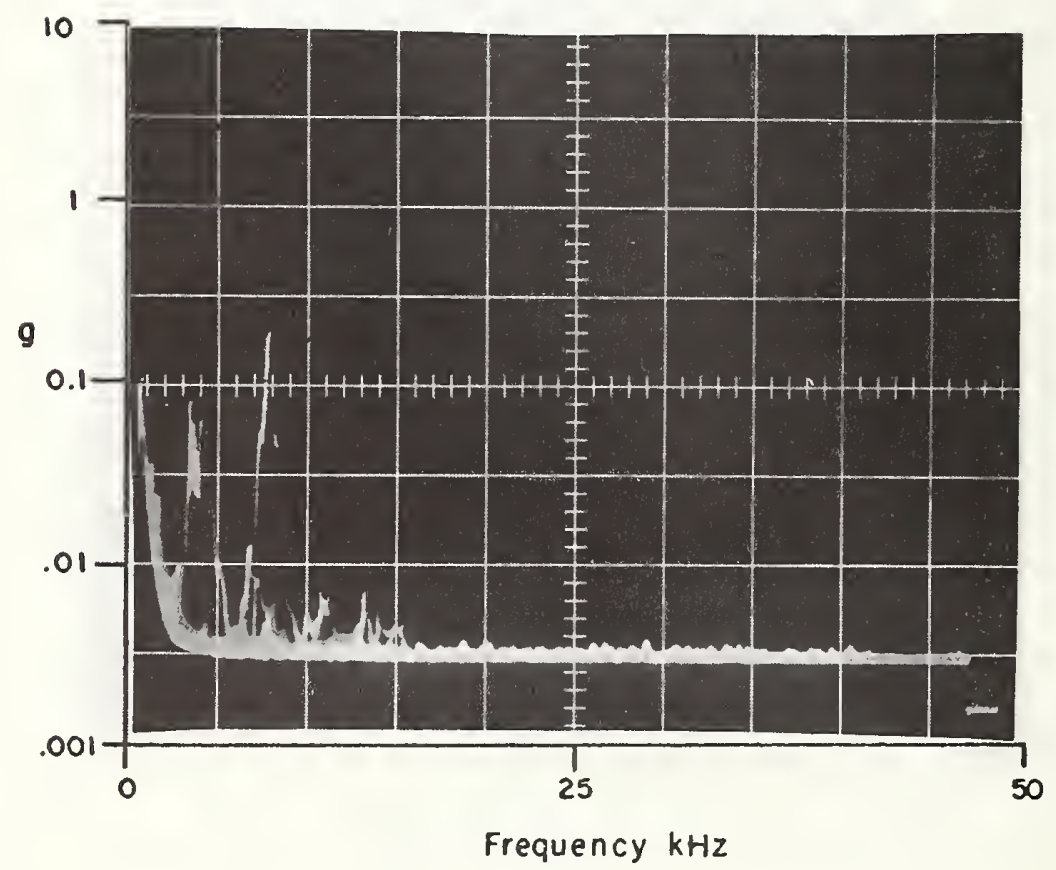

Figure 37. Vibration from Sledgehammer Attack on Draw Bolt 
Location 23B was on the roof of Room 2. The roof was 5-1/2" thick concrete reinforced with $1 / 2$ " bars located in the approximate center of thickness and spaced $8^{\prime \prime}$ apart in one direction and $12^{\prime \prime}$ apart in the other direction. An $8^{\prime \prime} \mathrm{X} \cdot 12^{\prime \prime}$ opening perimeter was laid out and hole locations were spotted at each corner, in the center of the rectangle and midway on each $12^{\prime \prime}$ side. Using the rotohammer, $1^{\prime \prime}$ diameter holes were drilled to a depth of $3-1 / 2^{\prime \prime}$ at each of these 7 locations as shown in figure 38. A $1^{\prime \prime}$ bull-point punch was then used in each hole and with a 12-pound sledgehammer the interior 2" of concrete was spalled away. At this point, inspection inside the room revealed the fact that the targeted opening straddled an electrical conduit, previously concealed in the concrete, which supplied power to Room 3 . Since this power would be needed in connection with later tests, the targeted opening was relocated by moving it 8 " along its short dimension. This required drilling and spalling out 4 new holes and the time for this was not included in the measurements reported for this attack. It took 151 seconds or 2.52 minutes to drill the 7 original holes. Since 24.51 inear inches of material was drilled in these 7 holes, the average drilling rate for the $1^{\prime \prime}$ diameter bit was 6.16 seconds per inch. Samples of the acoustical disturbances are shown in figure 39 and the vibrational disturbances in figure 40. The latter were obtained with the transducer mounted on the inside of the concrete roof at a distance of 8 ' from the center of the opening.

Spalling out the concrete below the bottoms of the holes required 2.92 minutes and produced a peak SPL of $91 \mathrm{~dB}$ observed $25^{\prime}$ away from the attack location. Multiple sweep photographs of the acoustical spectra are shown in figure 41 and the vibrational spectra in figure 42 . 


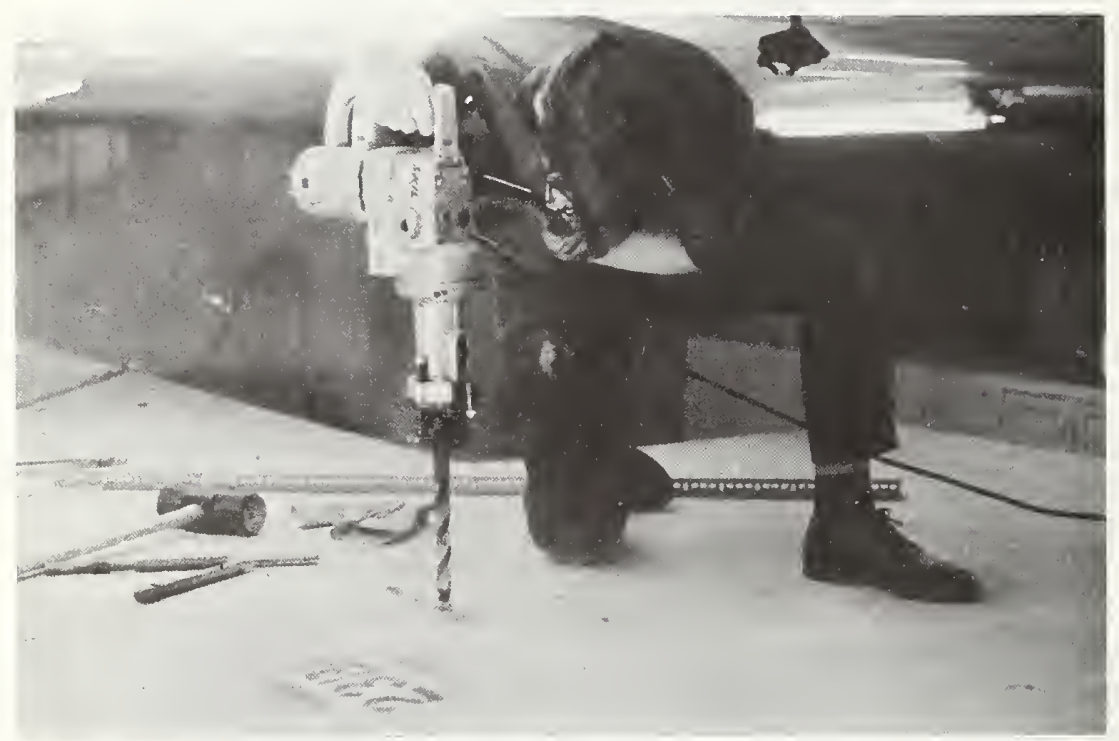

Figure 38. Attack 23B 


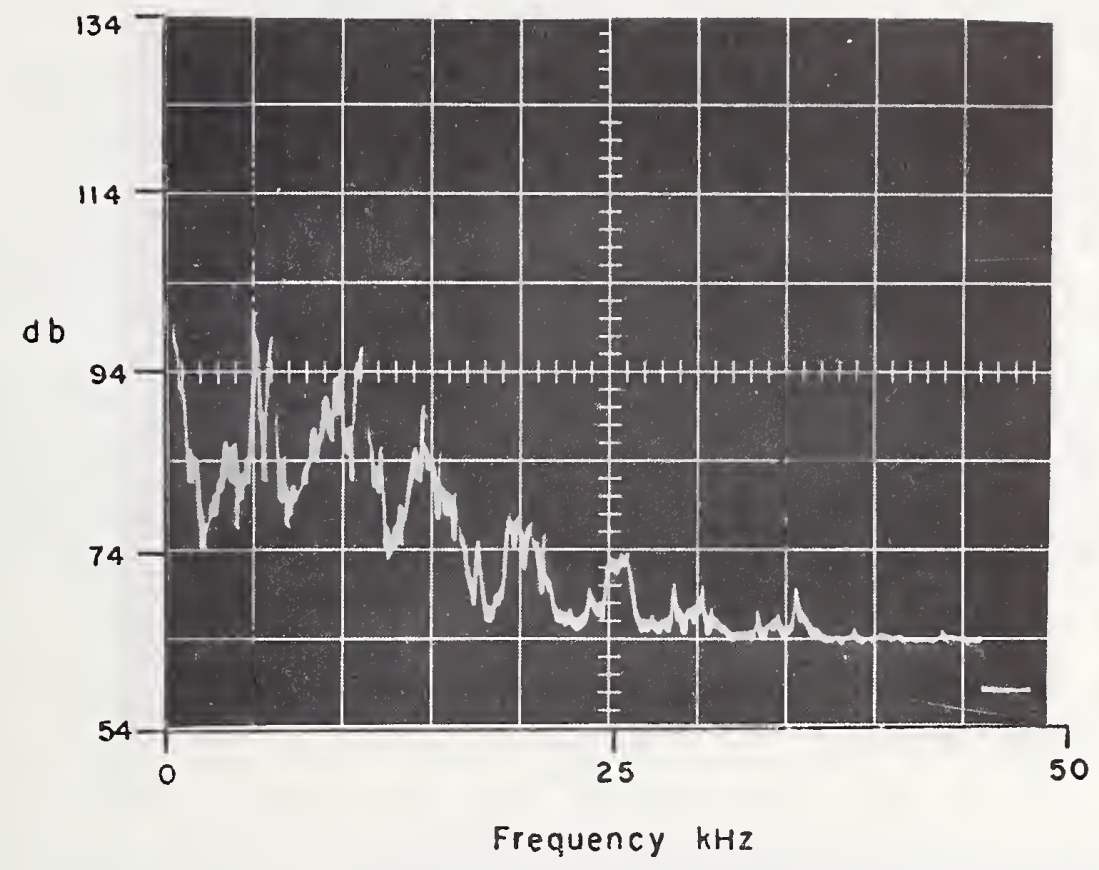

Figure 39. Acoustical Disturbance from Drilling

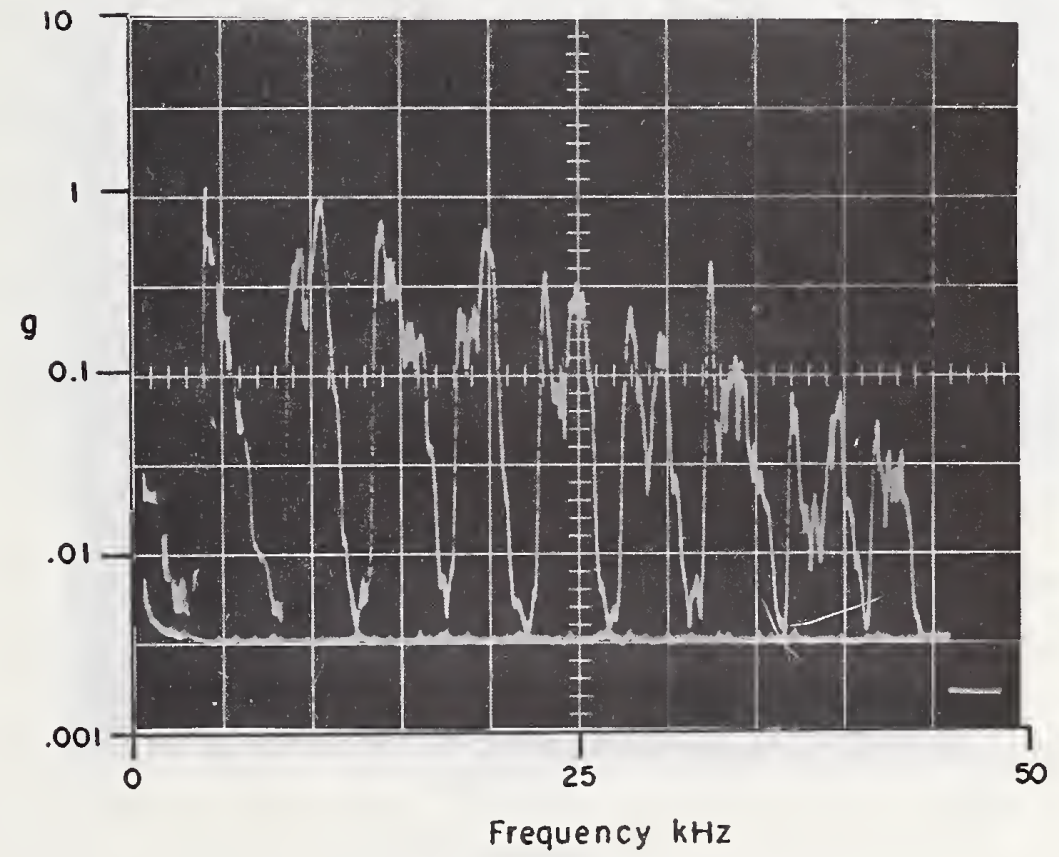

Figure 40. Vibrational Disturbance from Drilling 


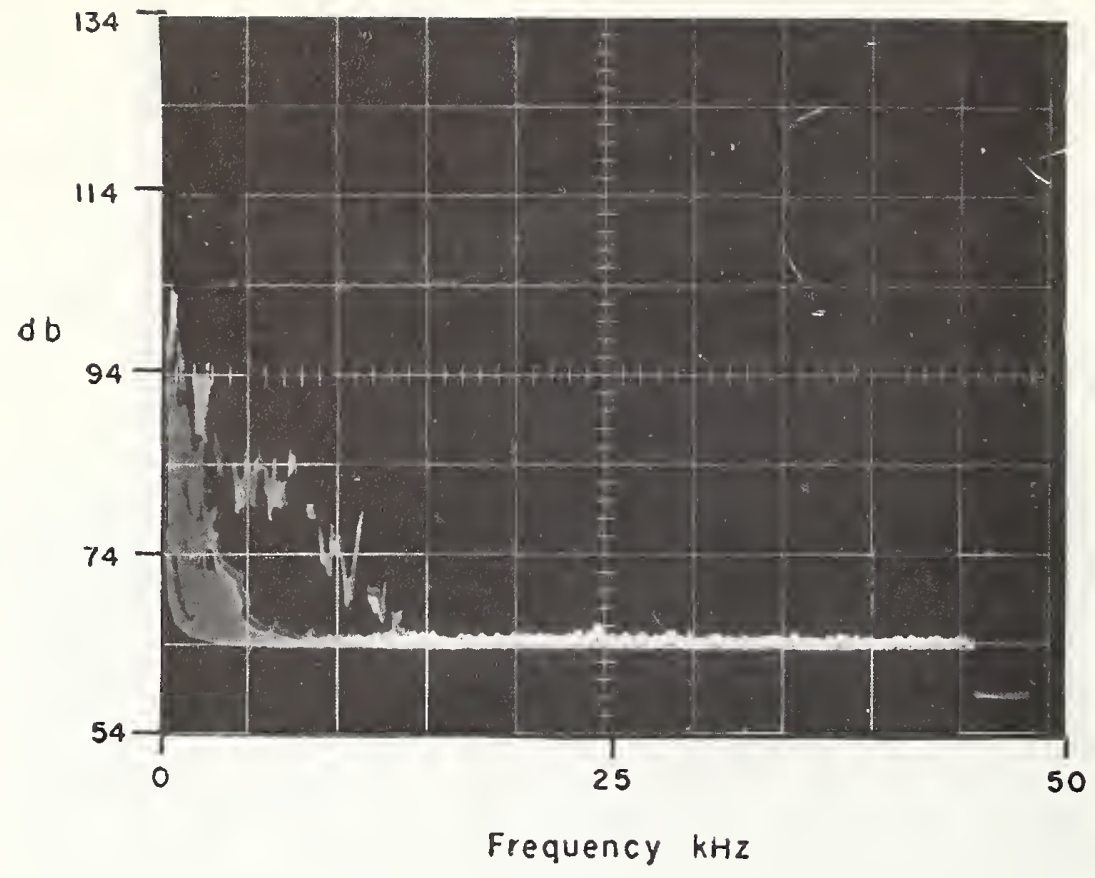

Figure 41. Acoustical Disturbance from Spalling

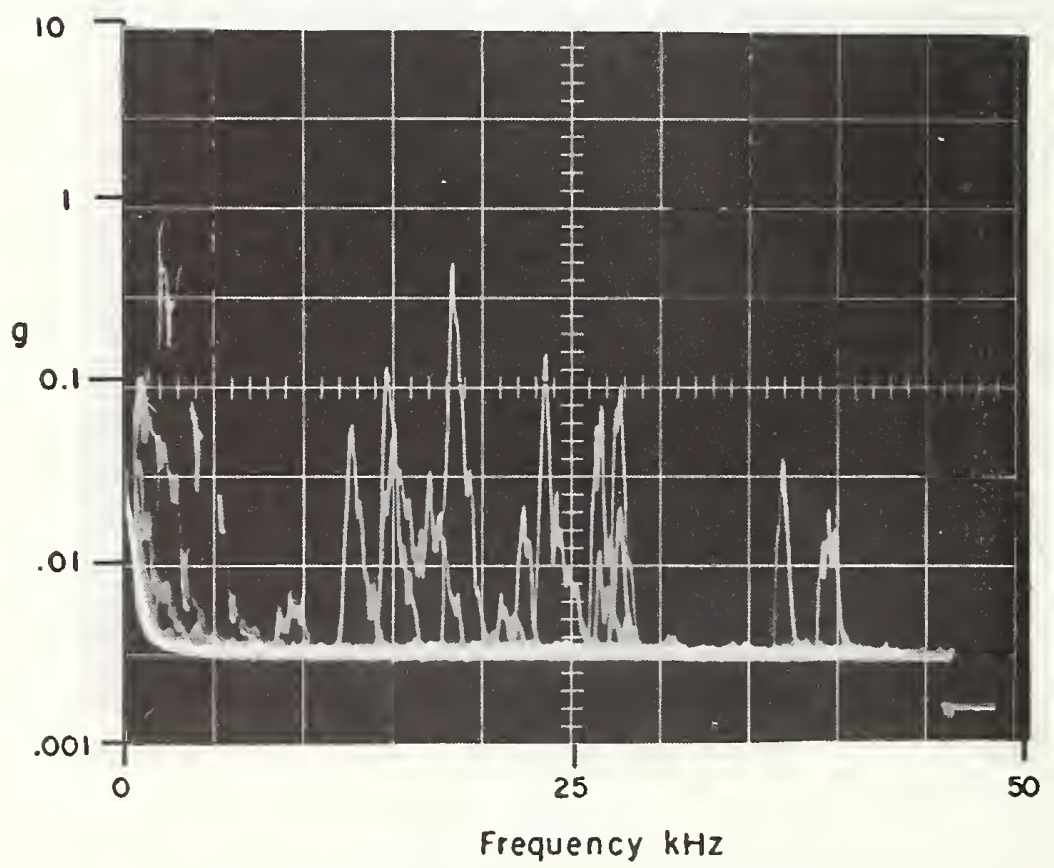

Figure 42. Vibration from Spalling 
Next, as shown in figure 43, a 5-horsepower gasoline-powered saw equipped with a $12^{\prime \prime}$ diameter abrasive cutoff wheel was used to cut a groove around the perimeter of the relocated opening. This took 5.06 minutes working time and it was necessary to replace the cutoff wheel about midway through this activity because of wheel wear. In addition, it was necessary to vacate the wing of the building housing the arms rooms after each of the 4 perimeter cuts while the dust and exhaust fumes were cleared away by fans. These latter time intervals were not included in the calculation of elapsed time.

Outside of the room the abrasive wheel cutoff saw produced $105 \mathrm{~dB}$ SPL at a distance of $25^{\prime}$. Samples of the acoustical spectrum within the room were lower and are shown in figure 44 and the vibrational spectrum are shown in figure 45 . Note how the latter peaks in the 15 to $35 \mathrm{kHz}$ frequency range.

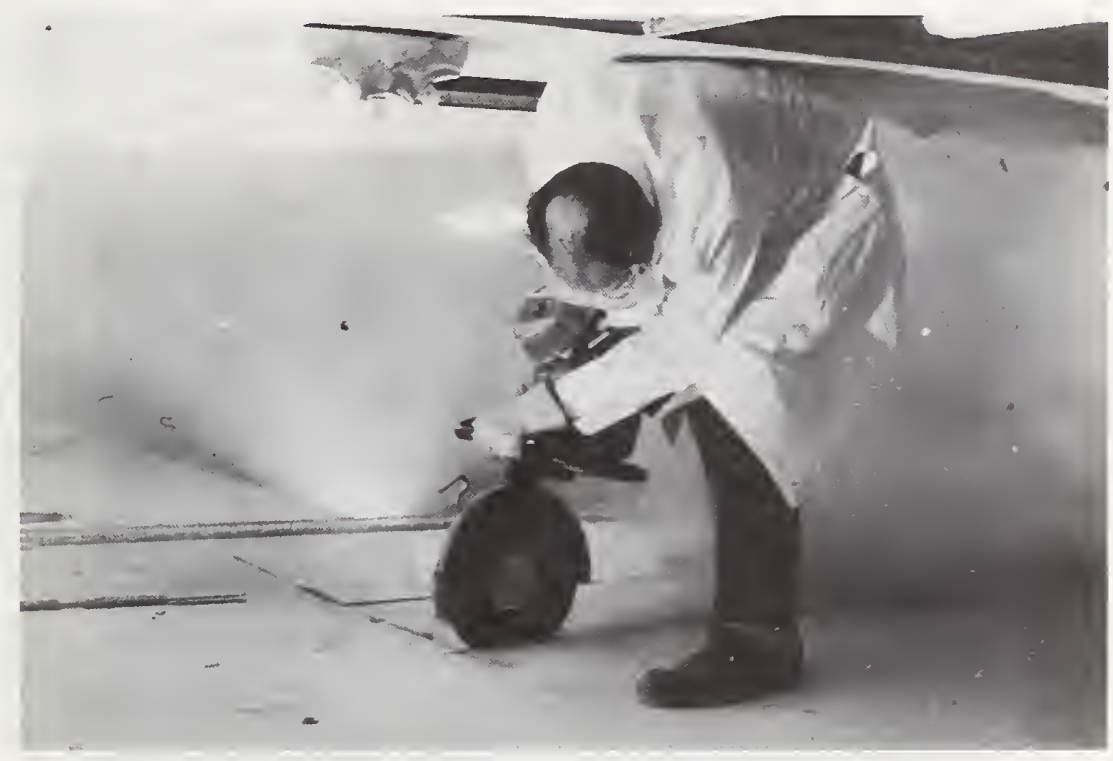

Figure 43. Abrasive Wheel Cutoff Saw Used in Attack 23B 


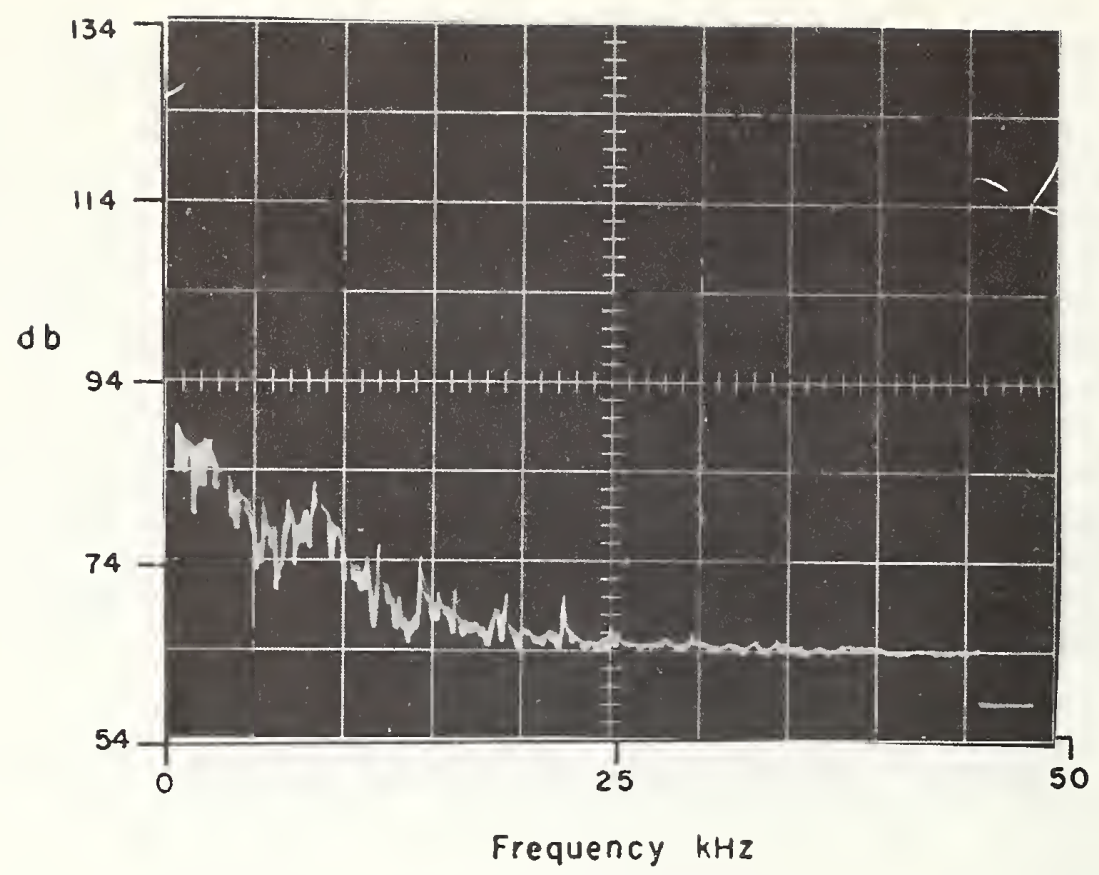

Figure 44. Acoustical Disturbances from Abrasive theel Cutoff Saw

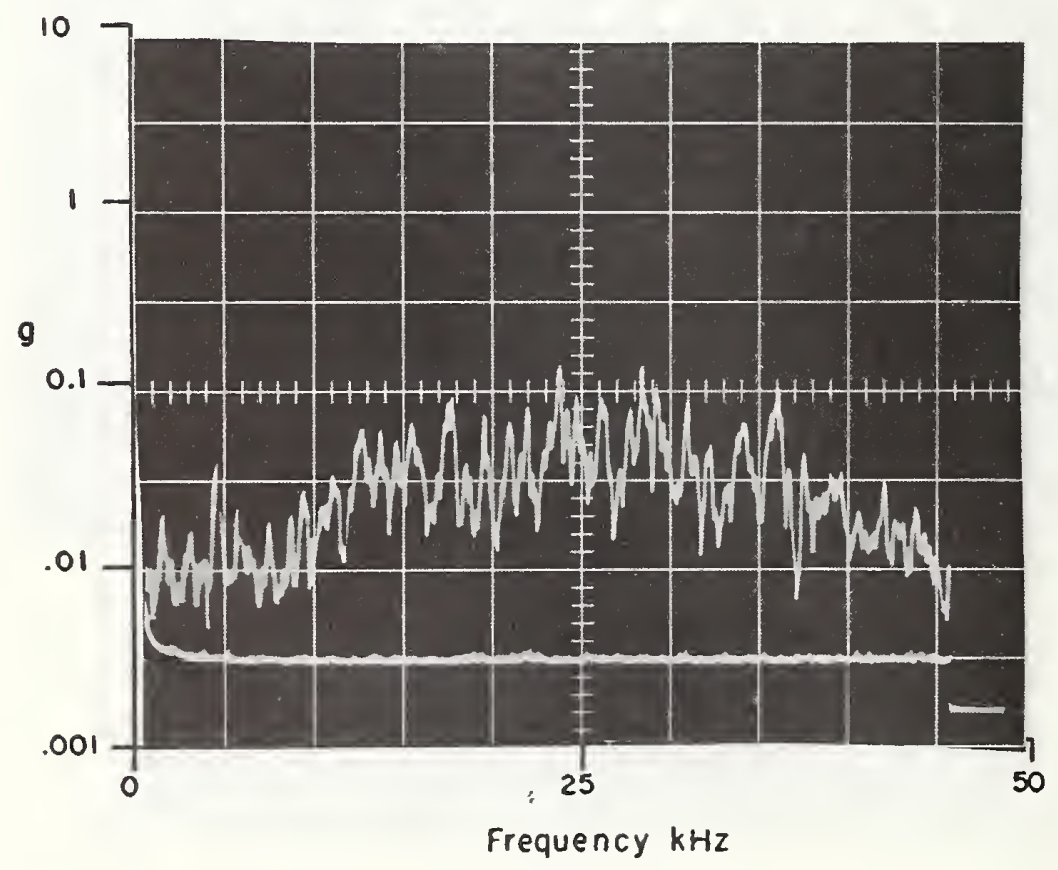

Figure 45. Vibration from Abrasive Wheel Cutoff Saw 
The cut made by the abrasive wheel saw around the perimeter of the opening penetrated to a depth of between $2^{\prime \prime}$ and $3^{\prime \prime}$. This left about an inch of concrete between the bottom of the cut and the top of the previously spalled interior area. It was hoped that the remaining plug could be broken out by a direct sledgehammer assault, but, when 50 seconds of effort with this tool produced only moderate spalling on the surface, it was decided to drill two more holes with the rotohammer. These were made in 18 seconds and then the sledgehammer attack was resumed. This time it was quite successful and only 23 more seconds were required to clear the concrete from the opening exposing the reinforcing rods for cutting as shown in figure 46. Acoustic disturbances produced by the sledgehammer are shown in figure 47 and vibrational disturbances in figure 48. Both of these are photographs of multiple sweeps of the output of the spectrum analyzer.

The reinforcing rod was cut in 1.42 minutes using a No. 5 tip, 25 p.s.i. oxygen pressure and 5 p.s.i. acetylene pressure. Acoustical disturbances are shown in figure 49 which exhibits the typical flat spectrum of a cutting torch.

The total working time to produce the final $9^{\prime \prime} \times 12-1 / 2$ " opening was 13.58 minutes and the calculated elapsed time was 17.0 minutes. The first J-SIIDS alarm occurred 5 seconds after the attack was started.

The relatively long working time required in this attack was undoubtedly due, in part, to the rather awkward working conditions associated with this location. The roof of Room 3 was only about 3-1/2' below the ceiling of the building housing the simulated arms rooms. This low clearance forced the attackers to work from a sitting or kneeling position and severely limited their freedom of movement and the effective application of their tools. Later attacks on the $8^{\prime \prime}$ thick reinforced concrete walls of Room 3 provide some indication of the magnitude of the influence of this constrained working space. 


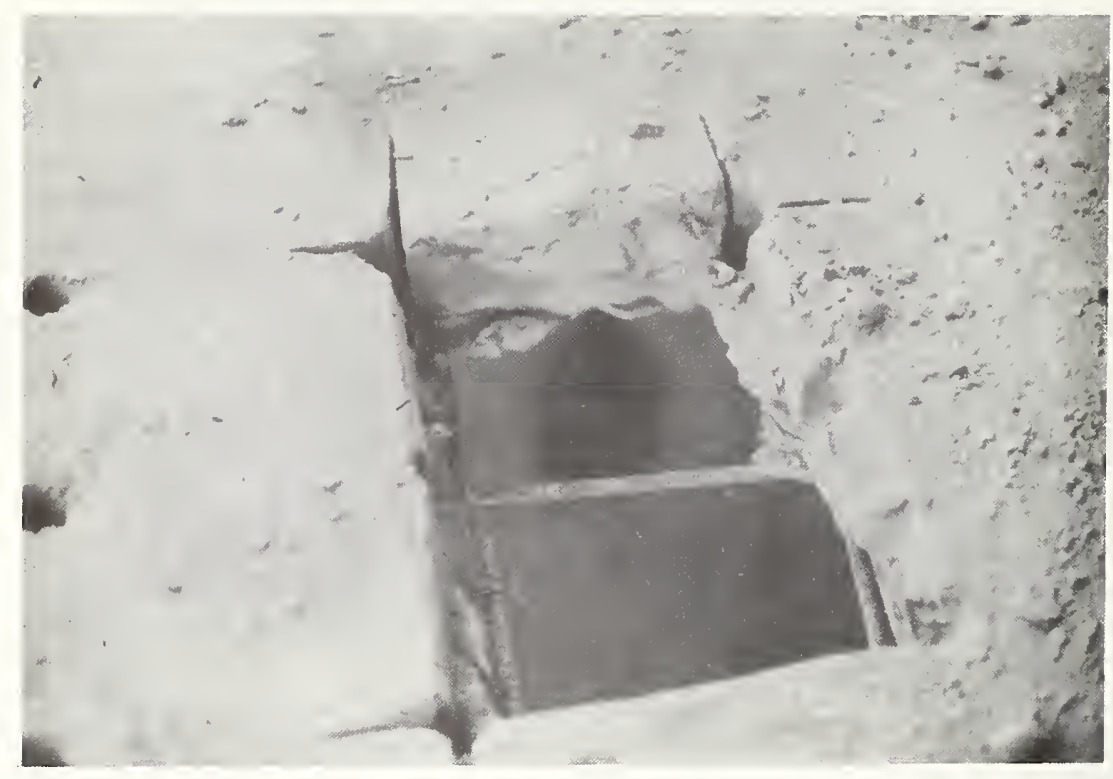

Figure 46. Opening Made by Attack 23B

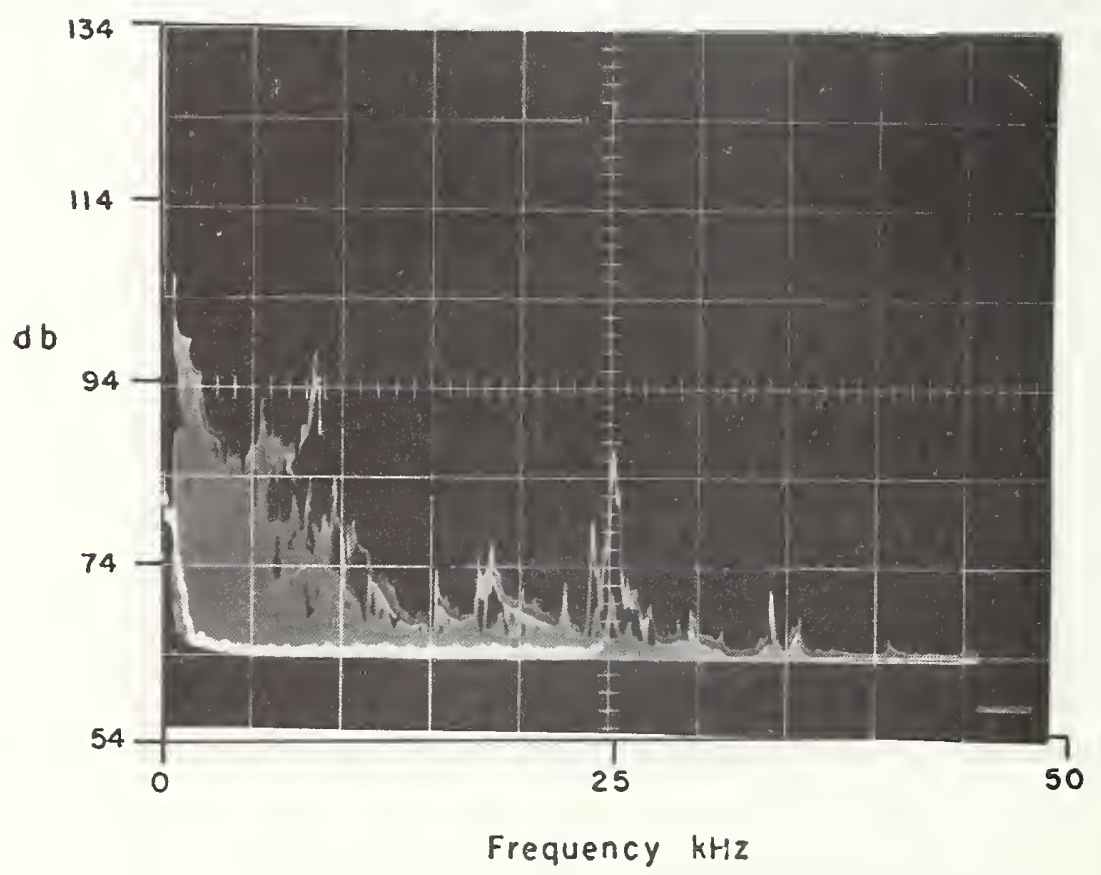

Figure 47. Acoustical Disturbances from Sledgehammer 


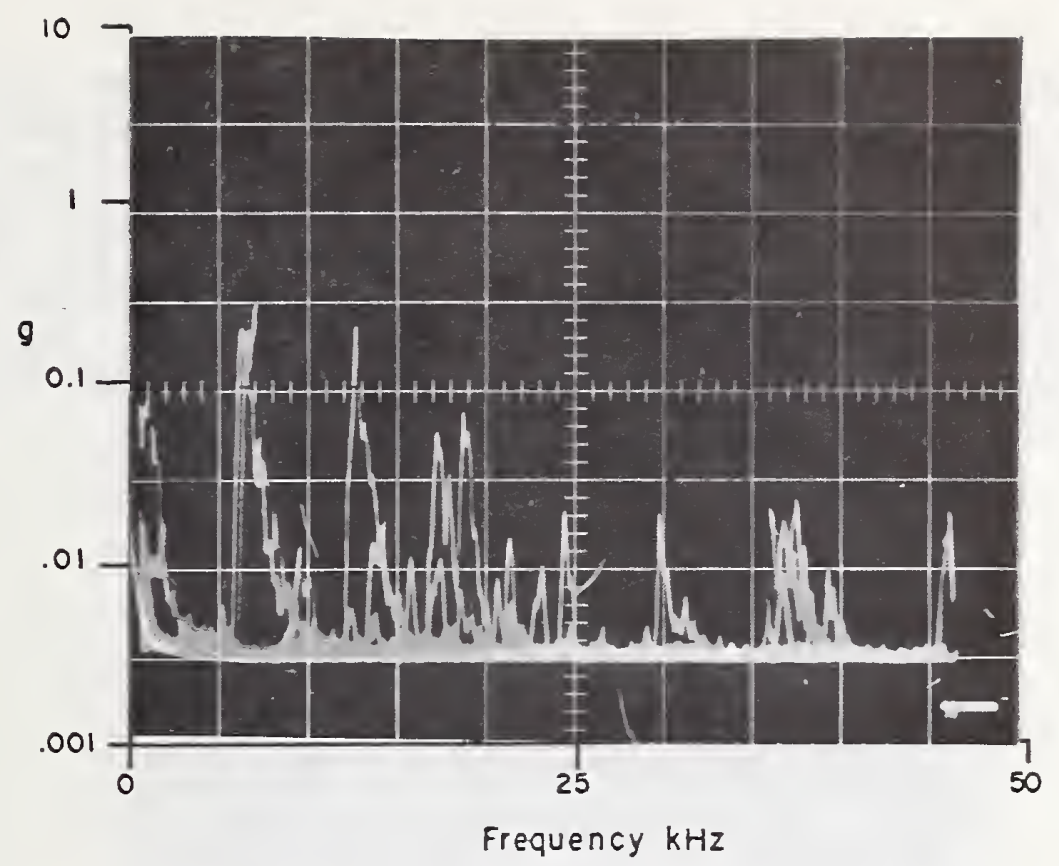

Figure 48. Vibration from Sledgehammer

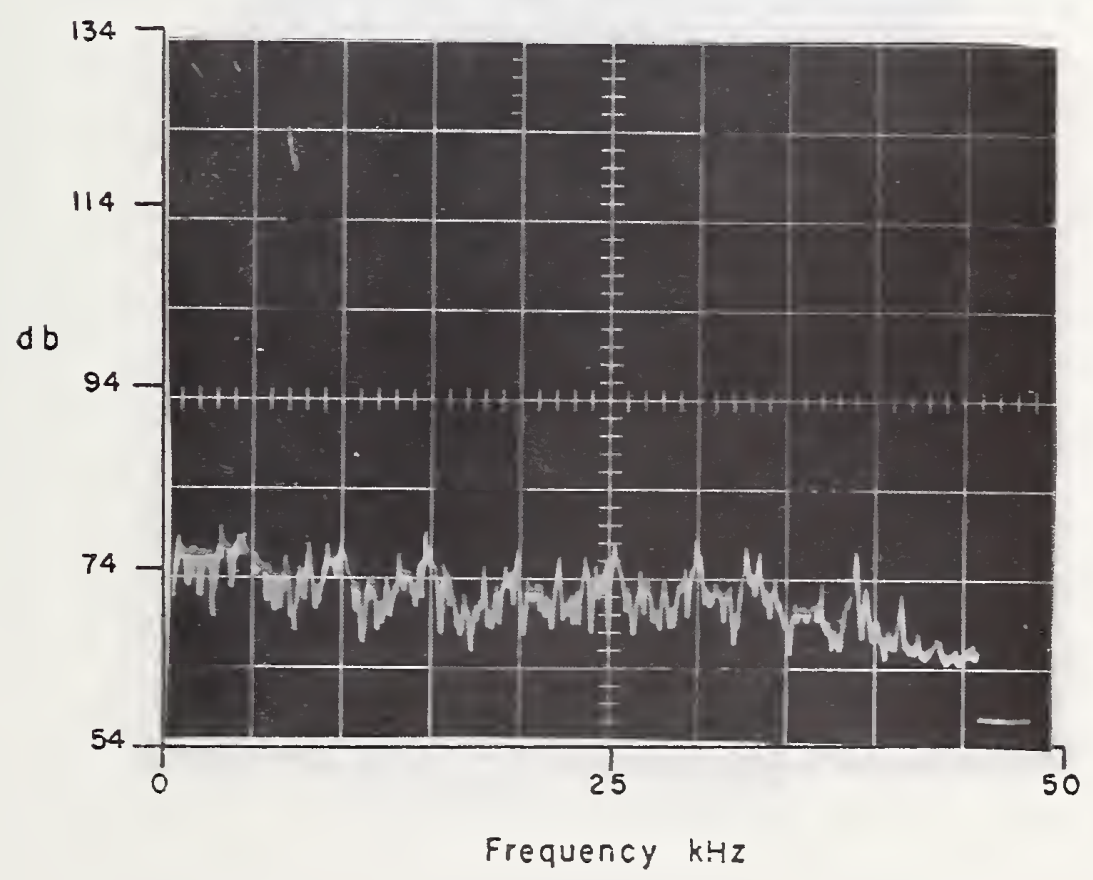

Figure 49. Acoustical Disturbances from the Cutting Torch 
The last attack on Room 2 was made on the un-veneered cinder-block wall. The attack was with a 12-pound sledgehammer, as shown in figure 50 , and required 47 blows and 1.26 minutes. No reinforcing bars were encountered, however, two horizontal reinforcing wires were exposed and these were cut with a No. 0 bolt cutter in 4 seconds. The total working time was 1.32 minutes and the elapsed time was 1.52 minutes. The first J-SIIDS alarm occurred 8 seconds after the attack began. Vibration disturbances picked up by a transducer mounted on the wall 4-1/2' from the center of the attack area are shown in figure 51 .

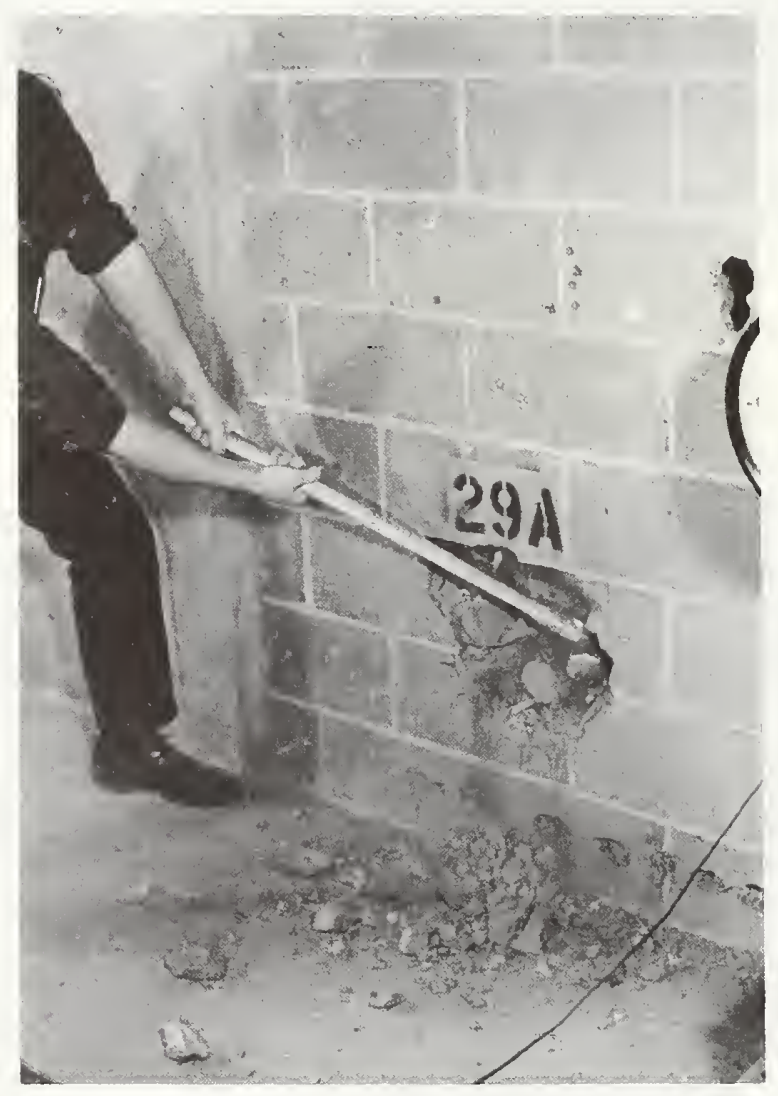

Figure 50. Attack 29A 


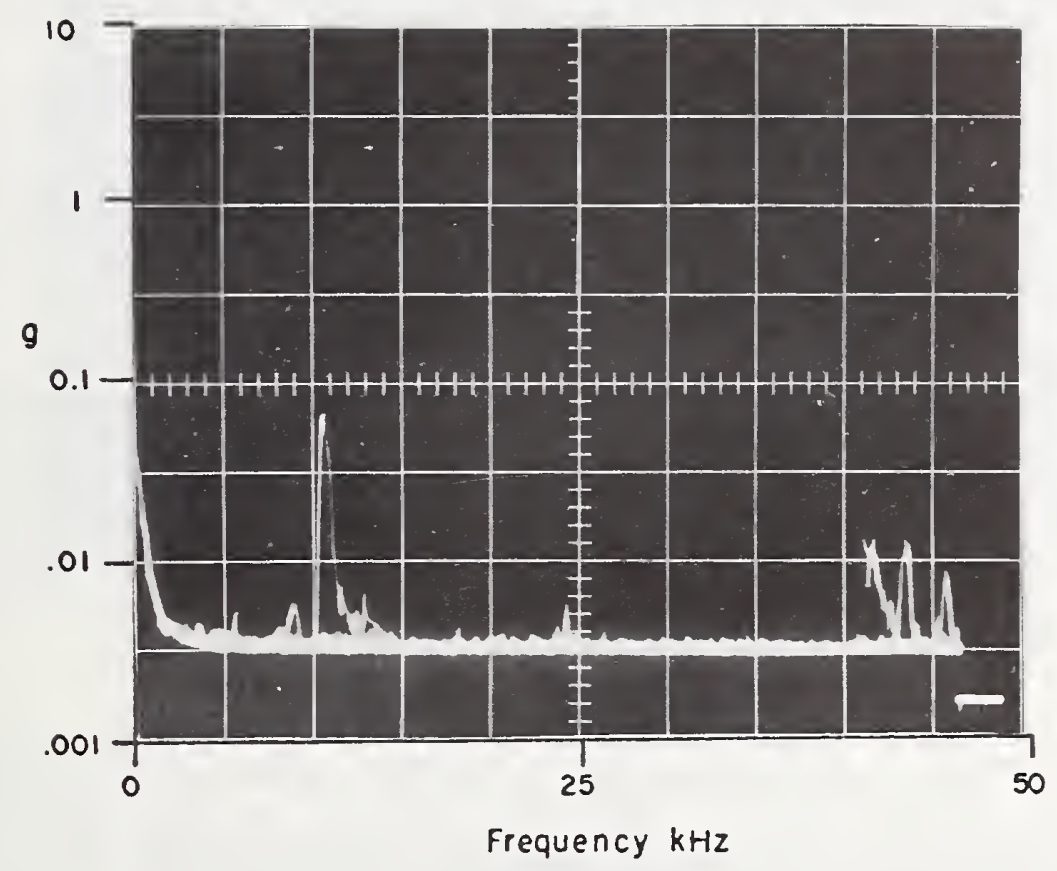

Figure 51. Vibration from Sledgehammer on Cinder-block Wall 
This test was identified as $25 \mathrm{~B}$ on the test plan but the physical location was stenciled as 25D and it will hereinafter be referenced by that identifier to be consistent with the photographic coverage. The attack was made on one of the $8^{\prime \prime}$ thick reinforced concrete walls of Room 3. It involved drilling a pattern of 1 " diameter holes partially through the concrete to predetermined depths, then spalling out concrete on the interior using a $1^{\prime \prime}$ bull-point punch and sledgehammer. Initial spalling was from the deepest holes and after the material was cleared out behind them the attack shifted to the shallower holes and finally to the surface of the remaining plug. Finally, reinforcing would be cut if necessary. As developed, the opening exposed but did not straddle a reinforcing bar and cutting was not necessary in this attack.

The hole pattern that was laid out was in the form of two concentric circles; the outer circle approximately $11-1 / 2^{\prime \prime}$ in diameter and the inner circle approximately 5-3/4" in diameter. Locations for the six holes were laid out at $60^{\circ}$ increments on the outer circle and for three holes at $120^{\circ}$ increments on the inner circle. These nine holes were to be drilled $5^{\prime \prime}$ deep. Nine more locations were then laid out midway between those of the original group and marked for drilling to a depth of 2-1/2". Figure 52 shows the hole pattern as laid out.

Using the rotohammer and $1^{\prime \prime}$ drill, it took 7.88 minutes to drill the nine holes $5^{\prime \prime}$ deep. This represents 45 linear inches and an average rate of 10.5 seconds per inch. There was a range of from 38 to 70 seconds of time required for individual holes but several were drilled in 42 to 47 seconds. The nine $2-1 / 2$ "deep holes required 3.27 minutes for an average rate of 8.7 seconds per inch. The overall average drilling rate was 9.91 seconds per inch.

Typical SPL values of 108 to $110 \mathrm{~dB}$ were observed at a distance of $7^{\prime}$. Acoustical disturbances inside Room 3 are shown in figure 53 . Vibrational disturbances recorded from a transducer mounted on the wall $10^{\prime}$ from the attack point are shown in figure 54 . 


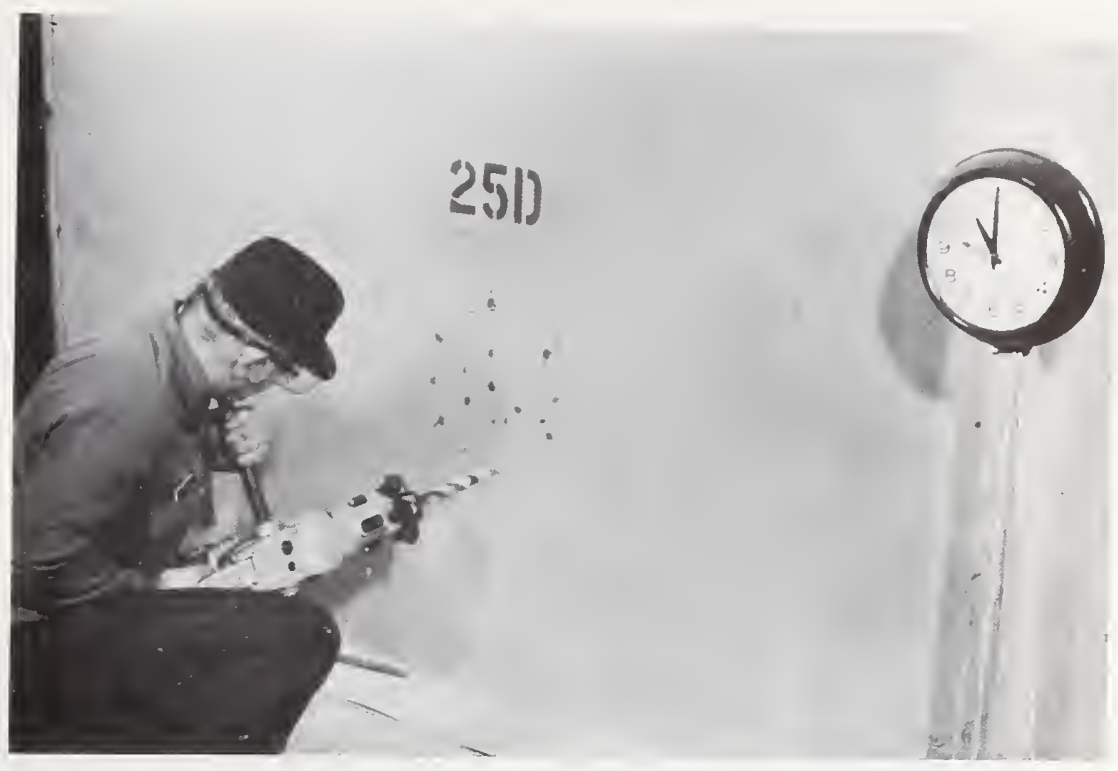

Figure 52. Attack 25D

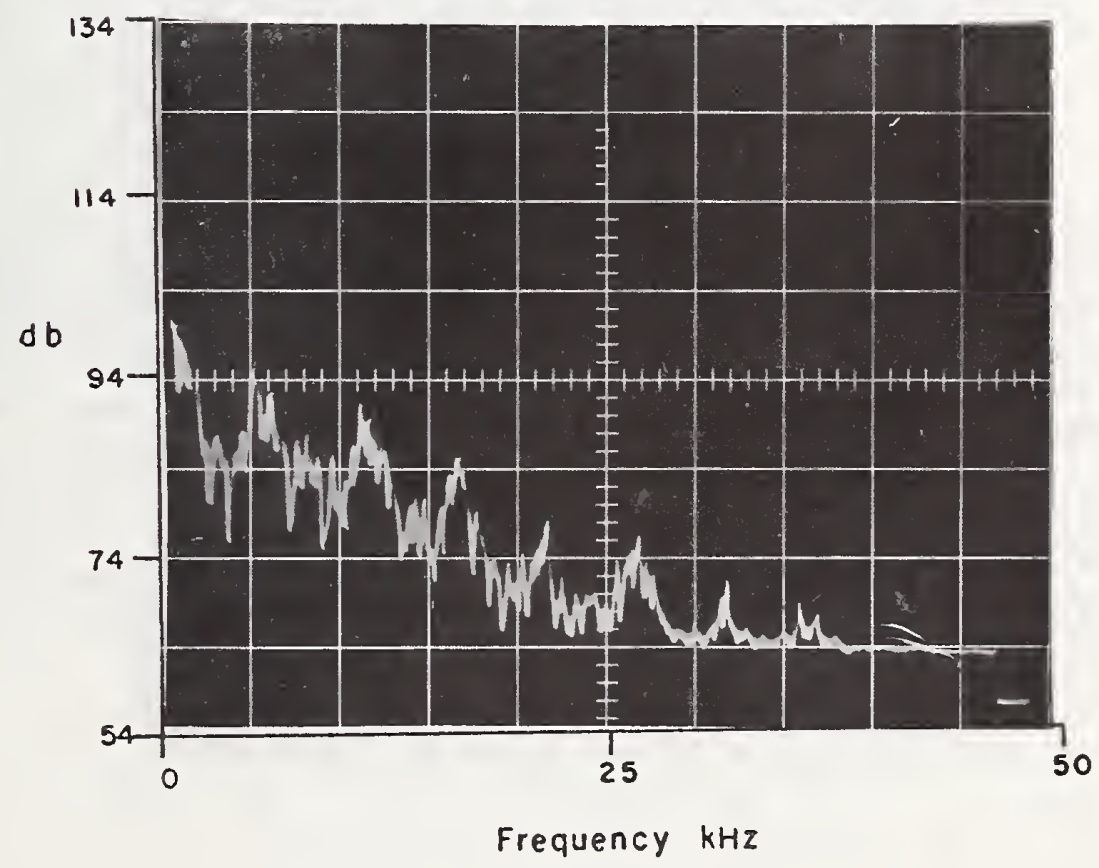

Figure 53. Acoustical Disturbances from Drilling Reinforced Concrete 


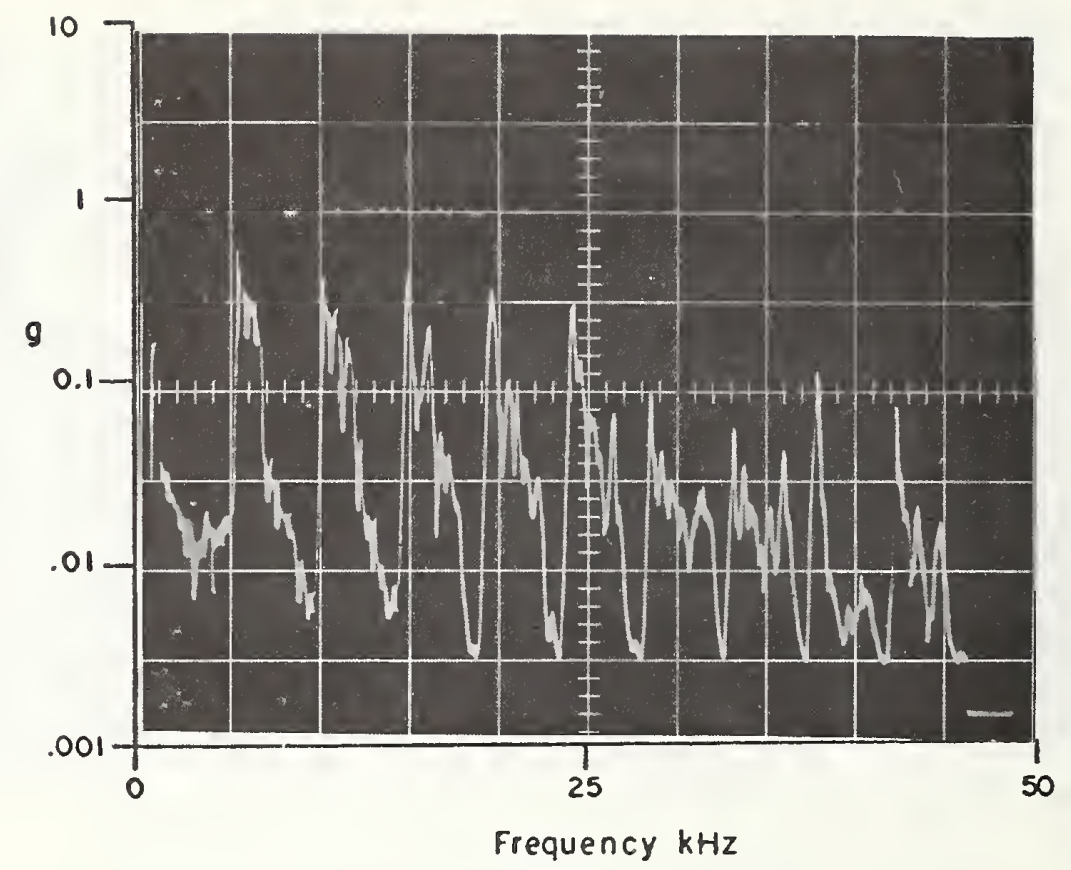

Figure 54. Vibration from Drilling Reinforced Concrete

Spalling the concrete from the interior beneath the holes was accomplished using a 10-pound sledgehammer and 1 " diameter bull-point punch and required 6.98 minutes. Figure 55 shows the interior of the wall with spalling nearly complete. Figure 56 is a multiple sweep photograph of the acoustical disturbances which were produced within Room 3. Outside SPL readings 99 to $102 \mathrm{~dB}$ were observed at a distance of $8^{\prime}$. Typical vibrational disturbances observed with a transducer located on the same wall as the attack and at a distance of $10^{\prime}$ are shown in figure 57. A second tranducer mounted on the opposite wall of Room 3 with a transmission path length of approximately $20^{\prime}$ yielded the spectrum shown in figure 58. 
After the spalling was completed, the remaining plug was broken out using a 20-pound sledgehammer for 23 seconds and a 10-pound sledgehammer for 13 seconds. Multisweep vibrational data from the 20-pound hammer is shown in figure 59 and from the 10-pound hammer in figure 60 . In both instances the transducer was $10^{\prime}$ from the attack point. Note the higher $g$ values developed by the 10-pound hammer. This is attributed to the higher velocity which could be developed in swinging this lighter hammer.

The total working time required to complete penetration 25D was 18.73 minutes. The first J-SIIDS alarm occurred 5 seconds after the attack began.

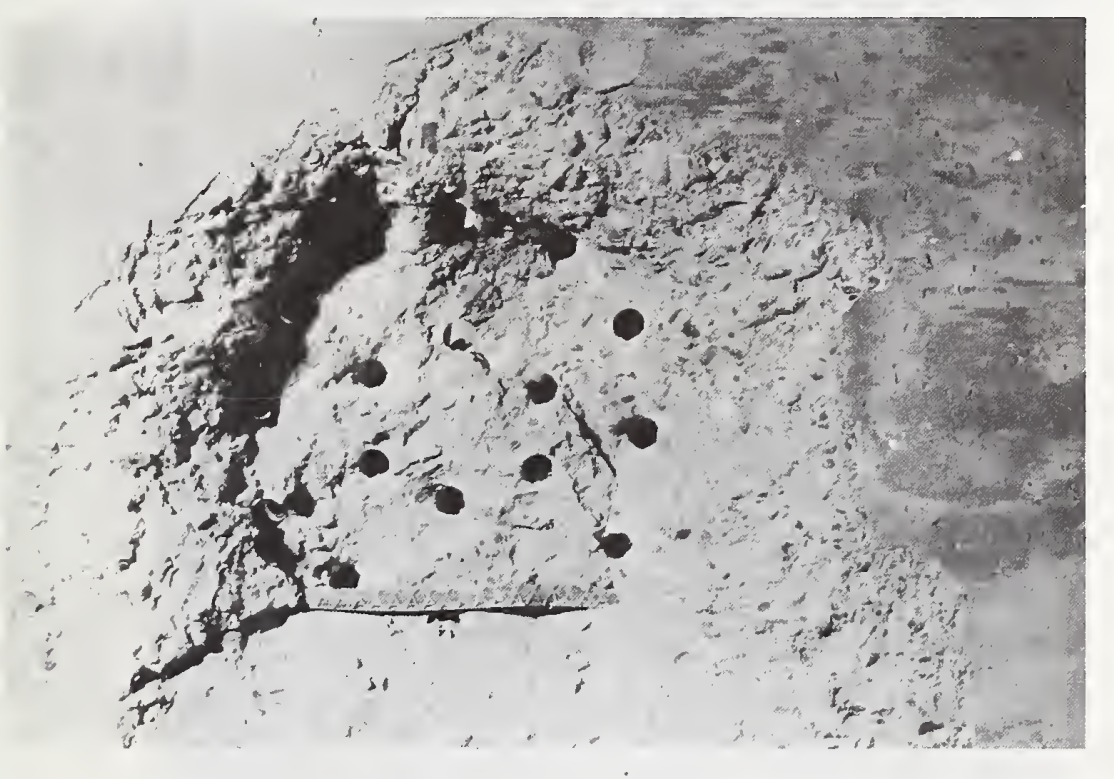

Figure 55. Interior of the Wall with Spalling Nearly Complete 


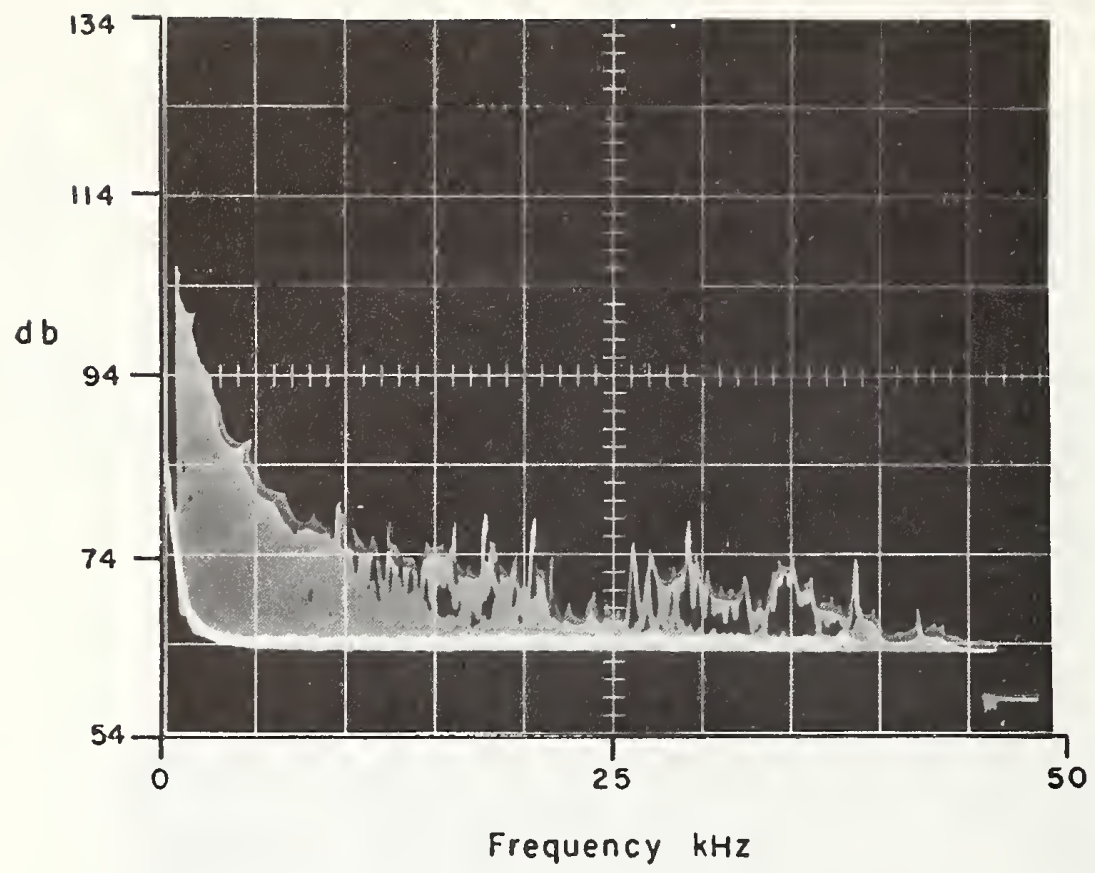

Figure 56. Multiple Sweep of Acoustical Disturbances Produced by Spalling

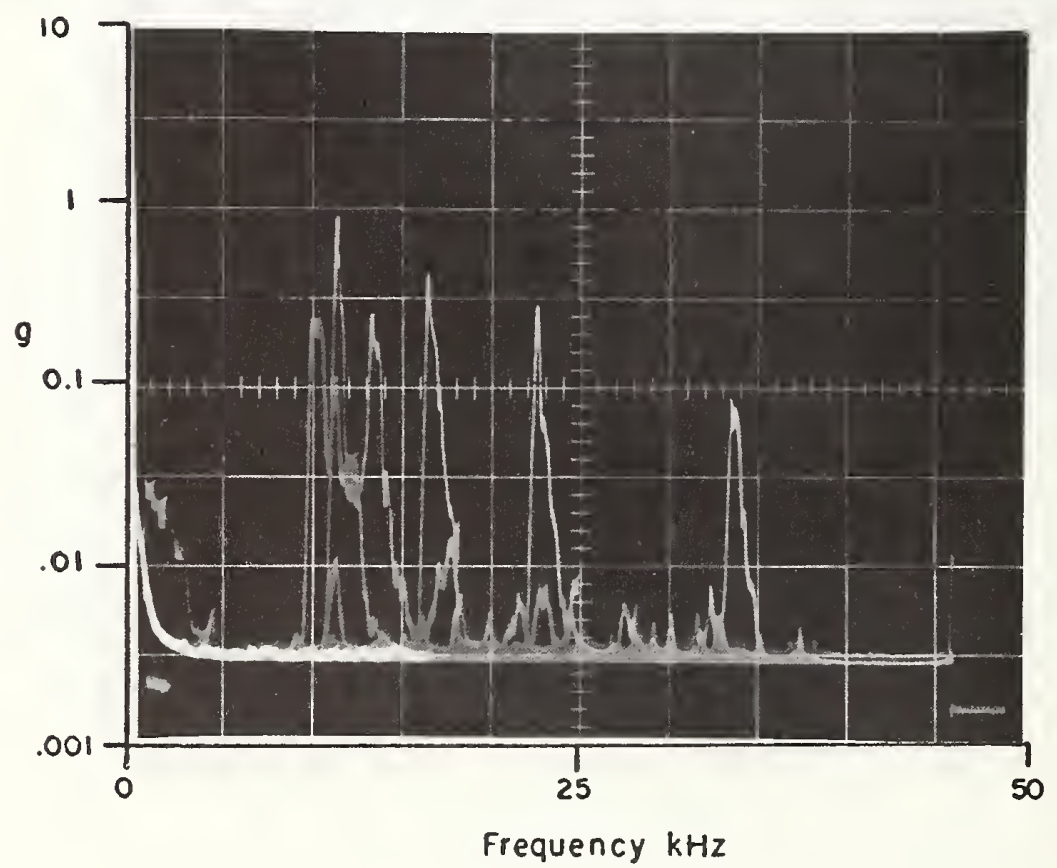

Figure 57. Vibration from Spalling with Transducer mounted $10^{\prime}$ from Attack Point 


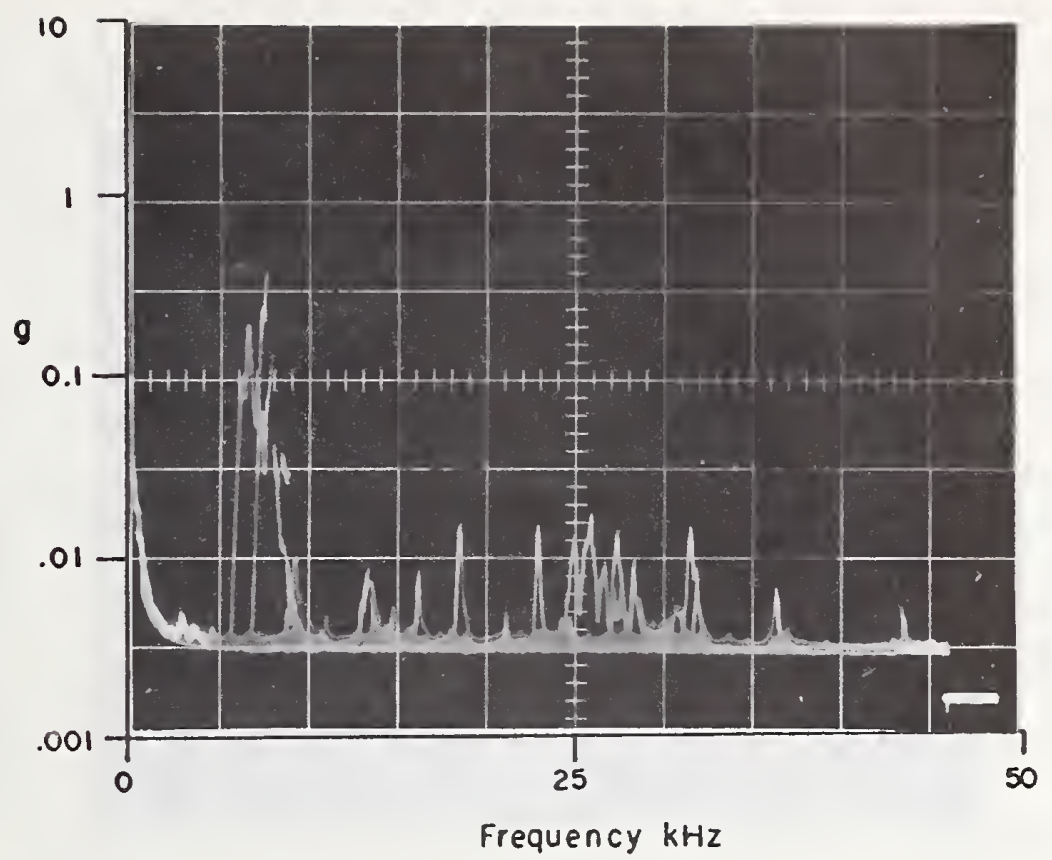

Figure 58. Vibration from Spalling with Transducer Mounted 20' from Attack Point

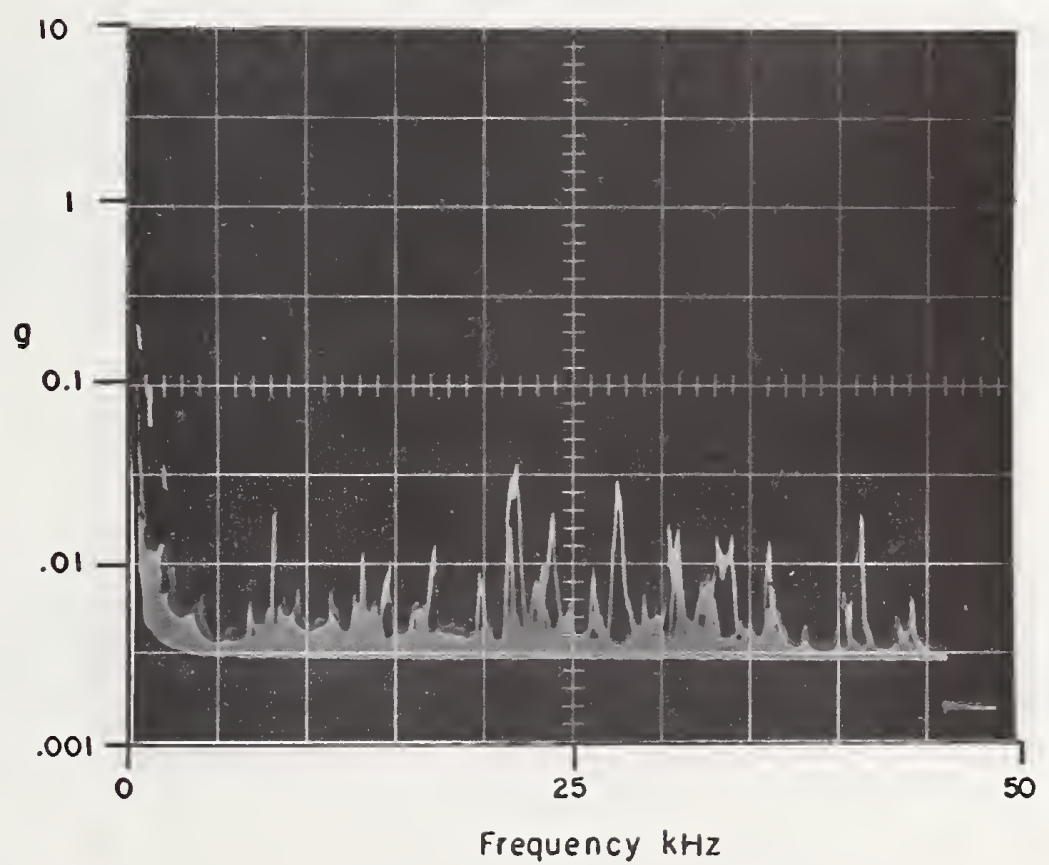

Figure 59. Vibration from 20-pound Sledgehammer 


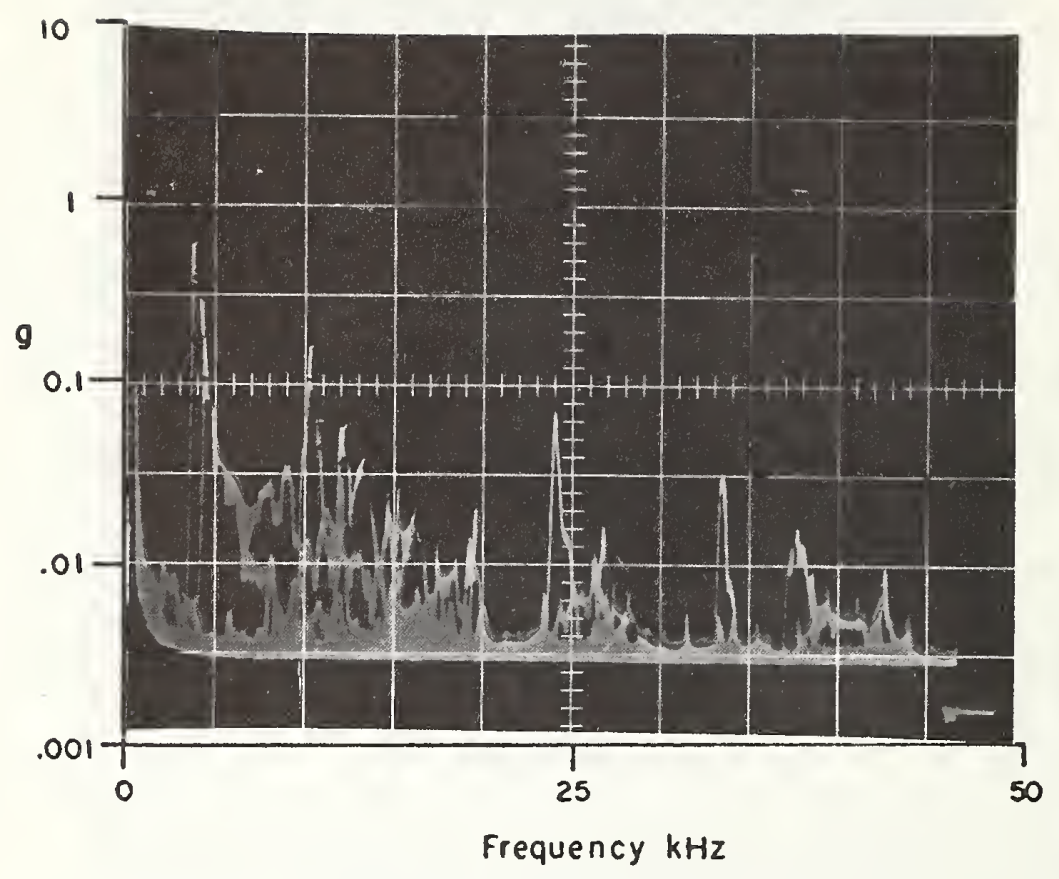

Figure 60. Vibration from 10-pound Sledgehammer 
Attack $24 \mathrm{~B}$ was similar in concept to 25D but employed a fewer number of smaller diameter holes to prepare for spalling. The size of the chunks of concrete initially spalled out in Attack 25D led to the conviction that more holes had been drilled than were necessary. Also, since earlier tests ${ }^{2}$ had shown that drilling rate with the rotohammer is dependent upon the volume of material removed in the case of hole diameters of $1^{\prime \prime}$ or less, drilling $3 / 4^{\prime \prime}$ holes would be appreciably faster than the $1^{\prime \prime}$ holes in Attack 25D. Whether or not a 3/4" diameter bulIpoint punch would hold up under the sledgehammer was not known.

The hole pattern selected consisted of eight holes equispaced around the perimeter of a circle 11-1/2" in diameter. Alternate holes were drilled $5^{\prime \prime}$ and 3-1/2" deep. A single $4^{\prime \prime}$ deep hole was drilled at the center of the circle. The rotohamer with $3 / 4^{\prime \prime}$ bit completed this 38 linear inches of drilling in 2.62 minutes at an average rate of 4.13 seconds per inch. SPL values of $104 \mathrm{~dB}$ were observed at $8^{\prime}$ and $112 \mathrm{~dB}$ at $2^{\prime}$ distance. Vibrational disturbances as observed with the transducer mounted on the interior of the wall at a distance of $5^{\prime}$ from the center of the opening are shown in figure 61 .

Spalling out the bottoms of the drilled holes was accomplished with the 3/4" diameter bull-point punch and 12-pound sledgehammer. It took 1.42 minutes and 63 hammer blows on the $5^{\prime \prime}$ deep holes followed by 1.26 minutes and 58 blows for the 3-1/2" deep holes and 0.2 minutes and 9 blows for the 4 " deep center hole. Samples of acoustic disturbances are shown in figure 62 and vibrational disturbances in figure 63 .

The $3 / 4^{\prime \prime}$ diameter bull-point punch performed satisfactorily in spalling out the first few holes. Then it received a glancing blow from the sledgehammer which produced a very slight bend about midway along the length of the punch. Subsequent hammer blows increased this bend and it became necessary to try to straighten the punch after each subsequent hole was spalled out. The marginal durability of the $3 / 4 "$ punch could easily be bolstered with a few extra spare punches.

2/ NBSIR 73-101, Penetration Resistance Tests of Reinforced Concrete Barriers, by R. T. Moore, Interim Report for Period October 31 November 3, 1972, prepared for Defense Nuclear Agency, Washington, D.C. 20305 . 


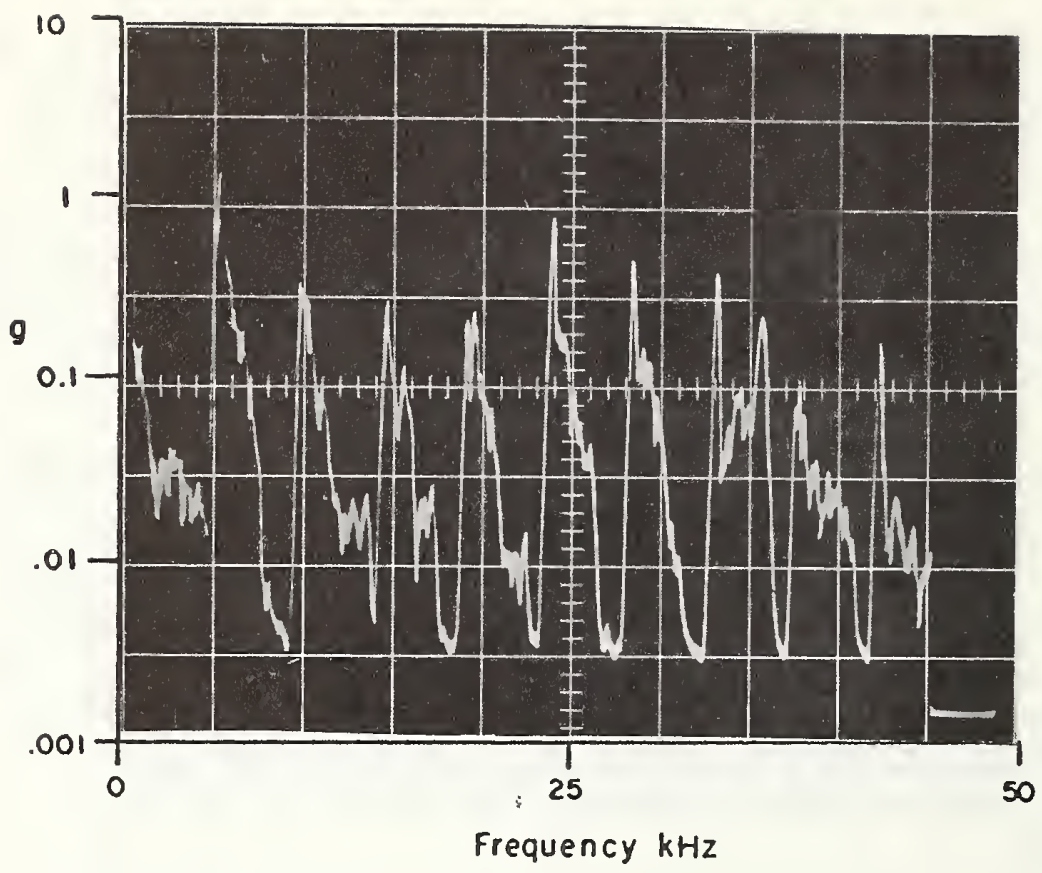

Figure 61. Vibration from Rotohammer

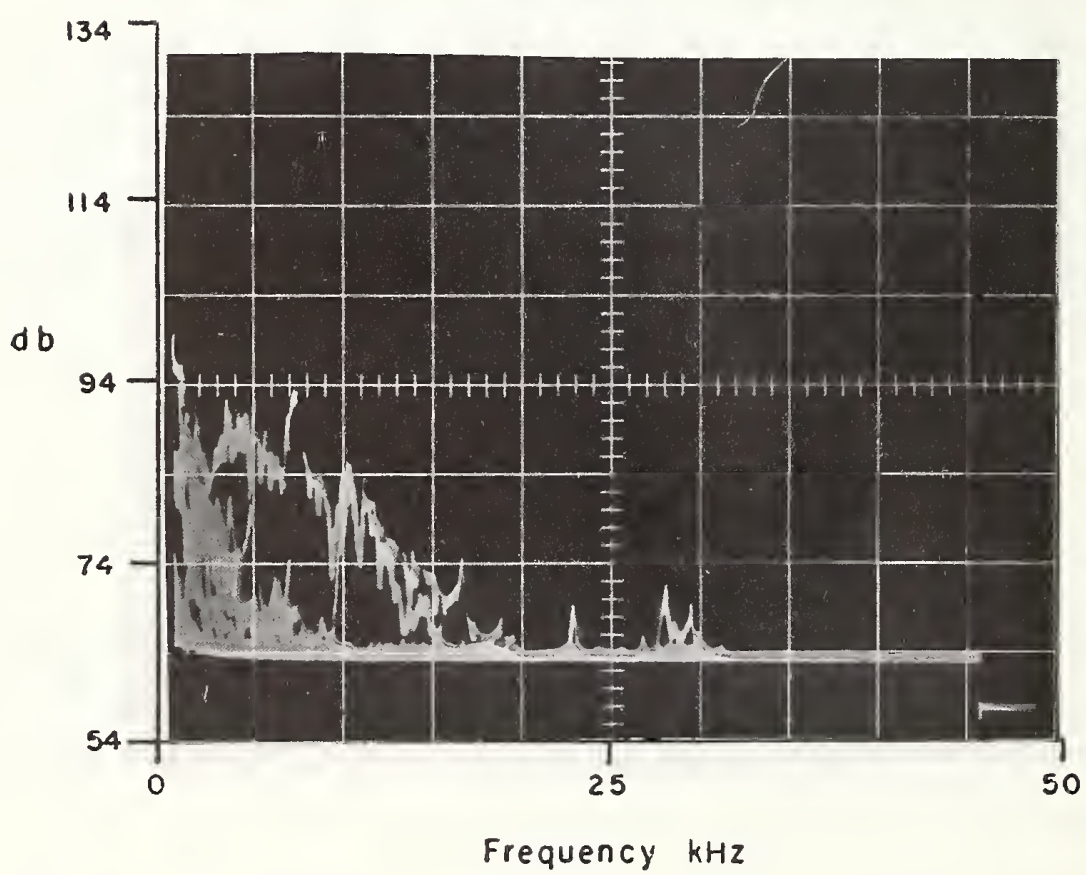

Figure 62. Acoustical Disturbances from Spalling 


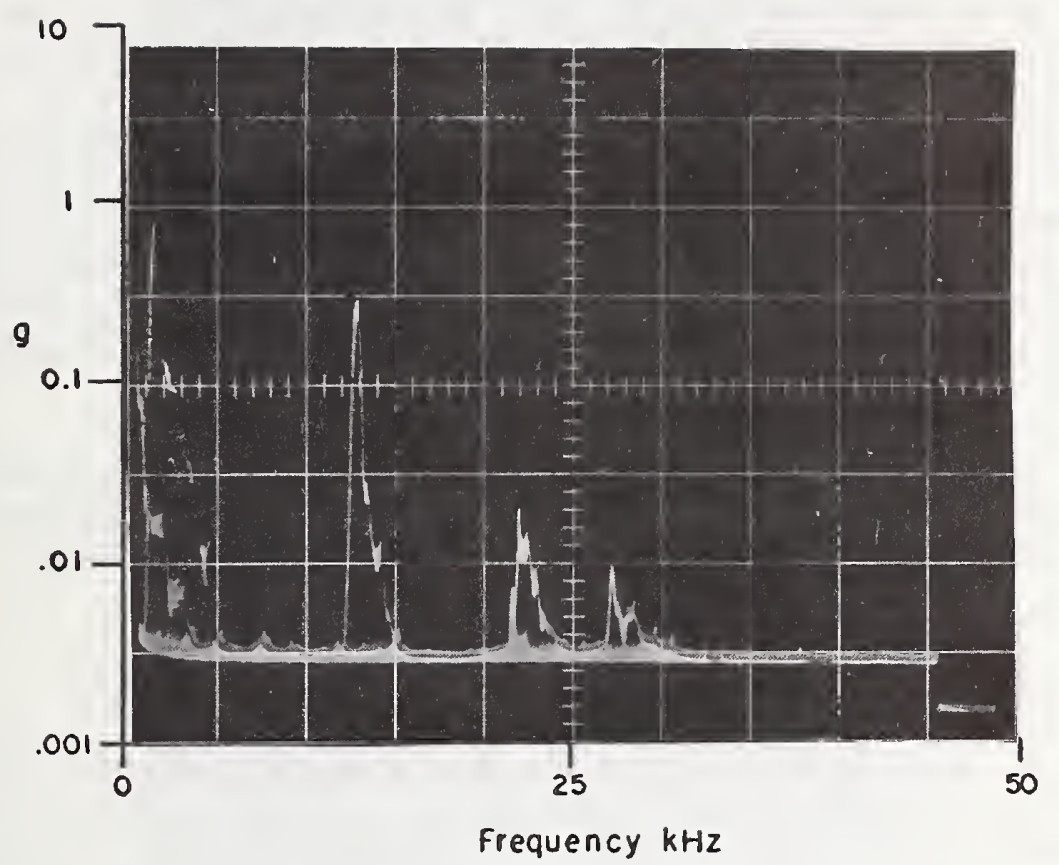

Figure 63. Vibration from Spalling 
The remaining plug in the center of the hole was now held in place by a perimeter ring of un-spalled concrete which ranged from 3-1/2" to 5" in thickness and it was expected that this could be rather quickly broken out. This did not prove to be the case. An initial breakthrough was produced in 2.56 minutes with a 20-pound sledgehammer, but, after another 1.07 minutes, it was apparent that the rate of enlargement was not very fast and an alternative strategy was adopted as shown in figure 64 . A tapered punch with a maximum diameter of $1-1 / 4^{\prime \prime}$ was driven into each of the 8 perimeter holes. This was quite effective in spalling the remaining concrete between the holes and the broken out center of the plug. It required 1.53 minutes and 66 blows from the 10-pound sledgehammer to complete the spalling from the perimeter holes. This was followed by 0.25 minute with the sledgehammer alone to break off a few remaining projecting points.

A single reinforcing bar was encountered in making this penetration. It was decided to defer cutting this until a later test using the burning bar. At that later time, the bar was cut in two places in 0.40 minute.

The total working time on Attack 24B was 11.31 minutes. The first J-SIIDS alarm occurred 5 seconds after the attack was started.

Although the time here was only about 60 percent of that required for Attack 25D, it could probably be further reduced to about 10 minutes. The 3.63 minutes of sledgehammering the central plug to make initial breakthrough could probably be reduced to about 2.5 minutes by drilling three central holes configured as an equilateral triangle with sides about $5 "$ long. If their depth was $2-1 / 2^{\prime \prime}$, the calculated drilling time would be .51 minute, spalling time with the bu11-point punch is estimated to take about 1.0 minute and then probably central breakthrough could have been accomplished with the sledge in about another minute. 


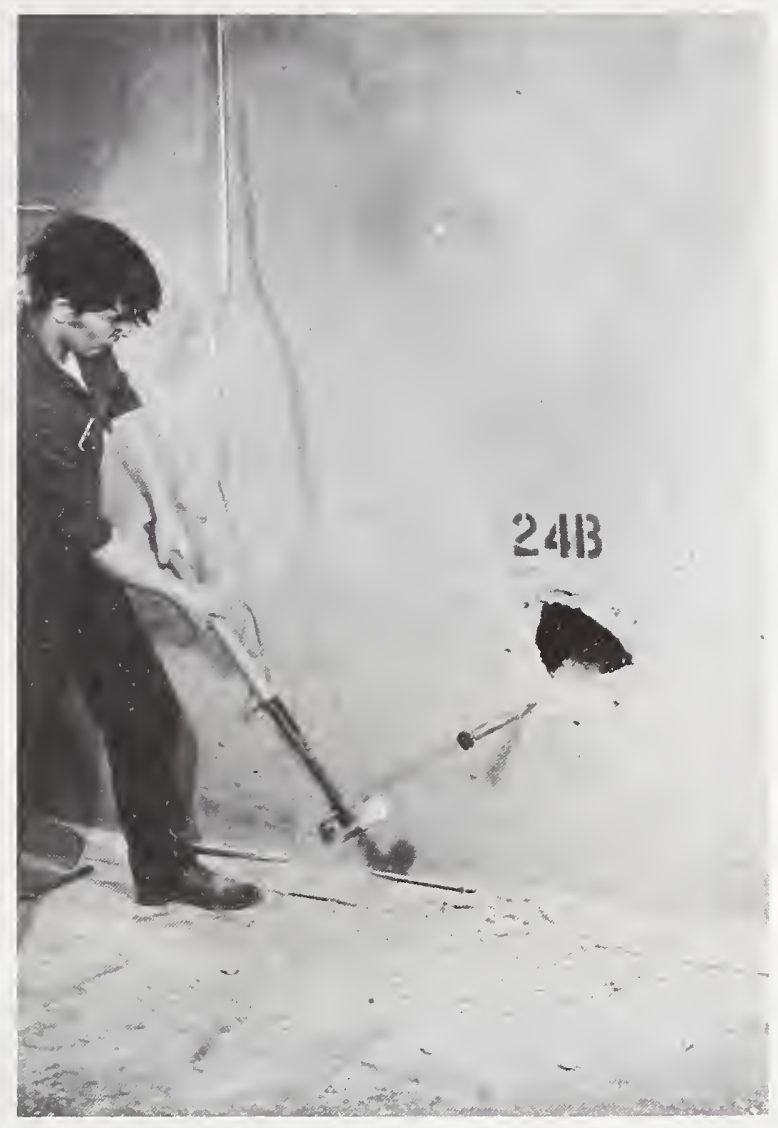

Figure 64. Use of Tapered Punch in Attack 24B 
Location 28 was a GSA Class 6 security vault door. Initial plans were to attack this with a burning bar but the plans were changed when the opportunity arose to test a portable rocket-powered cutting torch. Two approaches to making penetrations in this barrier were contemplated. The first involved making a small opening at a point which would permit the bolt-work blocking mechanism to be forced out of the way and permit the bolts to be withdrawn from their locked position by operating the vault door handle. The second involved making a 96 square inch circular cut through the door itself at an area where minimum resistance would be expected to be encountered.

Prior to pursuing either of these approaches, it was necessary to adjust the latch of the inner grilled day-door of the vault. In the process a rattail file was used to enlarge a bolt hole on the latch bracket which was mounted on the inner steel door frame. A vibration transducer had been mounted on the door frame about 20" away from this bracket and the vibrational disturbances produced by the filing are shown in figure 65 .

Next, because drilling could be used to attack the bolt-work blocking mechanism, a sample hole was started in the appropriate area to provide an opportunity to collect acoustical and vibrational disturbance data. A 9/32" high-speed steel bit was used in a $3 / 8^{\prime \prime}$ variable speed electric drill. Multiple sweeps of the resulting acoustical data appear in figure 66 and vibrational data in figure 67 . The vibrational transducer was on the inner frame of the vault door and the microphone was within the vault with the door closed, of course. On the outside, SPL values of $80 \mathrm{~dB}$ were observed with the drill running at low speed and 87 to $88 \mathrm{~dB}$ at high speed at a distance of $3^{\prime}$. 


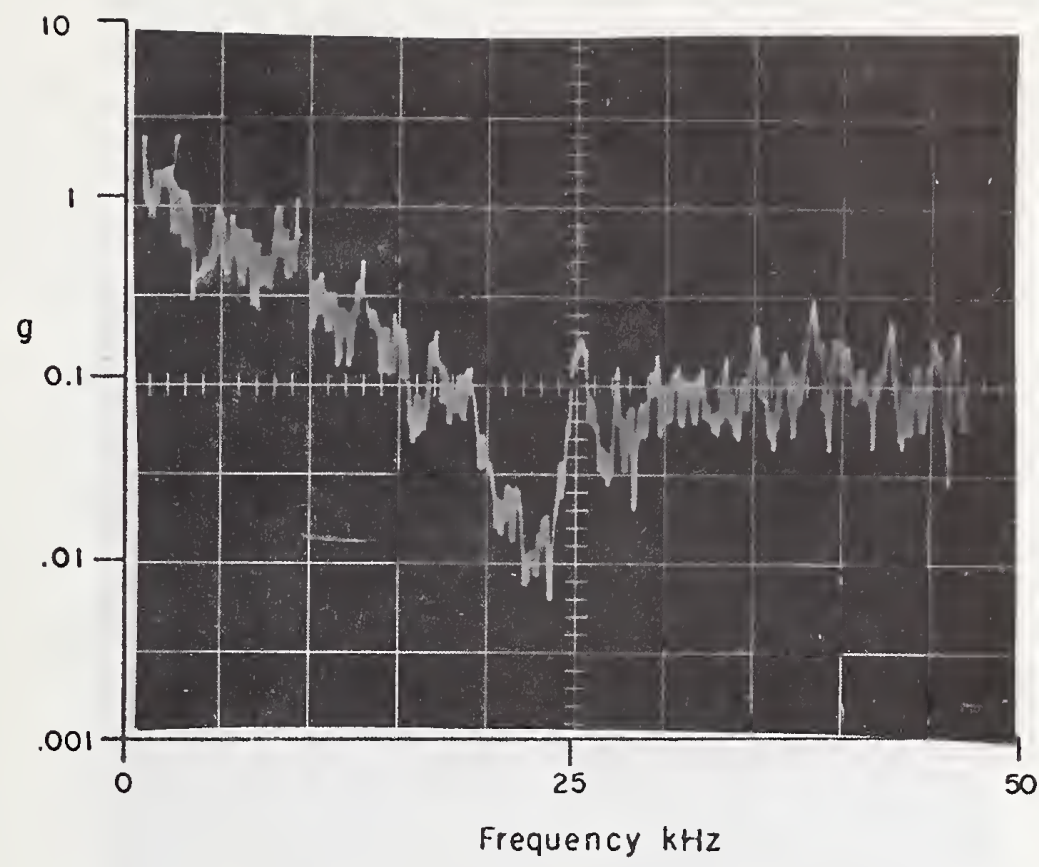

Figure 65. Vibration from File

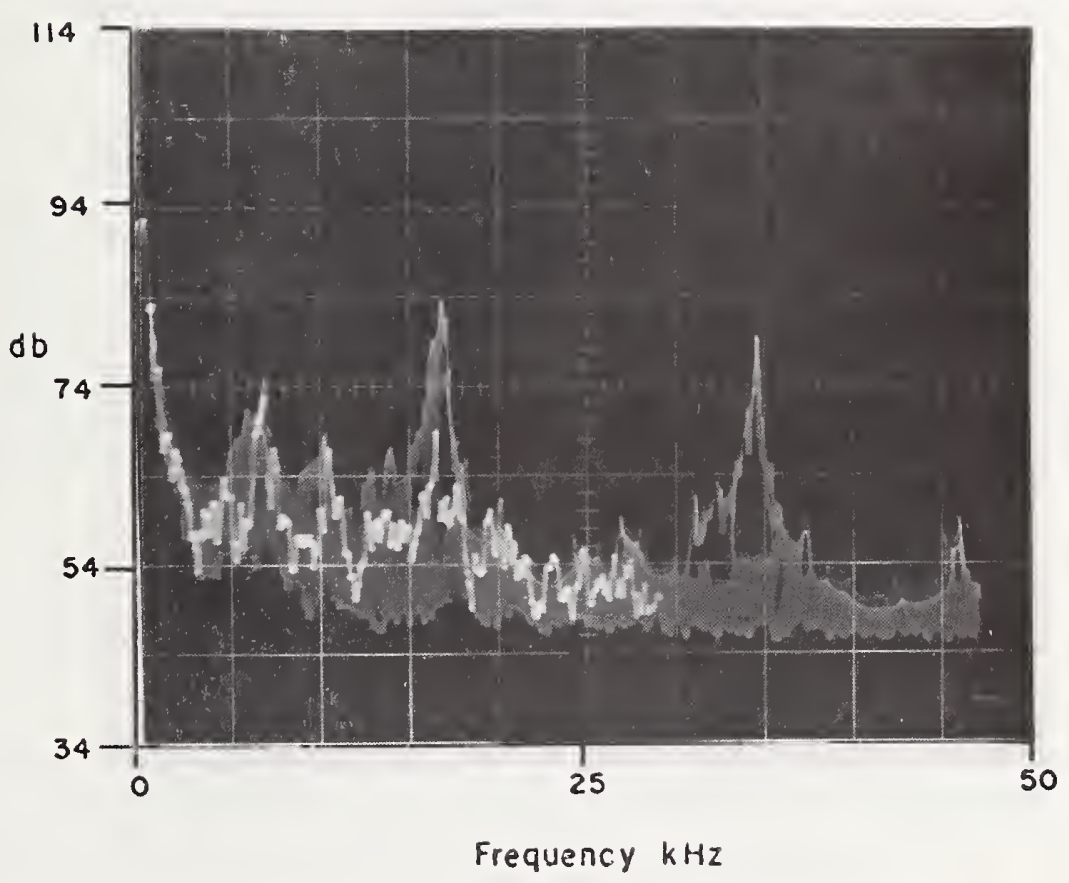

Figure 66. Acoustic Disturbance from Drilling on Vault Door 


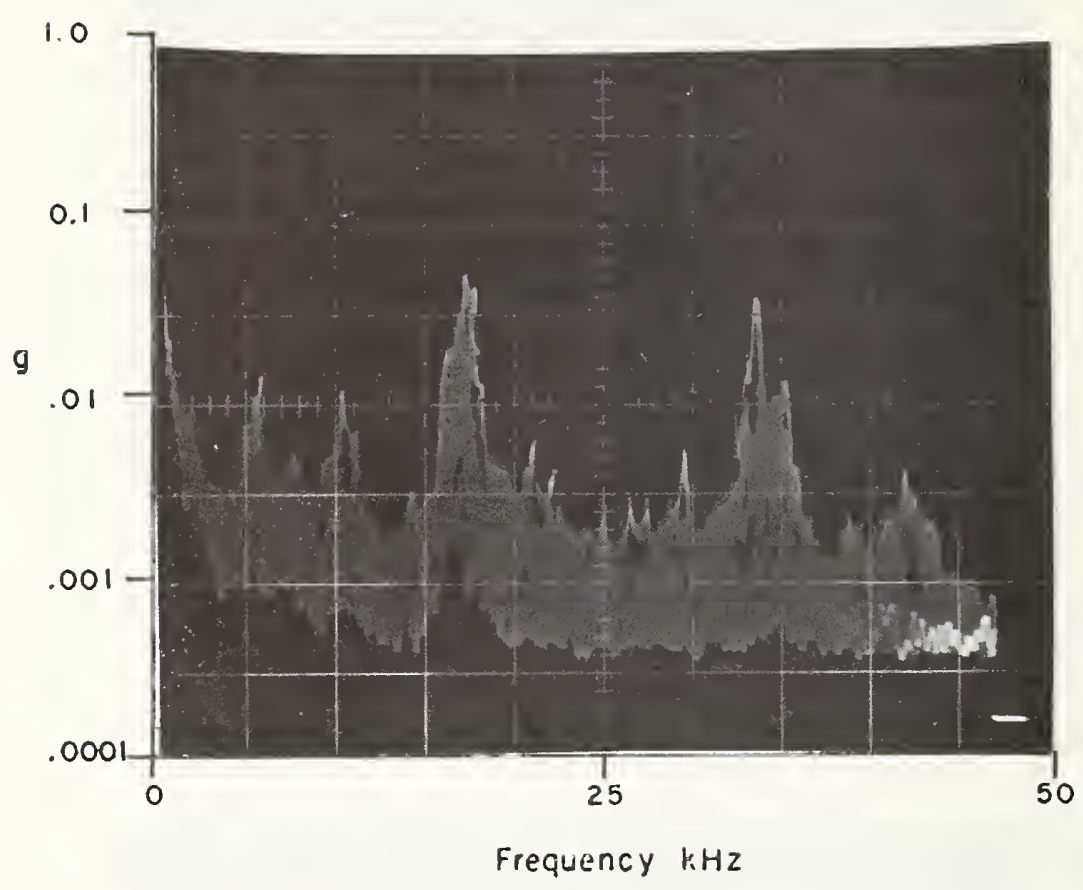

Figure 67. Vibration from Drilling on Vault Door 
Next, the portable cutting torch (rocket) was used to attack the area of the vault door over the bolt-work blocking mechanism. After 74 seconds it appeared unlikely that this attack could be successfully completed with the torch and a circular cut was immediately started in another area of the door. In the remaining 99 seconds, before the torch's fuel was consumed, an $80^{\circ}$ arc of an $11.3^{\prime \prime}$ diameter circle was cut in the $1 / 4^{\prime \prime}$ thick mild steel plate. The total burning time of the torch was 2.88 minutes. Acoustical disturbances are shown in figure 68 and vibrational disturbances in figure 69 .

The portable rocket torch was judged to be a suboptimal choice for use in an attack against the bolt-work blocking mechanism. The particular area involved is protected by $1 / 4^{\prime \prime}$ of mild steel, 3/8" of hard drill-resistant steel and $1 / 2^{\prime \prime}$ of stainless steel plate. During the 74 seconds that it was used against these, a hole was melted through the mild steel and partially through the drill resistant steel. This attack was abandoned at that point because it appeared likely that it would weld the bolt-work blocking mechanism in place if it were continued. A more concentrated and higher temperature heat source is preferred for this particular type of attack. On the circular cut, the $80^{\circ}$ arc represents a cut length of $7.89^{\prime \prime}$ in the $1 / 4^{\prime \prime}$ mild steel. This is a cutting rate of 12.5 seconds per inch. This is comparable to the cutting rate of an oxygen-fed electric arc torch on the same material, but at this rate, three of the rocket cartridges would be required to make an opening of the necessary diameter in the $1 / 4^{\prime \prime}$ mild steel outside of the door. This would require an estimated 7.5 minutes of working time and it would still be necessary to penetrate the thinner inside cover of the door. Figure 70 shows cuts made by the rocket torch and by the oxygen-fed electric arc which produced a much narrower cut.

On the assumption that the rocket torch might have annealed the drill-resistant plate, drilling was resumed after the door had cooled off to where it did not represent a burn hazard to the operator. This was continued for 3.55 minutes and then abandoned in favor of an oxygen-fed electric arc torch attack. The electric arc was used for 5.65 minutes to make a hole through which the bolt-work blocking mechanism could be accessed. Multiple sweeps of the acoustical disturbances produced by the arc are shown in figure 71 and the vibrational disturbances in figure 72 .

A 4" Iong cut was also made in the $1 / 4^{\prime \prime}$ mild steel door cover to establish an estimate of its cutting rate. The $4^{\prime \prime}$ cut took 48 seconds for an average rate of 12 seconds per inch.

Finally, the bolt-work blocking mechanism was forced using tooling which was worked through the opening produced by the electric arc. The time required for this activity was 8.0 minutes. The total working time required to release the bolt work was 18.27 minutes. 


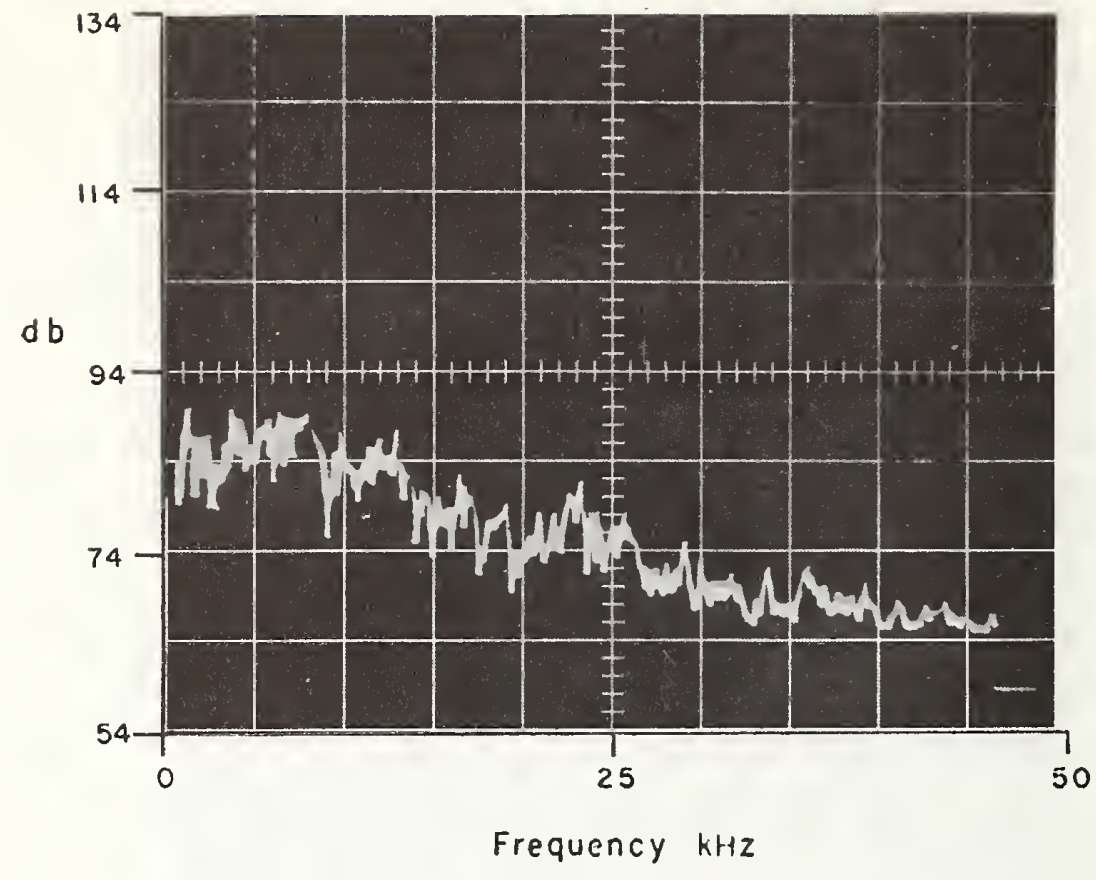

Figure 68. Acoustical Disturbances from Rocket Torch

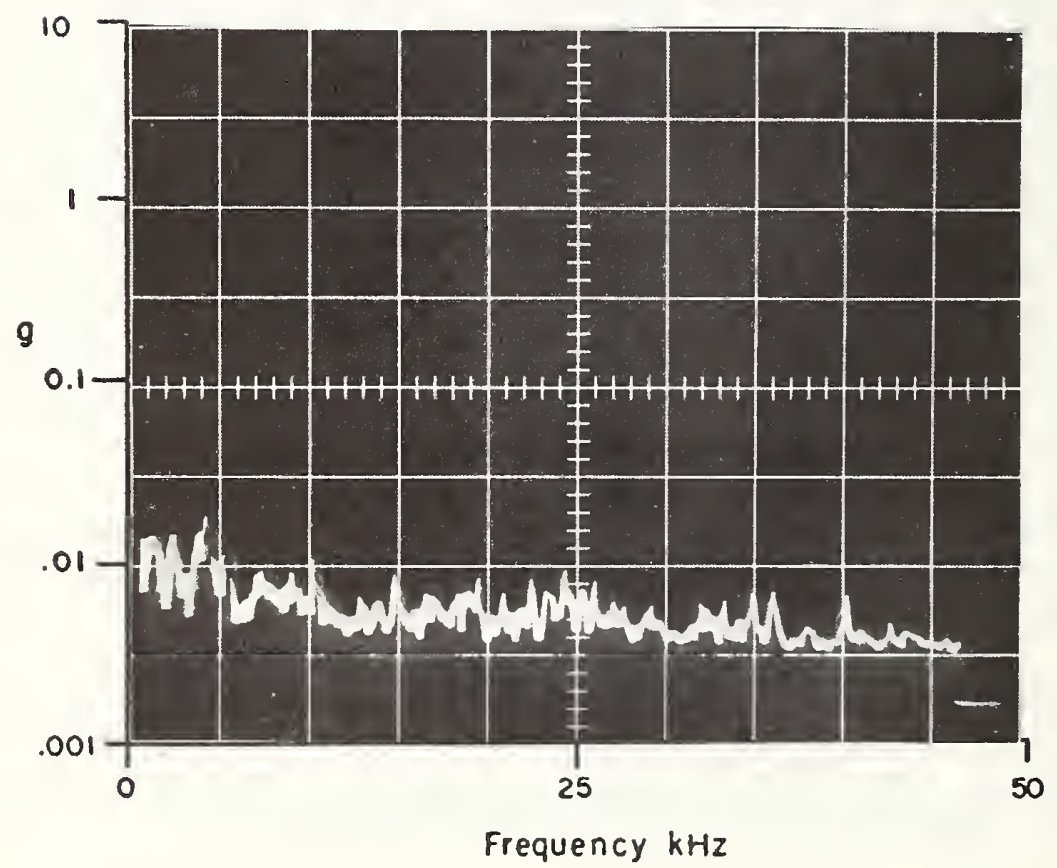

Figure 69. Vibration from Rocket Torch 


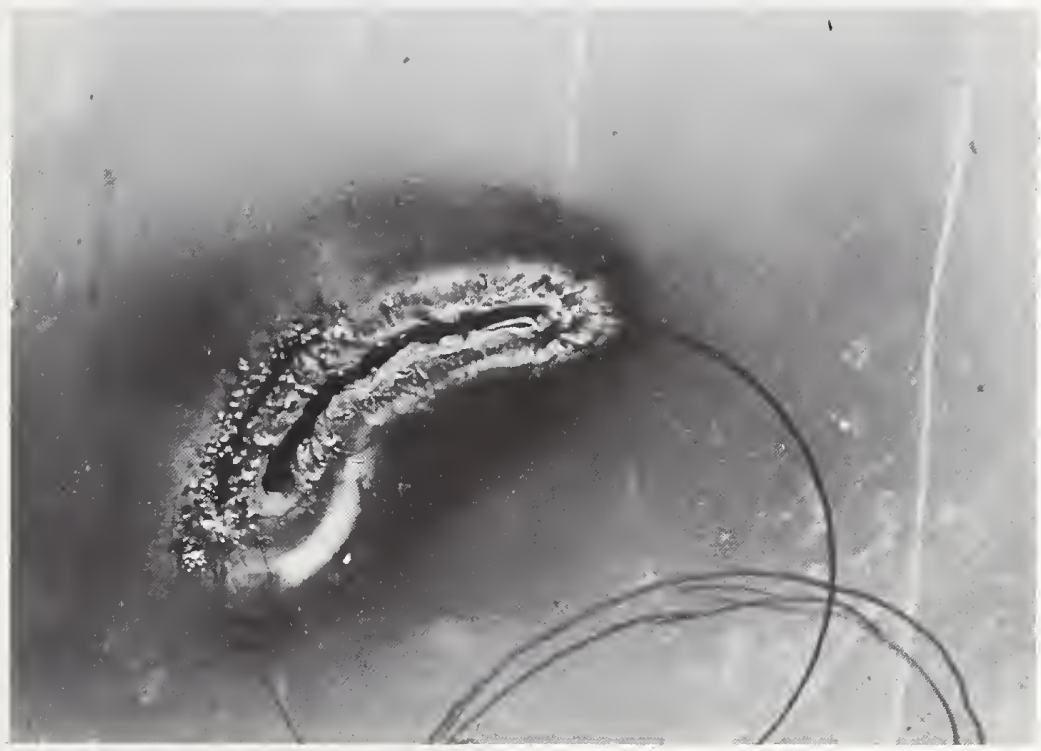

Figure 70. Comparison of Cuts Made by Rocket Torch (Wide) and Oxygenfed Electric Arc (Narrow) 


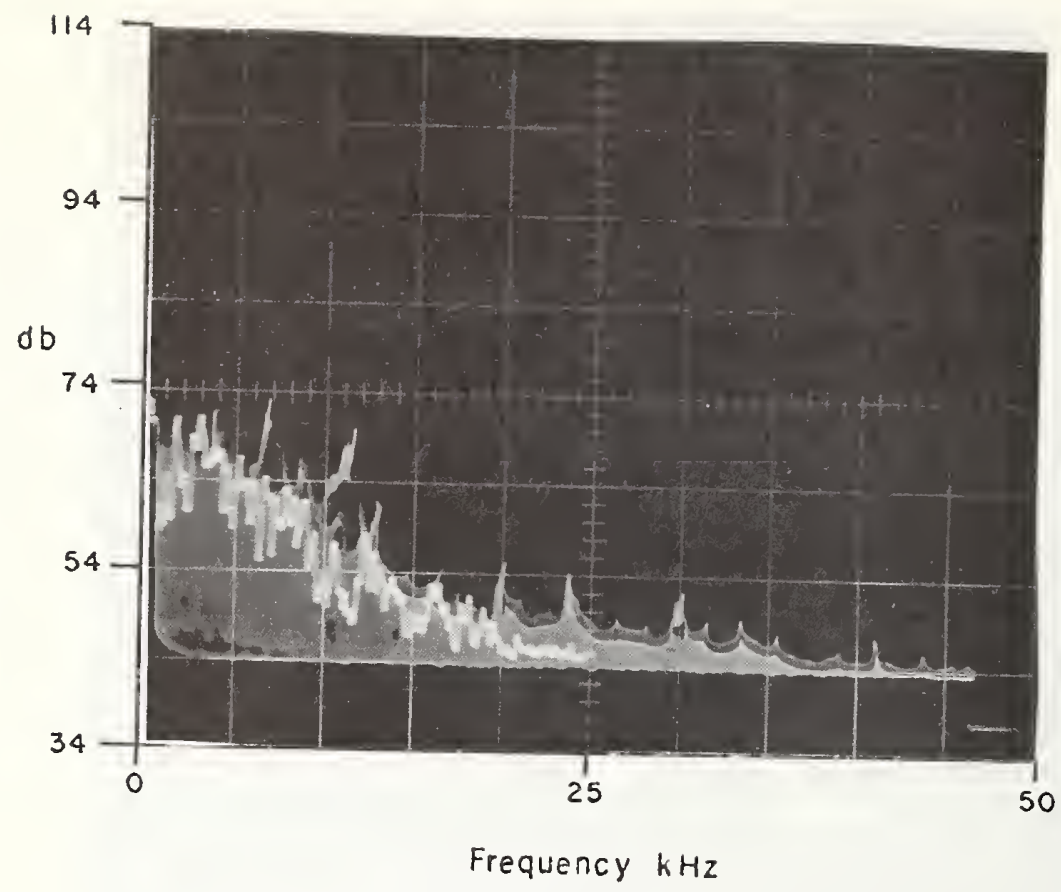

Figure 71. Acoustical Disturbances

from the Electric Arc Torch

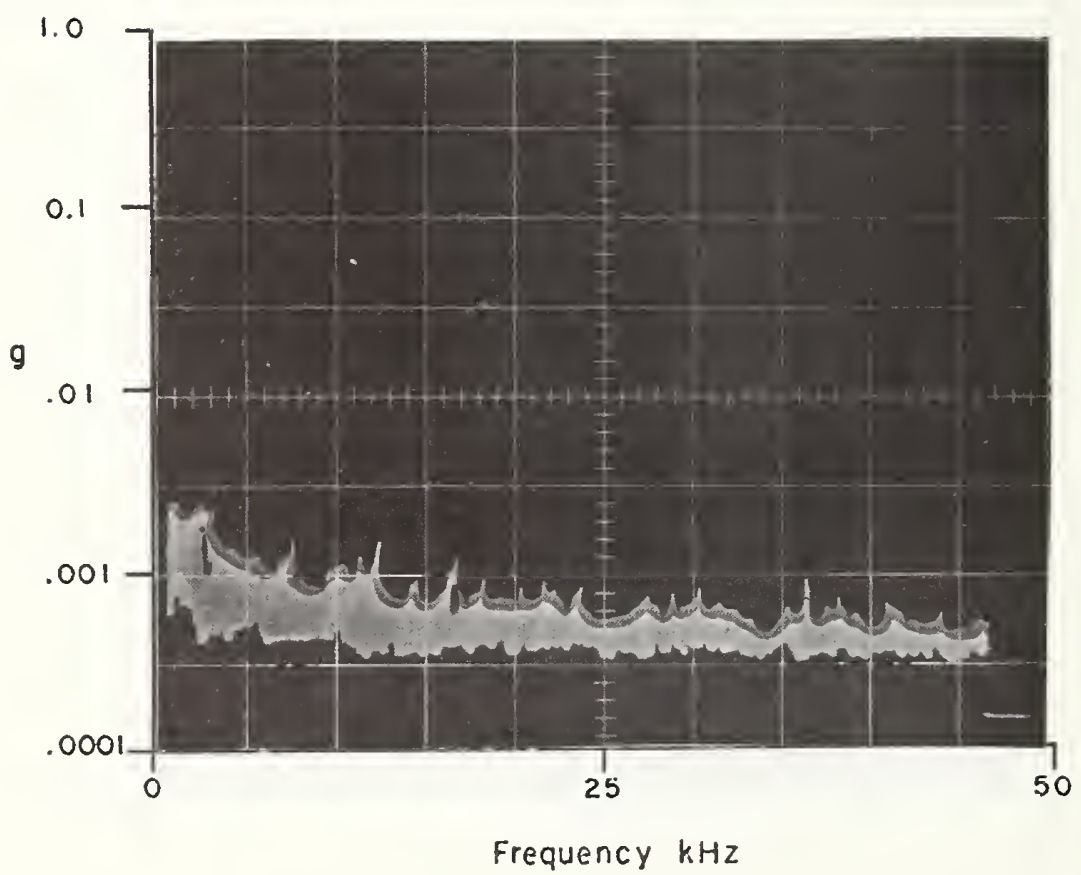

Figure 72. Vibration from the Electric Arc 
A burning bar was used to make a single hole in the $8^{\prime \prime}$ thick concrete wall of Room 3 as shown in figure 73 . It took .73 minute and used $40^{\prime \prime}$ of bar with the oxygen pressure at 160 p.s.i. Acoustical disturbances are shown in figure 74 and vibrational disturbances in figure 75. The vibration transducer was mounted on the inner surface of the wall at a distance of two feet from the attack point.

The first J-SIIDS alarm occurred when the bar penetrated the inner surface of the wall.

As a further demonstration of the burn bar, the aluminum panel covering the opening previously made in Attack $24 \mathrm{~B}$ was removed and replaced by a $3 / 16^{\prime \prime}$ thick expanded steel grating attached to the outside of the wall. With oxygen pressure at 100 p.s.i., the steel grating was cut along the perimeter of the previously made opening in 1.52 minutes. The reinforcing rod, left intact in the opening until this time, was then cut in 0.4 minute as shown in figure 76 . J-SIIDS alarms were produced by the oxyacetylene torch flame used to ignite the burning bar.

Acoustic disturbances produced by the burning bar are shown in figure 77 and vibrational disturbances in figure 78 . The vibrational transducer was located on the inner wall of Room 3 five feet from the $24 \mathrm{~B}$ opening.

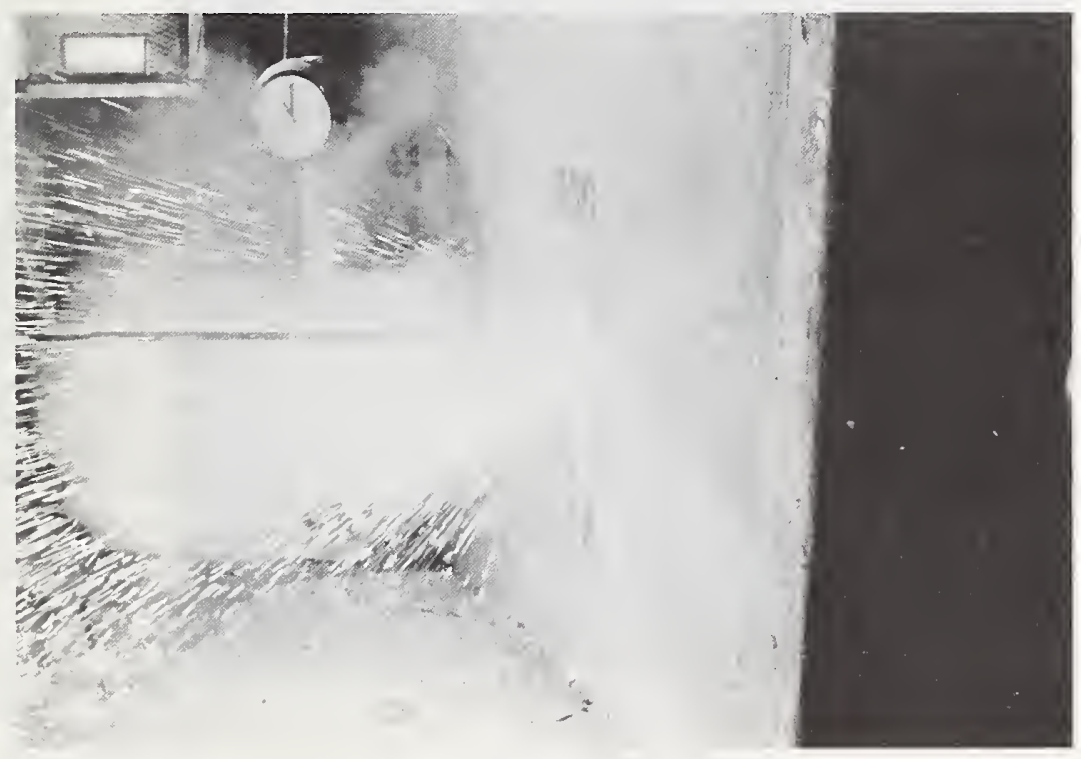

Figure 73. Burning Bar Melting a Hole through Concrete 


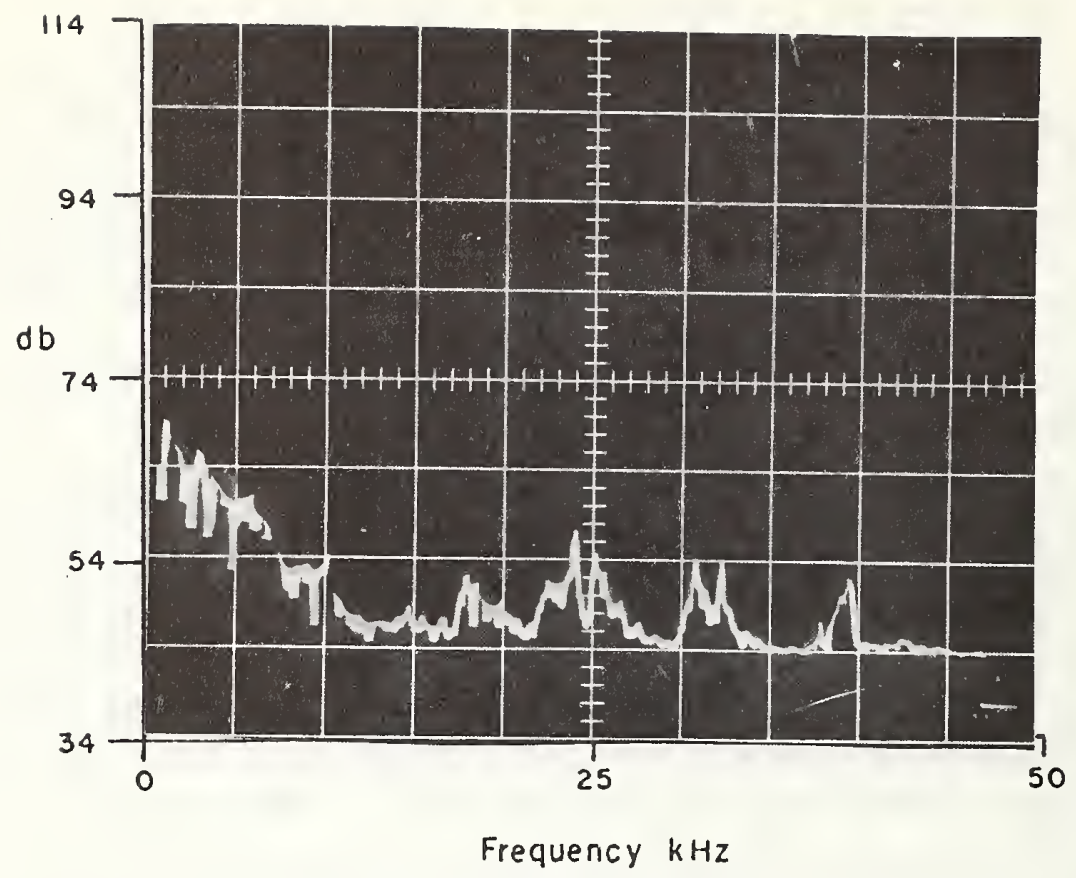

Figure 74. Acoustical Disturbance from Burning Bar Attack on Concrete

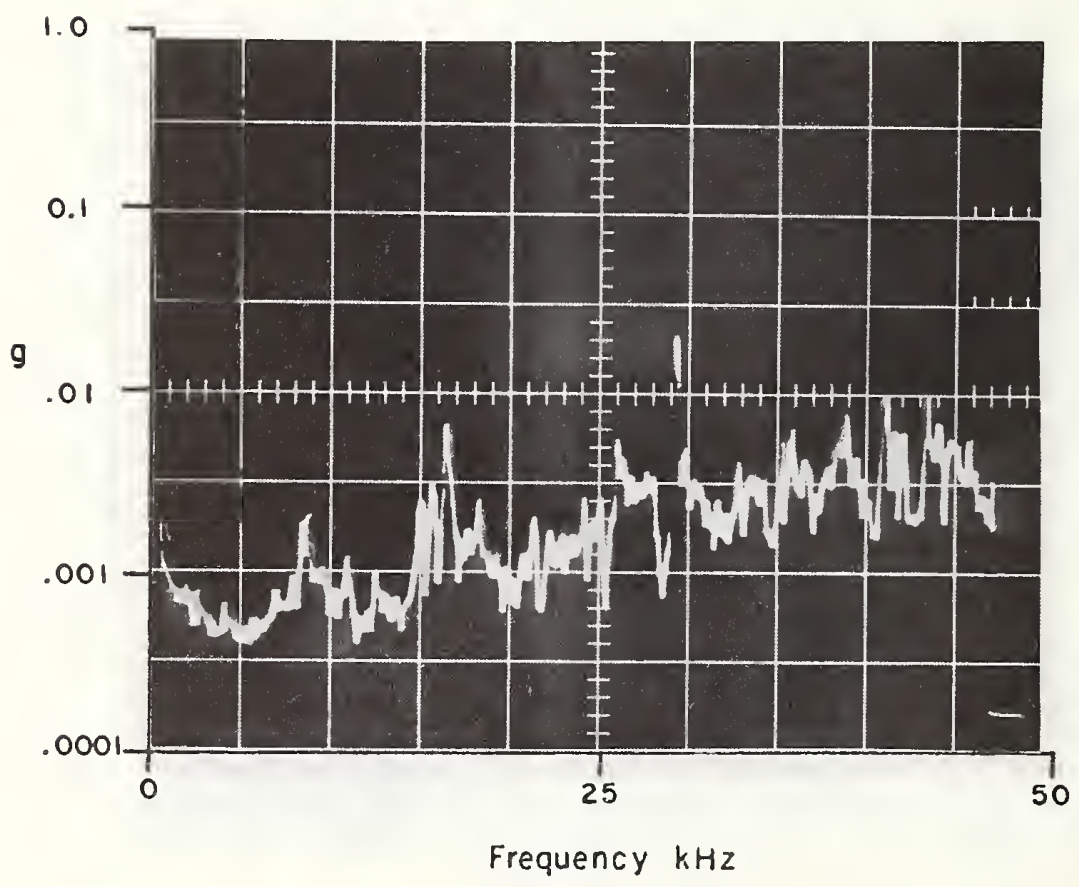

Figure 75. Vibration from Burning Bar Attack on Concrete 


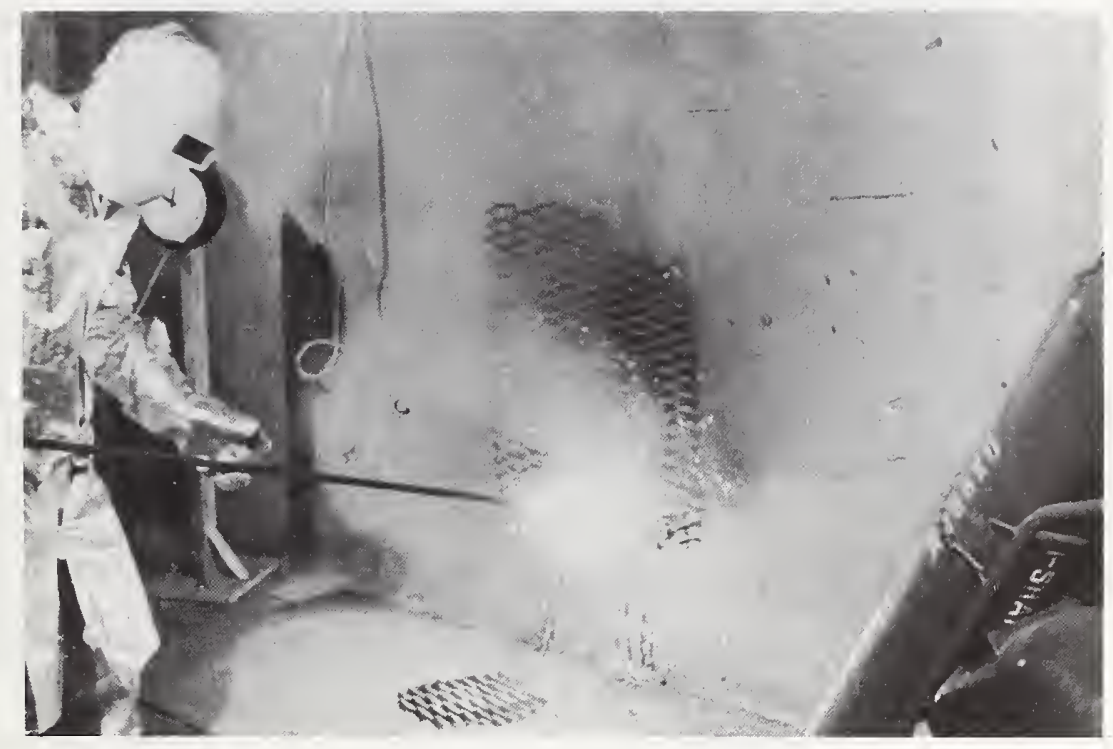

Figure 76. Burning Bar Cutting Reinforcing Rod at Location 24B 


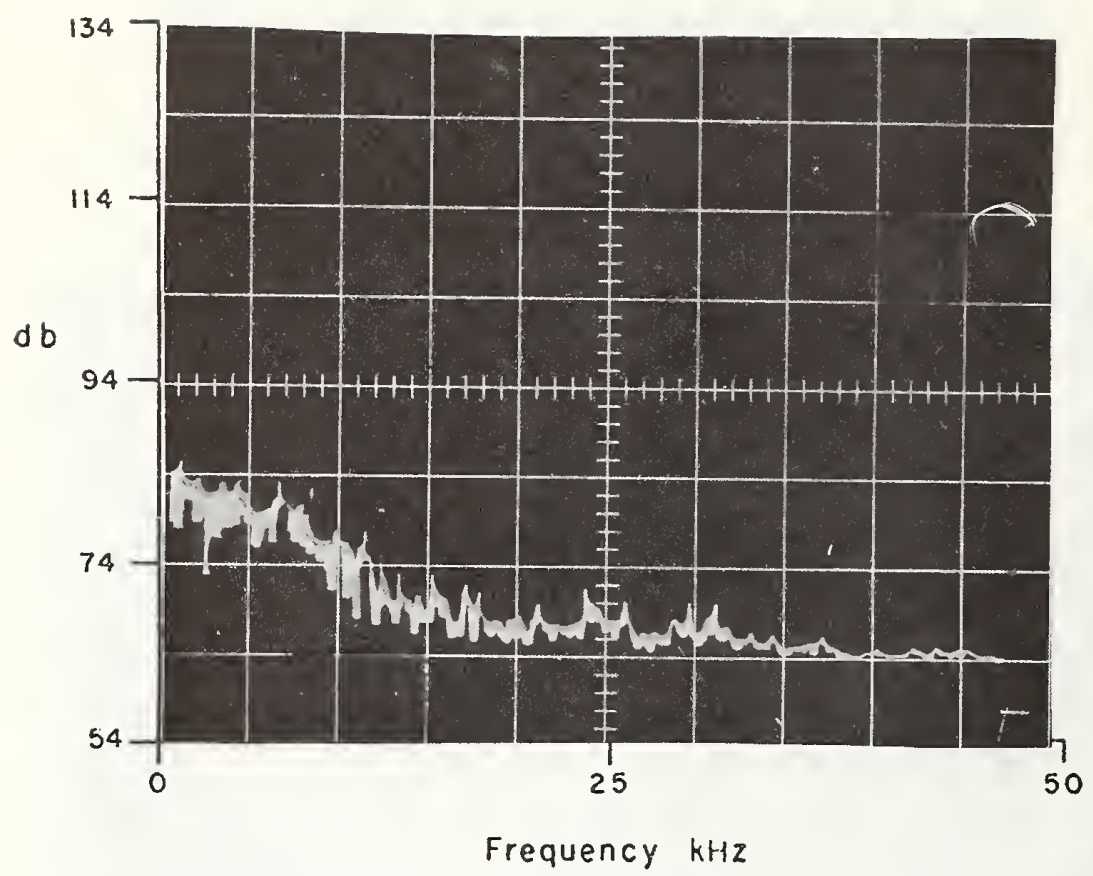

Figure 77. Acoustical Disturbance from Burning Bar Attack on Expanded Metal

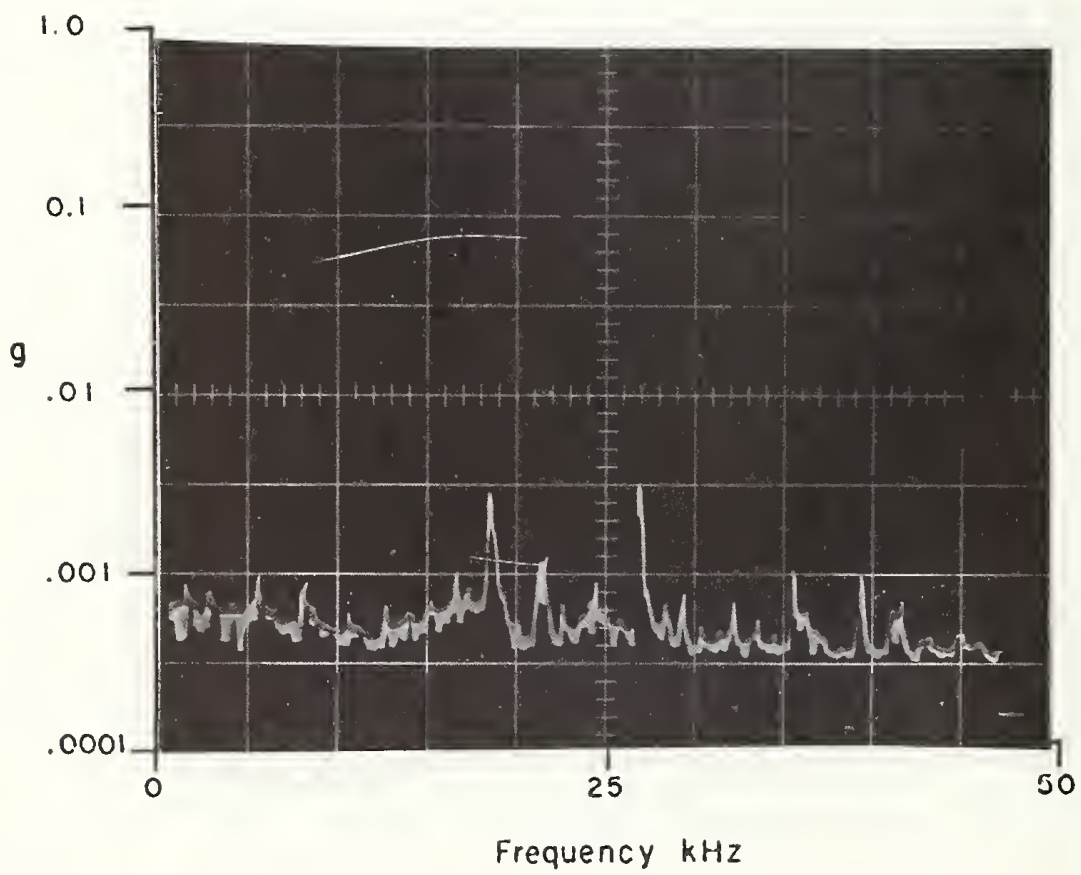

Figure 78. Vibration from Burning Bar Attack on Expanded Metal 


\section{CONCLUSIONS}

The observed penetration times ranging from 1.3 minutes for a double-planked wooden wall to 18.27 minutes for a GSA Class 6 vault door resulted from the use of portable, readily available tooling, manned by operators who worked willingly and purposefully but who obviously could not be motivated to the same extent as the would-be intruder team who might stand to gain or lose a great deal depending on the speed and vigor with which they pursued their attack. Such a team could probably reduce each of the observed penetration times by at least 10 percent and perhaps in some instances by as much as 50 percent.

All of the attack techniques that were used produced acoustical or vibrational or both types of disturbances which are readily detectable and were, in fact, detected by the J-SIIDS equipment. For adequate safeguarding of any area, the intrusion alarm system must be backed up with guard, police, or other reaction forces having response times which are less than the times required to complete a penetration. This response time should be less than one minute for situations where the barrier structures are similar to those in Rooms 1 and 2, and should be less than 10 minutes in the case of a vault structure similar to Room 3; even shorter response times would be necessary to safeguard against more powerful penetration attacks such as the use of explosives. 


\section{APPENDIX}

During some of the tests, audio frequency disturbances were picked up using a one-inch microphone located within the room under attack. These data were recorded on magnetic tape and subsequently reduced to $1 / 3$ octave bandwidth sound pressure levels in the 20 to $20,000 \mathrm{~Hz}$ frequency bands. The resulting tabulations are presented in this appendix grouped by attack identification designators.

These data should be considered as representative values rather than absolute as there were several uncontrolled variables associated with the data acquisition. These include the unknown acoustical characteristics of the simulated arms rooms and the variations in transmission path lengths between the microphone and the attack points. These factors could have an influence on the order of $\pm 6 \mathrm{~dB}$ on any of the tabulated values. 
ATTACK 20S

One-third octave sound pressure levels, $\mathrm{dB}$

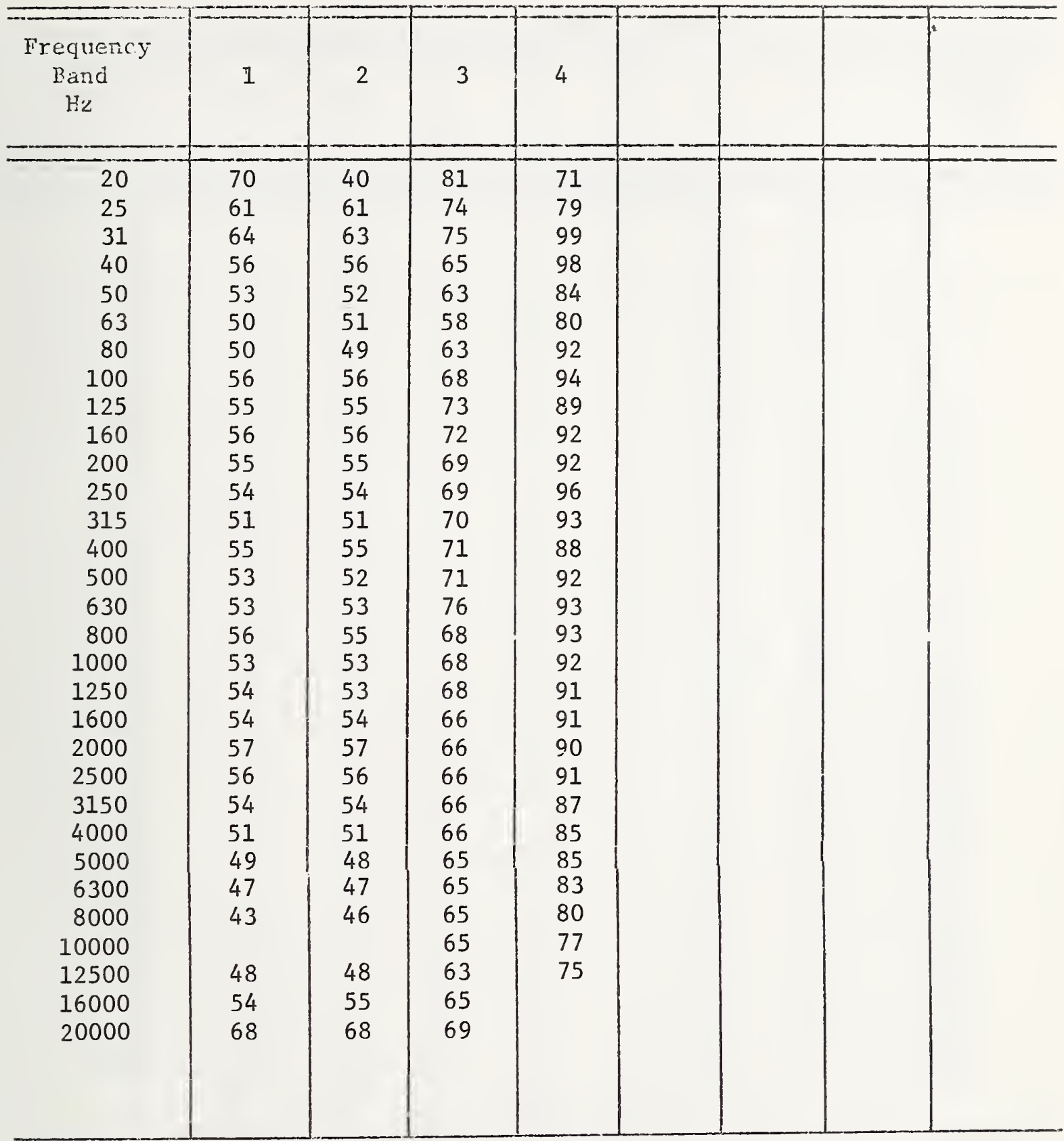

1. Hand brace and $1^{\prime \prime}$ wood bit, cutting.

2. Hand brace and $1^{\prime \prime}$ wood bit, cutting.

3. Hand brace and $1^{\prime \prime}$ wood bit at breakthrough.

4. Electric-powered saber saw. 
One-third octave sound pressure levels, $\mathrm{dB}$

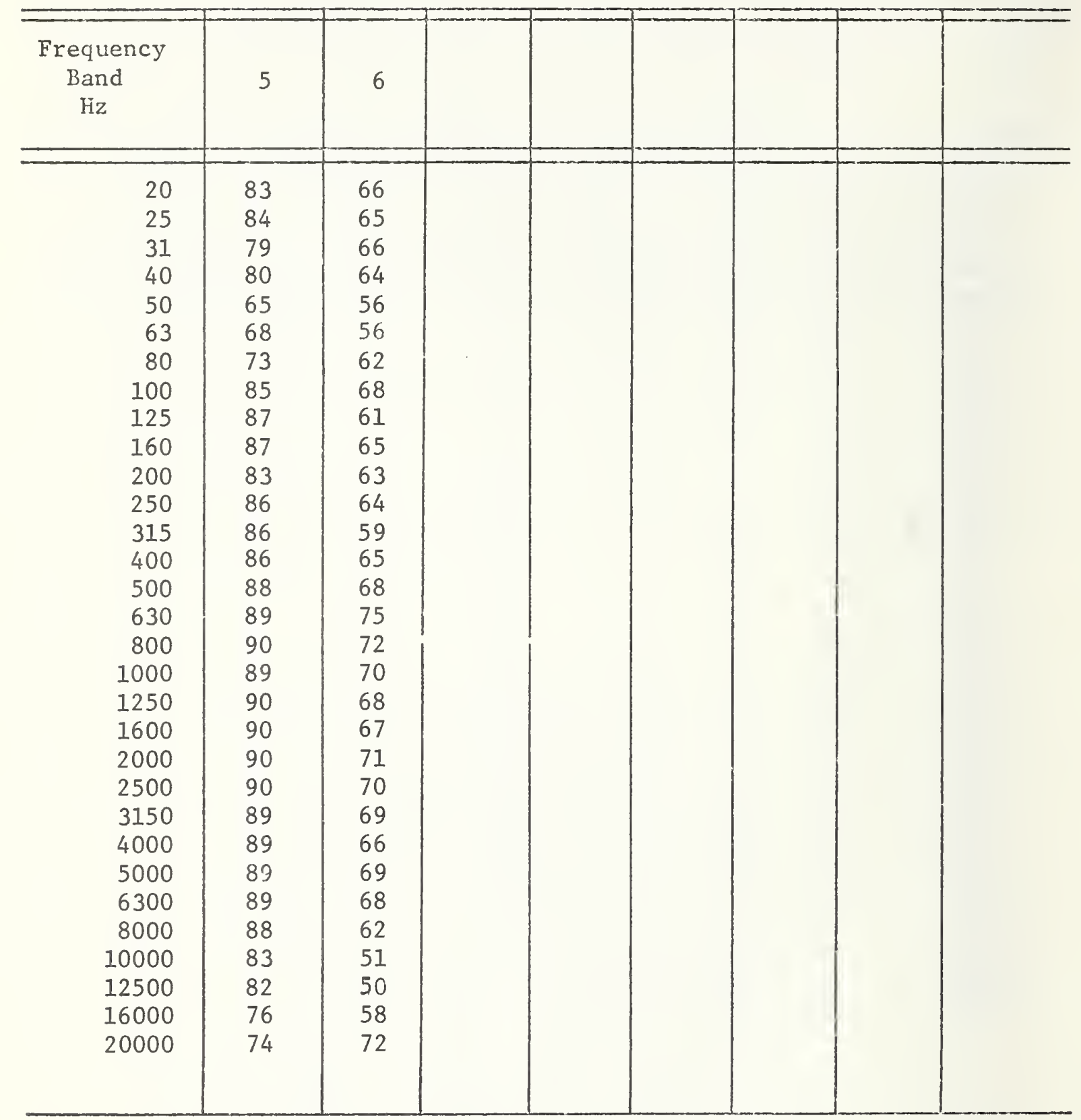

5. Electric-powered rotary saw.

6. Electric drill with $3 / 4^{\prime \prime}$ wood bit. 
One-third octave bandwidth sound pressure levels, dB

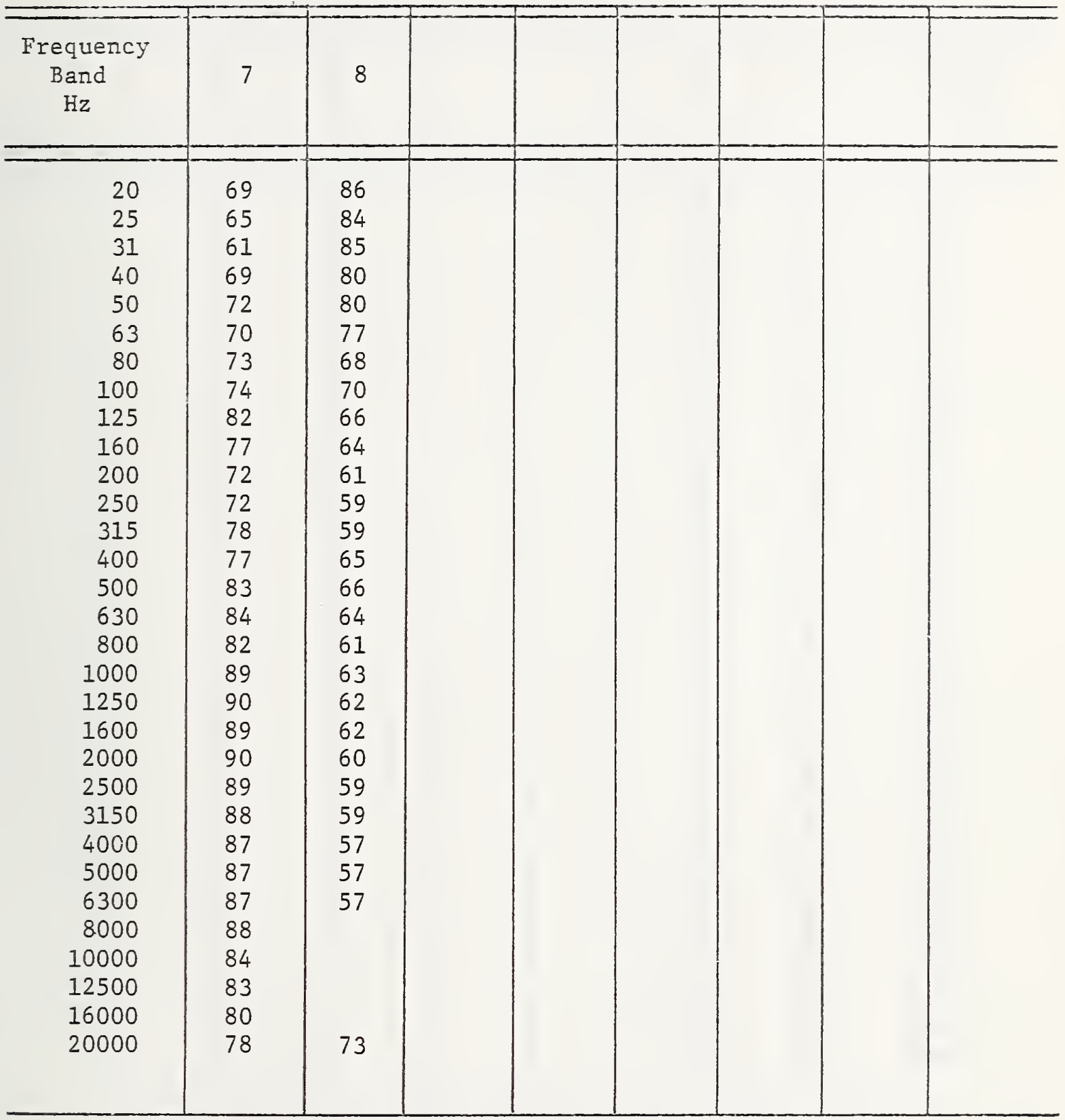

7. Electric-powered rotary saw.

8. Carpenter's hand saw cutting wooden joist. 
OTHER ATTACKS

One-third octave bandwidth sound pressure levels, $d B$

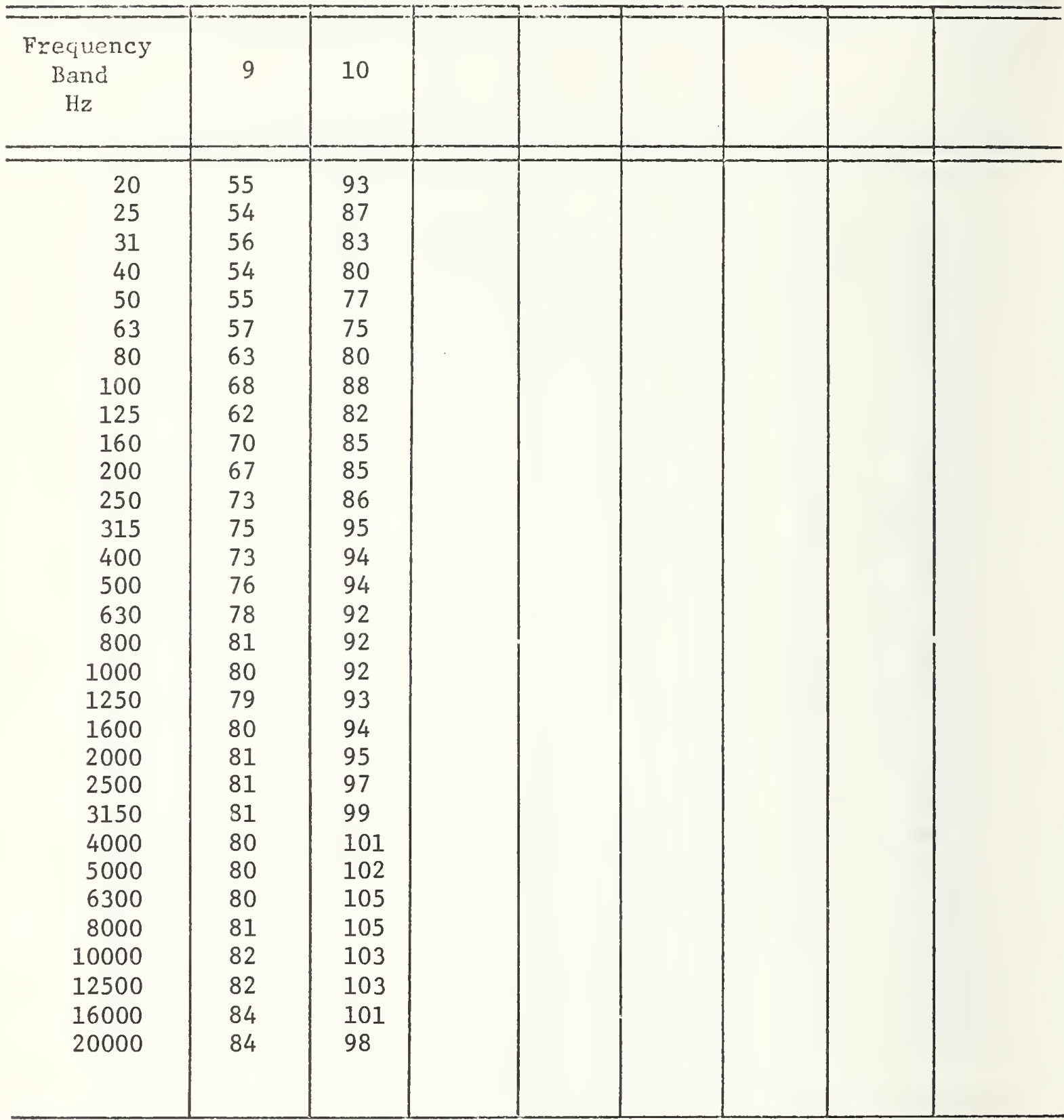

9. Oxyacetylene torch cutting metal grill.

10. Breaking window glass. 
ATTACK 22A

One-third octave bandwidth sound pressure level, dB

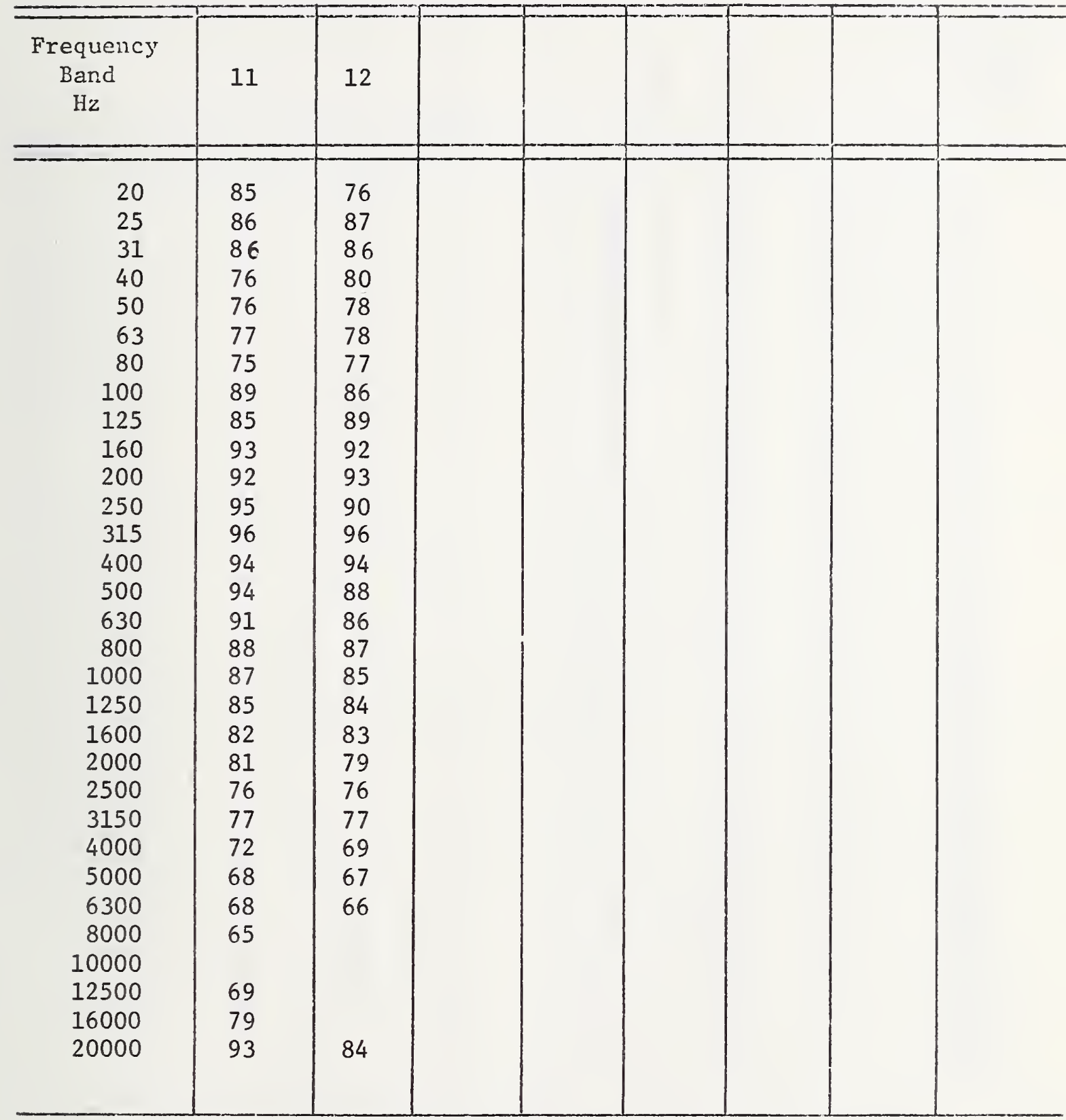

11. Twelve-pound sledgehammer attack on brick veneer.

12. Sledgehammer attack on cinder block after penetration of brick veneer. 
ATTACK 22B

One-third octave bandwidth sound pressure level, dB

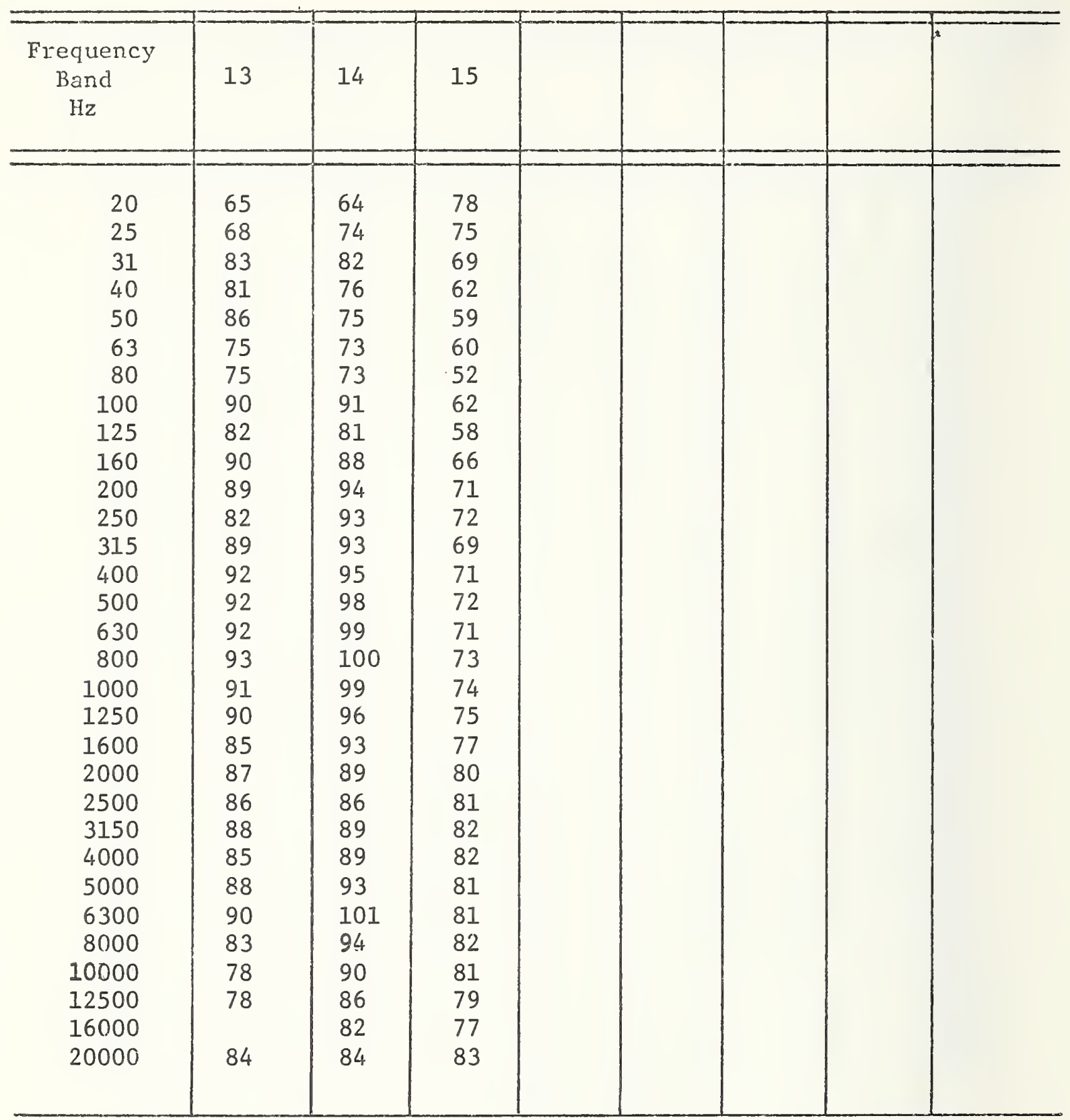

13. Rotohammer with $1-1 / 2^{\prime \prime}$ chisel attacking brick veneer.

14. Rotohammer with chisel attacking cinder block after penetration of brick venecr.

15. Oxyacetylene torch cutting reinforcing bar. 
One-third octave bandwidth sound pressure levels, dB

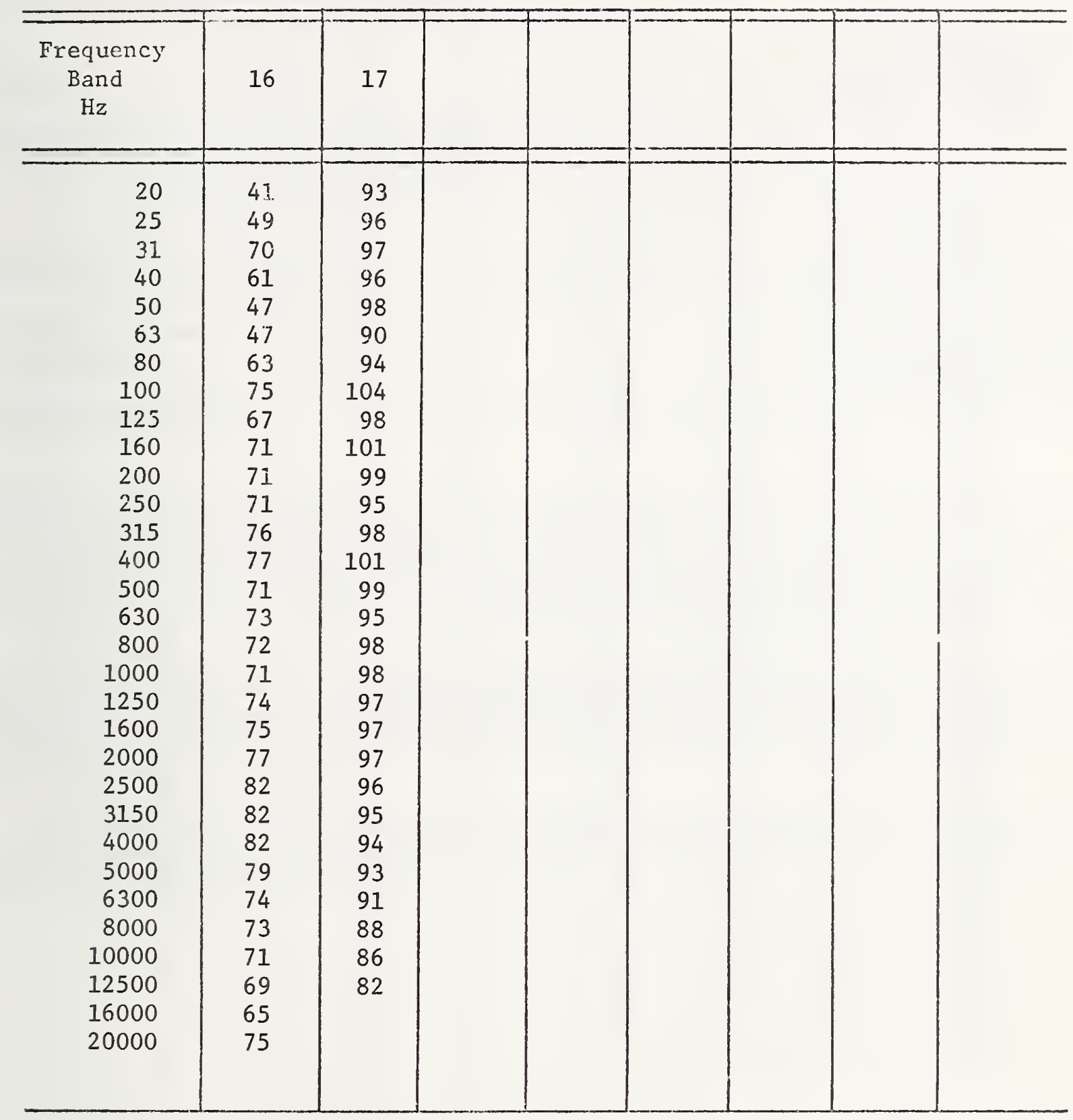

16. Bolt cutter clipping expanded metal.

17. Sledgehammer attacking metal-clad door. 
One-third octave bandwidth sound pressure level, dB

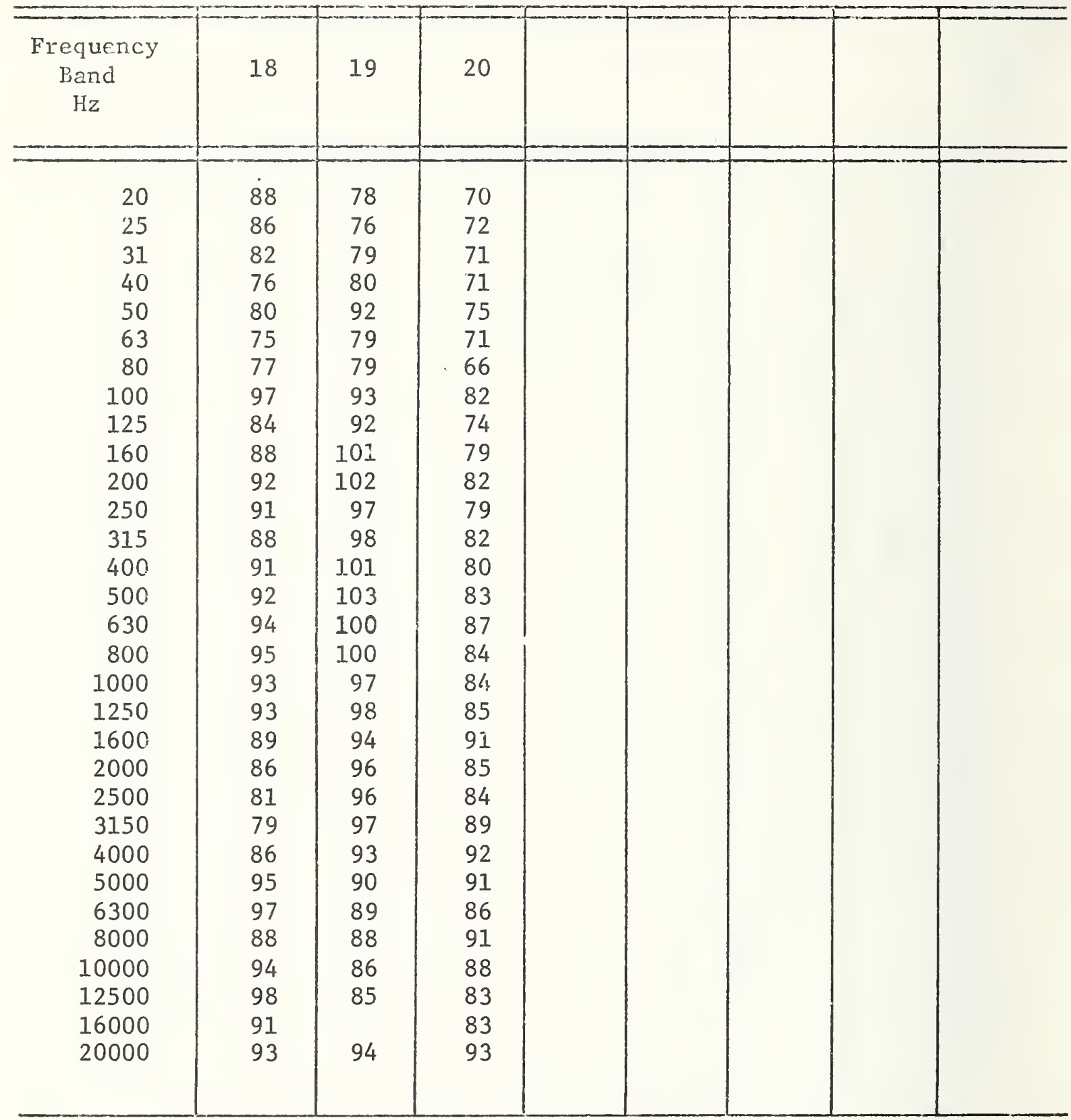

18. Rotohammer with $1^{\prime \prime}$ drill attacking concrete.

19. Spalling concrete with 12-pound sledgehammer.

20. Gasoline-powered abrasive wheel cutoff saw. 
FORM NBS.114A (1.71)

\begin{tabular}{|c|c|c|}
\hline $\begin{array}{l}\text { 1. PUBLICATION OR REPORT NO. } \\
\text { NBSIR 73-223 }\end{array}$ & $\begin{array}{l}\text { 2. Gov't Accession } \\
\text { No. }\end{array}$ & 3. Recipient's Accession No. \\
\hline \multirow{2}{*}{\multicolumn{2}{|c|}{$\begin{array}{l}\text { 4. TITLE AND SUBTITLE } \\
\text { PENETRATION TESTS ON J-SIIDS BARRIERS }\end{array}$}} & $\begin{array}{l}\text { 5. Publication Date } \\
\text { June 4, } 1973\end{array}$ \\
\hline & & $\begin{array}{l}\text { 6. Performing Organization Code } \\
650.01\end{array}$ \\
\hline R. T. Moore & & $\begin{array}{l}\text { 8. Performing Organization } \\
\text { NBSIR 73-223 }\end{array}$ \\
\hline \multirow{2}{*}{\multicolumn{2}{|c|}{$\begin{array}{l}\text { NATIONAL BUREAU OF STAND ARDS } \\
\text { DEPARTMENT OF COMMERCE } \\
\text { WASHINGTON, D.C. } 20234\end{array}$}} & $\begin{array}{c}\text { 10. Project/Task/Work Unit No. } \\
\text { Project } 6509419\end{array}$ \\
\hline & & $\begin{array}{l}\text { 11. Contract/Grant No. } \\
\text { IACRO DNA EO 72-201 } \\
\text { and 73-406 }\end{array}$ \\
\hline \multirow{2}{*}{\multicolumn{2}{|c|}{$\begin{array}{l}\text { 12. Sponsoring Organization Name and Address } \\
\text { Defense Nuclear Agency (DNA) } \\
\text { Washington, D. C. } 20305\end{array}$}} & $\begin{array}{l}\text { 13. Type of Report \& Period } \\
\text { Covered Interim Report } \\
\text { for Period } 3 / 13-16 / 73\end{array}$ \\
\hline & & $\begin{array}{c}\text { 14. Sponsoring Agency Code } \\
\text { DNA }\end{array}$ \\
\hline
\end{tabular}

15. SUPPLEMENTARY NOTES

16. ABSTRACT (A 200-word or less factual summaty of most significant information. If document includes a significant bibliography or literature survey, mention it here.)

A series of penetration tests were made on three simulated arms rooms which incorporated a variety of structural barriers which were intended to be representative of the broad range of construction likely to be encountered in existing arms rooms.

The observed penetration times varied from 1.3 minutes for a double-planked wooden wall, 11.31 minutes for an eight-inch thick, reinforced concrete wall and up to 18.27 minutes for a GSA Class 6 vault door. All penetrations were made with portable readily available tooling and produced acoustical or vibrational or both types of disturbances which are readily detectable.

The test results provide a basis for estimating the time in which response to an intrusion alarm must occur in order to adequately safeguard an arms room, a computer room or any other sensitive area.

17. KEY WORDS (Alphabetical order, separated by semicolons)

Barrier penetration; Intrusion resistance; physical security.

18. AVAILABILITY STATEMENT

[X] UNL IMIT ED.

FOR OFFICIAL DISTRIBUTION. DO NOT RELEASE TO NTIS.
19. SECURITY CLASS (THIS REPORT)

UNCL ASSIF IED

20. SE CURITY CLASS (THIS PAGE)

UNCL ASSIFIED
21. NO. OF PAGES

22. Price (1) 


